\title{
DEMAND
}

Freight Transportation Modal Shares: Scenarios for a Low-Carbon Future 



\title{
Transportation Energy Futures Series:
}

\section{Freight Transportation Modal Shares: \\ Scenarios for a Low-Carbon Future}

\author{
A Study Sponsored by \\ U.S. Department of Energy \\ Office of Energy Efficiency and Renewable Energy
}

March 2013

Prepared by

CAMBRIDGE SYSTEMATICS

Cambridge, MA 02140

under subcontract DGJ-1-11857-01

Technical monitoring performed by

NATIONAL RENEWABLE ENERGY LABORATORY

Golden, Colorado 80401-3305

managed by

Alliance for Sustainable Energy, LLC

for the

U.S. DEPARTMENT OF ENERGY

Under contract DC-A36-08GO28308

This report was prepared as an account of work sponsored by an agency of the United States Government. Neither the United States Government nor any agency thereof, nor any of their employees, makes any warranty, expressed or implied, or assumes any legal liability or responsibility for the accuracy, completeness, or usefulness of any information, apparatus, product, or process disclosed, or represents that its use would not infringe privately owned rights. Reference herein to any specific commercial product, process, or service by trade name, trademark, manufacturer, or otherwise, does not necessarily constitute or imply its endorsement, recommendation, or favoring by the United States Government or any agency thereof. The views and opinions of authors expressed herein do not necessarily state or reflect those of the United States Government or any agency thereof. 


\section{About The Transportation Energy Futures Project}

This is one of a series of reports produced as a result of the Transportation Energy Futures (TEF) project, a U.S. Department of Energy (DOE)-sponsored multi-agency project initiated to identify underexplored strategies for abating greenhouse gases (GHG) and reducing petroleum dependence related to transportation. The project was designed to consolidate existing transportation energy knowledge, advance analytic capacity-building, and uncover opportunities for sound strategic action.

Transportation currently accounts for $71 \%$ of total U.S. petroleum use and $33 \%$ of the nation's total carbon emissions. The TEF project explores how combining multiple strategies could reduce GHG emissions and petroleum use by $80 \%$. Researchers examined four key areas - lightduty vehicles, non-light-duty vehicles, fuels, and transportation demand - in the context of the marketplace, consumer behavior, industry capabilities, technology and the energy and transportation infrastructure. The TEF reports support DOE long-term planning. The reports provide analysis to inform decisions about transportation energy research investments, as well as the role of advanced transportation energy technologies and systems in the development of new physical, strategic, and policy alternatives.

In addition to the DOE and its Office of Energy Efficiency and Renewable Energy, TEF benefitted from the collaboration of experts from the National Renewable Energy Laboratory and Argonne National Laboratory, along with steering committee members from the Environmental Protection Agency, the Department of Transportation, academic institutions and industry associations. More detail on the project, as well as the full series of reports, can be found at http://www.eere.energy.gov/analysis/transportationenergyfutures.

Contract Nos.

DC-A36-08GO28308 and DE-AC02-06CH11357 


\section{AVAILABILITY}

This report is available electronically at http://www.osti.gov/bridge

Available for a processing fee to U.S. Department of Energy and its contractors, in paper form, from:

U.S. Department of Energy

Office of Scientific and Technical Information

P.O. Box 62

Oak Ridge, TN 37831-0062

phone: 865.576 .8401

fax: 865.576 .5728

email: reports@adonis.osti
Available for sale to the public, in paper form, from:

U.S. Department of Commerce

National Technical Information Service 5285 Port Royal Road

Springfield, VA 22161

phone: 800.553 .6847

fax: 703.605 .6900

email: orders@ntis.fedworld.gov

online ordering:

http://www.ntis.gov/help/ordermethods.aspx

\section{Citation}

Please cite as follows:

Brogan, J.J.; Aeppli, A.E.; Beagan, D.F; Brown, A.; Fischer, M.J.; Grenzeback, L.R.; McKenzie, E.; Vimmerstedt, L.; Vyas, A.D.; Witzke, E.; (March 2013). Freight Transportation Modal

Shares: Scenarios for a Low-Carbon Future. Transportation Energy Futures Series. Prepared by Cambridge Systematics, Inc. (Cambridge, MA), and the National Renewable Energy Laboratory (Golden, CO) for the U.S. Department of Energy, Washington, DC. DOE/GO-102013-3705. $80 \mathrm{pp}$. 


\author{
REPORT CONTRIBUTORS AND ROLES \\ National Renewable Energy Laboratory \\ Austin Brown Co-lead \\ Laura Vimmerstedt Co-lead \\ Argonne National Laboratory \\ Anant D. Vyas Co-lead and contributing author \\ Cambridge Systematics \\ James J. Brogan Primary author \\ Michael J. Fischer Contributing author \\ Daniel F. Beagan, P.E. Contributing author \\ Lance R. Grenzeback Contributing author \\ Dr. Elaine McKenzie Contributing author \\ Erika Witzke Contributing author \\ Andreas E. Aeppli Contributing author
}




\section{ACKNOWLedgments}

We are grateful to colleagues who reviewed portions or the entirety of this report in draft form, including:

Sarah Froman, Policy Advisor, Office of Transportation and Air Quality, U.S. Environmental Protection Agency

John Maples, Transportation Team Lead, Office of Energy Analysis, Energy Information Administration, U.S. Department of Energy

Dr. Gerard McCullough, Associate Professor, Department of Applied Economics, University of Minnesota

Rolf Schmitt, Acting Director, Office of Freight Management and Operations, Federal Highways Administration, U.S. Department of Transportation

Dr. James Winebrake, Professor and Dean, College of Liberal Arts, Rochester Institute of Technology

Participants in an initial Transportation Energy Futures scoping meeting in June 2010 representing the U.S. Department of Energy and national laboratories - assisted by formulating innovative and timely ideas to consider for the project. Steering Committee members and observers offered their thoughtful perspective on transportation analytic research needs as well as insightful comments on an initial Transportation Energy Futures work plan in a December 2010 meeting, and periodic teleconferences through the project.

Many analysts and managers at the U.S. Department of Energy played important roles in sponsoring this work and providing valuable guidance. From the Office of Energy Efficiency and Renewable Energy, Sam Baldwin and Carla Frisch provided leadership in conceptualizing the project. A core team of analysts collaborated closely with the national lab team throughout implementation of the project. These included:

Jacob Ward and Philip Patterson (now retired), Vehicle Technologies Office

Tien Nguyen and Fred Joseck, Fuel Cell Technologies Office

Zia Haq, Kristen Johnson, and Alicia Lindauer-Thompson, Bioenergy Technologies Office

The national lab project management team consisted of Austin Brown, Project Lead, and Laura Vimmerstedt, Project Manager (from the National Renewable Energy Laboratory); and Tom Stephens, Argonne Lead (from Argonne National Laboratory). Data analysts, life cycle assessment analysts, managers, contract administrators, administrative staff, and editors at both labs offered their dedication and support to this effort. 



\section{TABLE OF Contents}

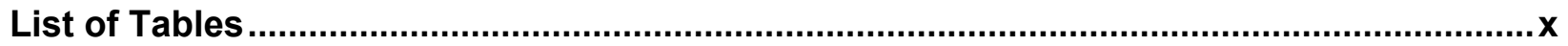

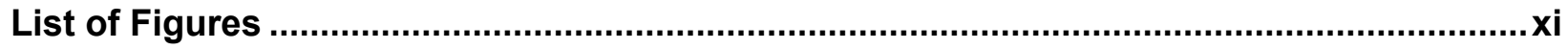

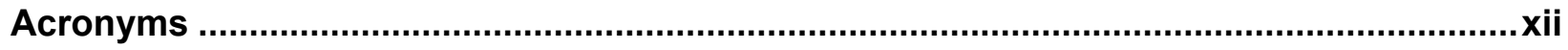

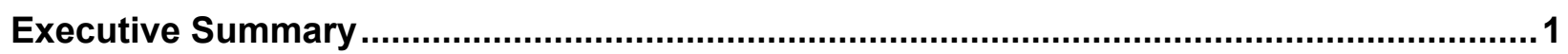

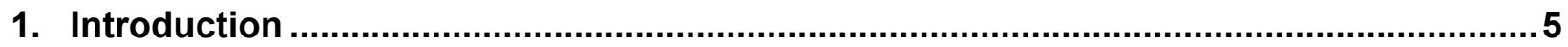

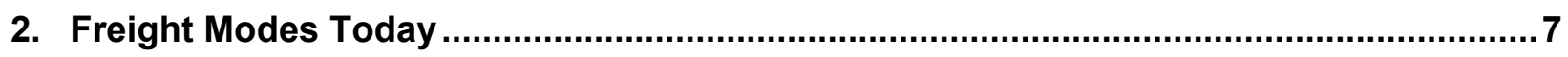

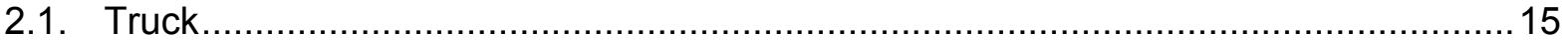

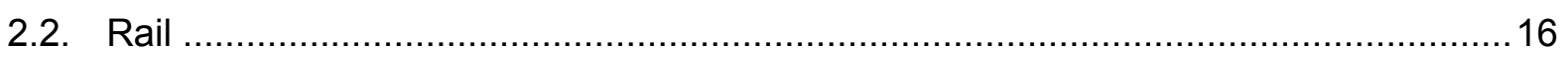

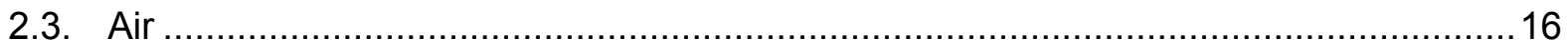

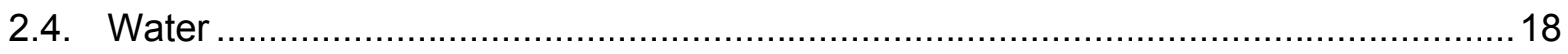

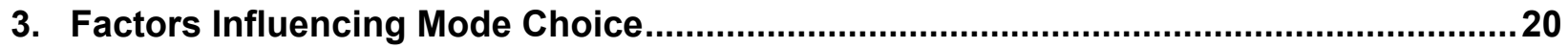

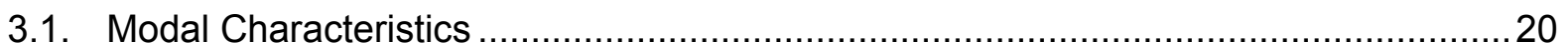

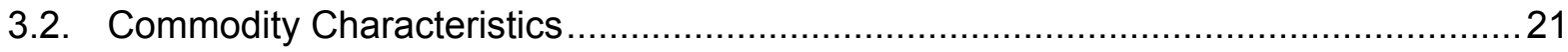

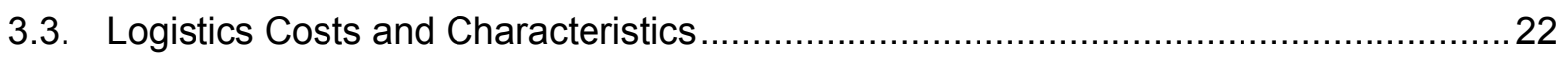

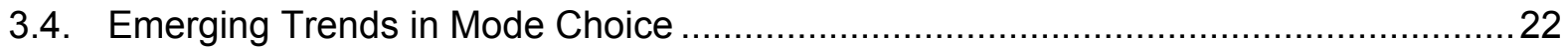

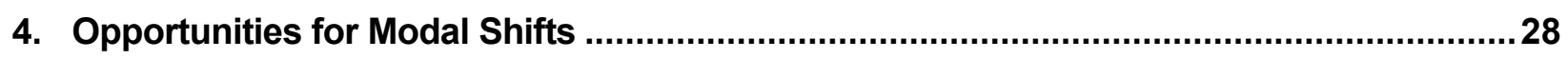

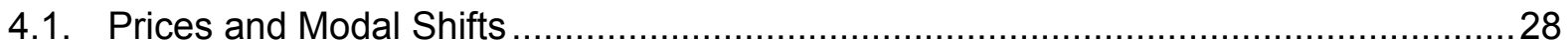

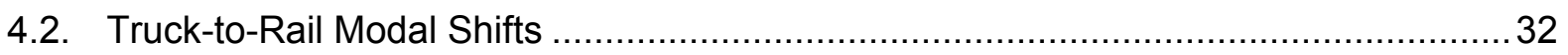

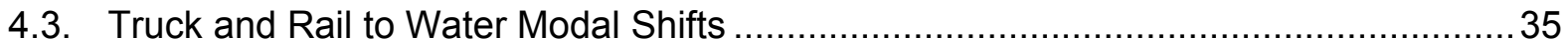

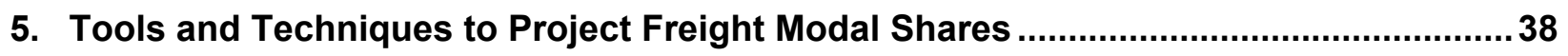

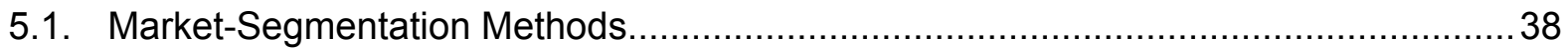

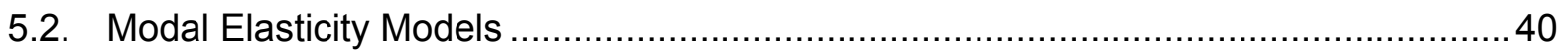

5.3. Mode Choice Models ......................................................................................... 45

6. Federal Actions to Influence Freight Modal Shifts ................................................50

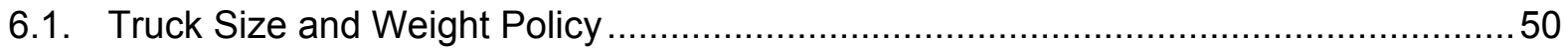

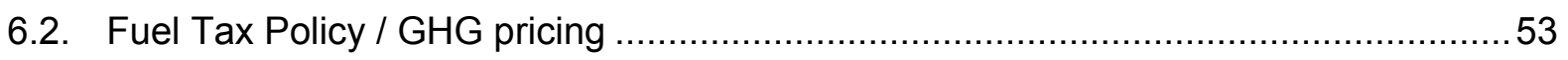

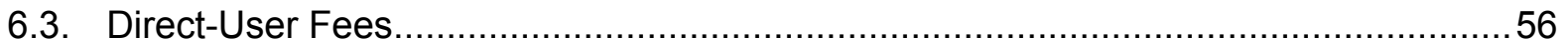

6.4. Freight Rail Corridor and Waterway Investments ..........................................59

6.5. Commercial Vehicle Hours of Service Regulations .............................................. 62

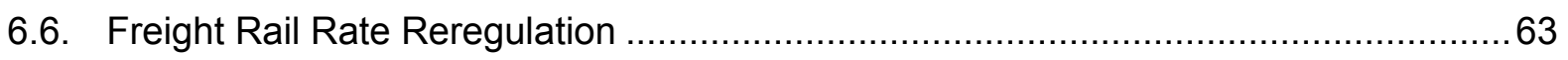

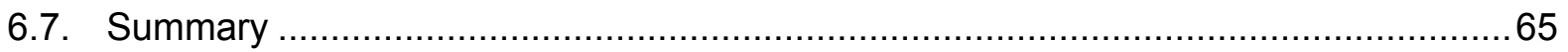

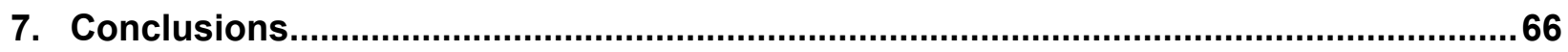

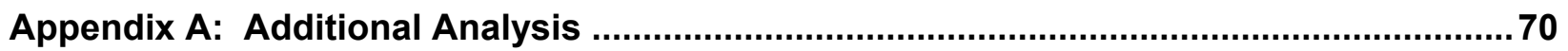

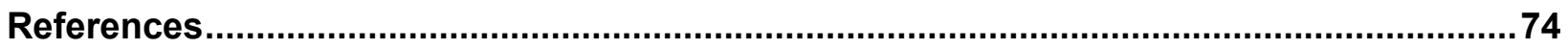




\section{LIST OF TABLES}

Table ES.1. Opportunity Matrix for Freight Transportation Modal Share Shifts ....................... 4

Table 3.1. Factors that Affect Freight Modal Choice ........................................................ 20

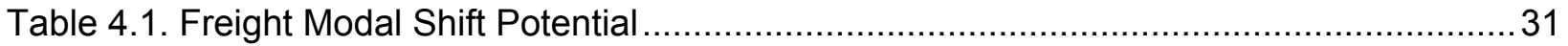

Table 5.1. Summary of Freight Modal Share Projection Tools .......................................... 38

Table 5.2. Mid-Atlantic Rail Operations Freight Flow Scenarios .......................................... 40

Table 6.1. Summary of Potential Policy Actions ............................................................ 50

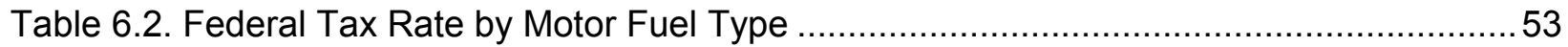

Table 6.3. Cost and Benefit Factors of Oregon Road Fee Pilot Program ...............................58

Table 6.4. Marco Polo I (2003-2006) and II (2007-2009) Evaluation of Total Modal Shift ......... 61

Table 6.5. Opportunity Matrix for Freight Transportation Modal Share Shifts..........................65

Table 7.1. Opportunity Matrix for Freight Transportation Modal Share Shifts.........................68

Table 7.2. Summary of Areas Recommended for Additional Research ...............................6 68

Table A.1. Performance Measures Corresponding to Modal Diversion and Related Policy Needs 


\section{LIST OF FIGURES}

Figure ES.1. Freight modal shares and tons by distance for all commodities, $2007 \ldots \ldots \ldots \ldots \ldots \ldots .2$

Figure 2.1. Freight transportation demand in tons, ton-miles, and value by mode, $2010 \ldots \ldots \ldots \ldots .8$

Figure 2.2. Freight transportation service spectrum .................................................. 8

Figure 2.3. Petroleum fuel consumption by U.S. domestic transportation mode, 2005/2007 ..... 10

Figure 2.4. U.S. GHG emissions by U.S. domestic transportation mode, $2009 \ldots \ldots \ldots \ldots \ldots \ldots \ldots . \ldots \ldots$

Figure 2.5. Freight modal shares and tons by distance for all commodities, 2007 .................. 12

Figure 2.6. Freight modal shares and ton-miles by distance for all commodities, 2007 ...........13

Figure 2.7. Freight modal shares and cumulative ton-miles by distance for mixed freight

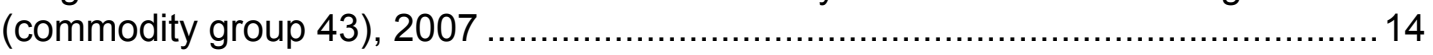

Figure 2.8. Freight modal shares and ton-miles by distance for machinery (commodity

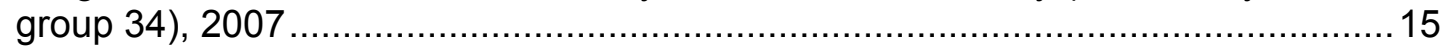

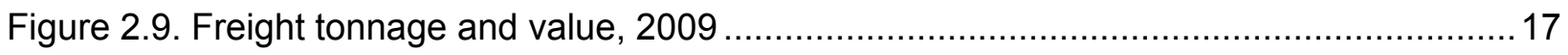

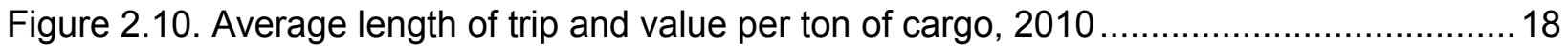

Figure 2.11. Modal capacity comparisons ................................................................. 19

Figure 3.1. Freight truck and rail miles per gallon and miles traveled, 1960 to $2009 \ldots \ldots \ldots \ldots \ldots . . . .24$

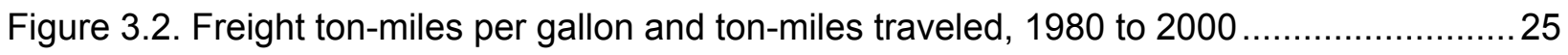

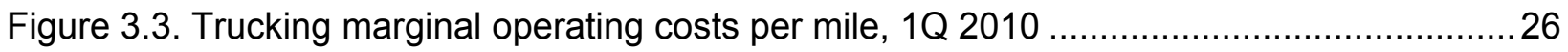

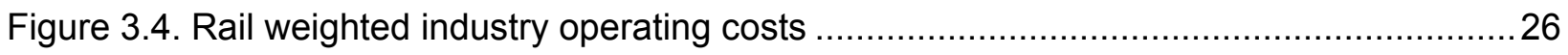

Figure 4.1. Most likely range of elasticities of demand for freight transport ...........................29

Figure 4.2. Cross-price rail-to-truck and truck-to-rail elasticities .......................................... 30

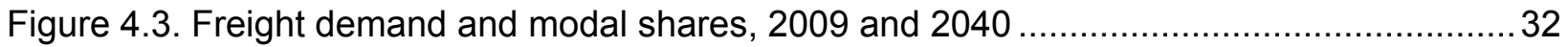

Figure 4.4. Truck hauling intermodal container on a trailer chassis (top), and truck hauling

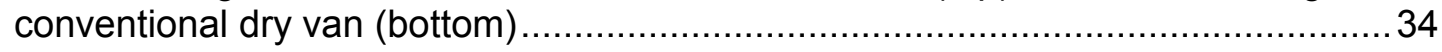

Figure 4.5. Major Norfolk Southern Rail Investment Corridors ............................................ 35

Figure 5.1. Infrastructure differences between the build and no-build TDOT scenarios .............41

Figure 5.2. Variables affecting choice of supplier, shipment size, and mode in freight transportation in the ITIC-IM Model................................................................. 44

Figure 5.3. Sample links and nodes from mesoscale prototype national network ....................49

Figure 6.1 . What we pay for in a gallon of diesel ............................................................ 54

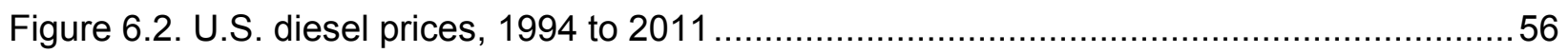

Figure A.1. A conceptual supply chain linking sources to markets ..................................... 72 


\section{ACRONYMS}

$\begin{array}{ll}\text { AAR } & \text { Association of American Railroads } \\ \text { DOT } & \text { department of transportation } \\ \text { EIA } & \text { Energy Information Administration } \\ \text { EPA } & \text { U.S. Environmental Protection Agency } \\ \text { FAF } & \text { Freight Analysis Framework } \\ \text { FHWA } & \text { Federal Highway Administration } \\ \text { FMCSA } & \text { Federal Motor Carrier Safety Administration } \\ \text { FRA } & \text { Federal Railroad Administration } \\ \text { GAO } & \text { Government Accountability Office } \\ \text { GHG } & \text { greenhouse gas } \\ \text { HOS } & \text { hours of service } \\ \text { ICM } & \text { Intermodal Competition Model } \\ \text { ITIC } & \text { Intermodal Transportation and Inventory Cost Models } \\ \text { MAROps } & \text { Mid-Atlantic Rail Operations } \\ \text { MPO } & \text { metropolitan planning organization } \\ \text { NCHRP } & \text { National Cooperative Highway Research Program } \\ \text { NHTSA } & \text { National Highway Traffic Safety Administration ( } \\ \text { O/D } & \text { origin/destination } \\ \text { STB } & \text { Surface Transportation Board } \\ \text { TDOT } & \text { Tennessee Department of Transportation } \\ \text { TEF } & \text { Transportation Energy Futures } \\ \text { TIGER } & \text { Transportation Investment Generating Economic Recovery } \\ \text { TRB } & \text { Transportation Research Board of the National Academies } \\ \text { U.S. DOT } & \text { U.S. Department of Transportation } \\ \text { USACE } & \text { U.S. Army Corps of Engineers } \\ \text { VMT } & \text { vehicle miles of travel } \\ & \end{array}$




\section{EXECUTIVE SUMMARY}

Freight transportation modes - truck, rail, water, air, and pipeline - each serve a distinct share of the freight transportation market. A variety of factors influence the modes chosen by shippers, carriers, and others involved in freight supply chains. Analytical methods can be used to project future modal shares, and federal policy actions could influence future freight mode choices. This report considers how these topics have been addressed in existing literature and offers insights on federal policy decisions with the potential to prompt mode choices that reduce energy use and greenhouse gas emissions.

\section{Options for Moving 18.5 Billion Tons of Freight}

Truck, rail, water, air, and pipeline services provide a spectrum of competitive and complementary freight transportation options, with each mode offering advantages and disadvantages in terms of price, speed, reliability, accessibility, visibility, security, and safety. However, capacity, cost, and service differences, combined with economic competition, compel each mode to target the commodities and markets that it serves best and most economically. As a result, truck and air modes are typically used for higher-value, lower-weight, and more time-sensitive freight, while rail and water freight transportation usually serve lower-value, heavier weight, and less time-sensitive shipments.

The Federal Highway Administration (FHWA) Freight Analysis Framework model estimates that 18.5 billion tons of goods were moved in the United States in 2007, generating 5.4 trillion ton-miles of travel, with a value approaching $\$ 16.7$ trillion (FHWA 2012). Trucks transported about $72 \%$ of all freight tonnage, accounting for $42 \%$ of all ton-miles and $70 \%$ of freight commodity value. Rail accounted for only $11 \%$ of tons moved, but $28 \%$ of ton-miles, and $3.5 \%$ of total value-reflecting rail's costeffectiveness in hauling heavier, lower-value commodities, such as coal and grain, over long distances. Excluding international maritime shipments, waterborne transportation accounted for a smaller percentage of tons and ton-miles. Air freight constituted an even smaller share, except when measured by value.

Trucks dominate the market for shipments under 550 miles, which account for almost $80 \%$ of all domestic freight tonnage. Figure ES.1 compares modal shares in tons by shipment distance for trucks and rail and other modes. The amount of tonnage moving distances of 500 to 1,500 miles is much smaller than the amount being moved less than 500 miles. While there are opportunities to shift some of this longer-distance freight from truck to rail or water, the smaller volume of freight that is moved over 500 miles limits this potential.

\section{Key Findings}

- Different freight modes offer different specialized services, limiting opportunities for shifting freight from one mode to another.

- Major mode shifts are unlikely without substantial changes in costs or strong regulatory measures.

- The types of policy measures that affect freight mode choice include actions to price fuel (motor fuel taxes) and roadway access; regulate trucker hours of service and truck sizes and weights; and increase or decrease investment in capital and operations improvements.

- Truck-to-rail modal shifts have the greatest overall potential for energy reduction, because trucks are the dominant mode in terms of freight tonnage and freight commodity value, while rail serves many of the same routes and uses substantially less energy. 


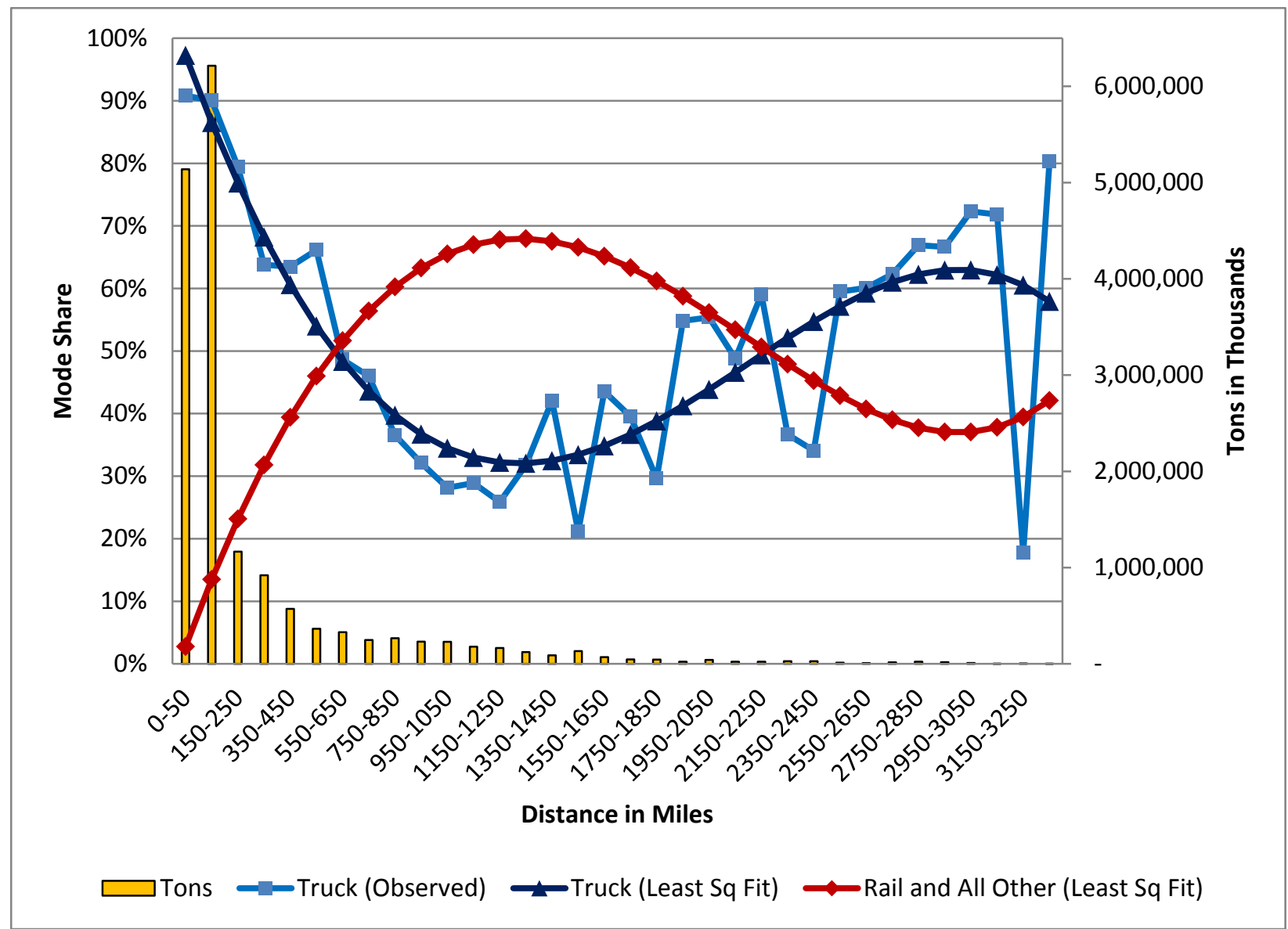

Figure ES.1. Freight modal shares and tons by distance for all commodities, 2007

[Source: Cambridge Systematics, Inc., National Renewable Energy Laboratory Freight Energy Analysis Tool, Freight Analysis Framework (FAF) 3.2]

Note: Least squares fit is a mathematical procedure for finding the best-fitting curve to a given set of points by minimizing the sum of the squares of the offsets ("the residuals") of the points from the curve.

\section{Modes with Maximum Energy Efficiency}

Different modes use significantly different amounts of energy per unit of freight movement, spanning almost two orders of magnitude. Energy use in British thermal units (Btu) per ton-mile of freight is nearly 30 for air, 4 for truck, 0.5 for water, and 0.4 for rail (Davis, Diegel, and Boundy 2012). Modal share of freight markets has implications for energy use because of these differences. Figure ES.2 compares modal shares and ton-miles, using ton-miles as a broad proxy for the amount of energy consumed in freight transportation. This distribution shows substantial ton-miles accruing to truck, rail, and other modes in the 250- to 1,500-mile distance bands. This suggests opportunities to reduce energy use by improving the energy efficiency of truck, rail, and water freight operations, as well as by shifting more tons and ton-miles from truck to rail in 250- to 750 -mile range. 


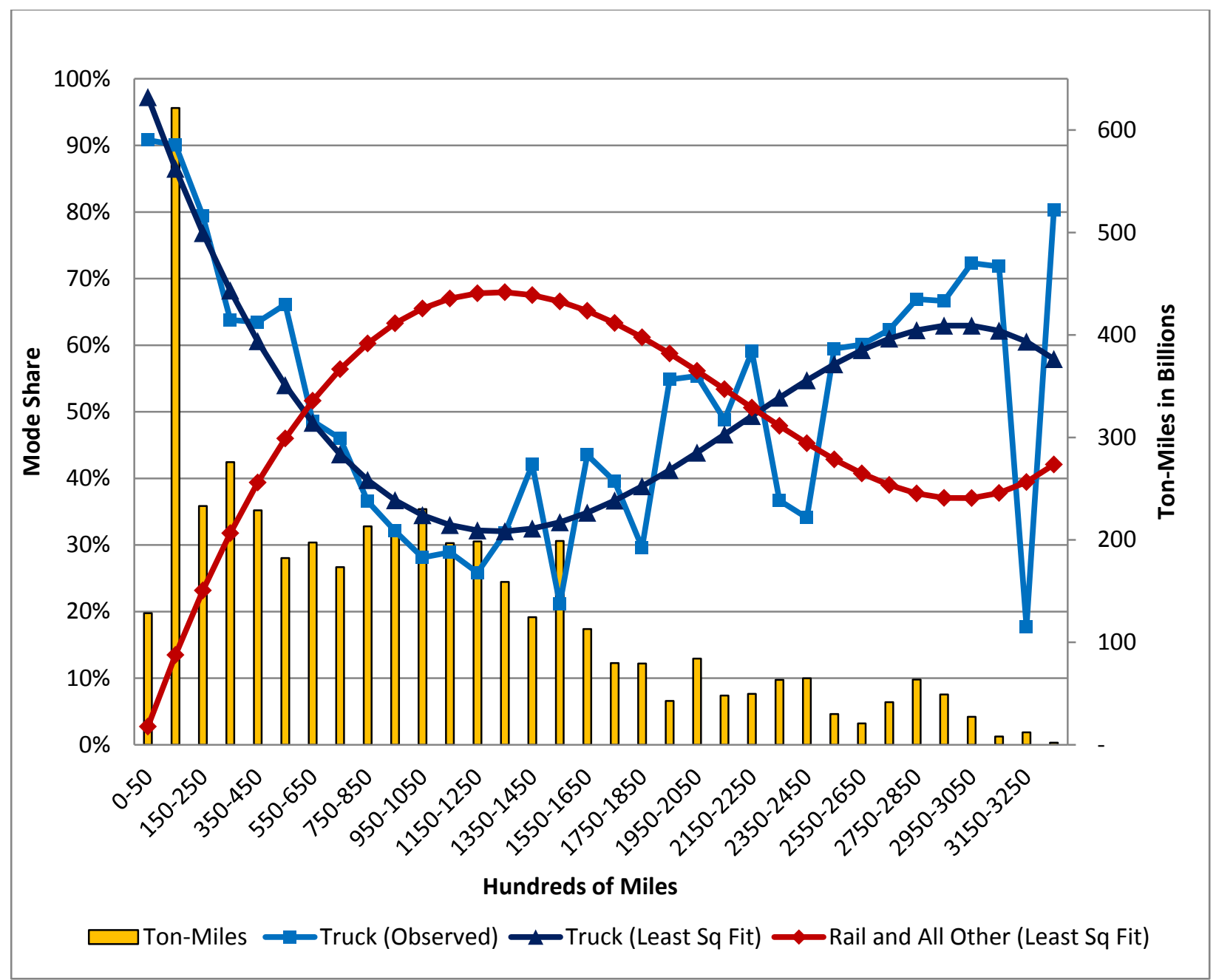

Figure ES.2. Freight modal shares and ton-miles by distance for all commodities, 2007

(Source: Cambridge Systematics, Inc., National Renewable Energy Laboratory Freight Energy Analysis Tool, FAF 3.2)

Note: Least squares fit is a mathematical procedure for finding the best-fitting curve to a given set of points by minimizing the sum of the squares of the offsets ("the residuals") of the points from the curve.

\section{Opportunities to Shift Modes Through Federal Policy}

Transportation economics literature, historical case studies, and industry market assessments demonstrate that federal policy actions can influence mode choice. However, the literature also shows that, barring major changes in freight transportation technology or regulation, these actions will likely result in relatively small shifts of tons and ton-miles from truck to rail. Our assessments of potential federal actions and the anticipated modal shifts are as follows:

- Increasing Motor Fuel Taxes. An increase in diesel fuel taxes could increase the cost of trucking relative to rail and make it more economically attractive to shippers to shift traffic from truck to rail, but the authors' assessment of the literature suggests that diesel prices would have to nearly double to increase rail tonnage by more than a few percent.

- Charging User Fees. Increasing the cost of trucking with tolls could encourage shippers to explore other modes, although rail is not competitive with trucking on price or service at shorter distances, because rail service cannot achieve the economies of scale needed to keep unit costs low. 
- Imposing Greenhouse Gas Pricing/Regulations. Carbon taxes and regulations restricting greenhouse gas emissions could increase the cost of trucking and air freight, making it economically attractive to shippers to shift some traffic from roads to rails. Effects would range from a few percent to about 5\%, based on the authors' understanding of the literature.

- Reducing Truck Driver Hours of Service. Regulations further limiting truck driver hours of service would likely increase trucking costs, especially for long distances, resulting in truck-torail diversion within the range of a $2 \%-3 \%$ shift in tonnage.

- Changing Truck Size and Weight Limits. Prior studies and carrier experience have shown that increasing allowable truck sizes and weights on Interstates and major state roads would divert some freight from rail to truck. We estimate that a nationwide increase in allowable truck size and weight, permitting 100,000-pound trucks on all Interstate routes might result in 5\% of tonnage shift in rail to truck shipments.

- Re-regulating Freight Rail Rates and Services. Reintroduction of interstate freight rate regulation would reduce prices for some shippers, but also increase overall rail costs, potentially diverting up to $10 \%$ of rail tonnage to trucking nationally.

- Investing in Freight Rail Corridor and Service Improvements. A radical increase in public investment in rail could reduce prices and improve service, allowing rail to capture more freight from trucking, with the potential to increase rail tonnage by an estimated $10 \%-20 \%$.

The opportunity matrix in Table ES.1 takes the current technology and regulatory framework and shows the potential that federal policy actions would have along two dimensions: the probability of implementation, and the likely payoff measured in potential size of modal share shift from truck to rail.

Table ES.1. Opportunity Matrix for Freight Transportation Modal Share Shifts

\begin{tabular}{|c|c|c|c|}
\hline & & Potential Moda & rom Truck to Rail \\
\hline & & Low & Moderate \\
\hline \multirow{2}{*}{ 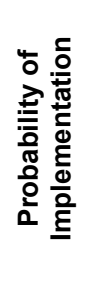 } & 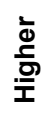 & $\begin{array}{c}\text { Truck Size and Weight Regulation } \\
\text { Truck Hours-of-Service Regulation } \\
\text { Freight Re-Regulation }\end{array}$ & Direct User Fees \\
\hline & ఏ్త & $\begin{array}{c}\text { Fuel Tax } \\
\text { Greenhouse Gas Regulation/Pricing }\end{array}$ & $\begin{array}{l}\text { Freight Rail and Waterway Infrastructure } \\
\text { Improvements and Expansion }\end{array}$ \\
\hline
\end{tabular}

(Source: Cambridge Systematics, Inc.)

\section{Potential for Shift to More Energy-Efficient Modes}

The current allocation of freight by mode is the product of technologic, economic, and regulatory frameworks. There are substantial opportunities to improve the energy efficiency of freight transportation, especially in urban areas, but relatively modest opportunities to shift substantial volumes of longer-haul freight from one mode to another without imposing considerable additional costs on businesses and consumers. Federal policy actions affecting modal shares could play a small part in reducing national energy consumption and greenhouse gas emissions. 


\section{INTRODUCTION}

The primary objective of this report is to quantify modal shares for freight movement and identify factors that influence mode choice decisions made by shippers, carriers, and others involved in freight supply chains. Intended to support decisions about how to reduce energy use and greenhouse gas (GHG) emissions in the freight transportation sector, this report summarizes existing methods for projecting future modal shares and describes federal policy actions that could influence future freight mode choices. This report, along with several others in the Transportation Energy Futures series, addresses transportation demand.

While numerous studies exist on freight mode choice, little of this material focuses on the potential for policy action to impact energy use and GHG emissions. A key factor that shaped this report was the need for an energy-policy-relevant understanding of freight modal choice decisions. The report is not intended to propose or promote policy actions.

A team of analysts at Argonne National Laboratory, Cambridge Systematics, and the National Renewable Energy Laboratory conducted a survey of existing literature on the subject, and then performed original analysis to evaluate mode shifting as a strategy for improving freight transportation energy efficiency to reduce U.S. dependence on petroleum fuels and climate impacts. The report draws on a range of evidence, including empirically verifiable statements of fact and quantitative findings from published studies, as well as interpretations and judgments.

This report uses a range of economic analysis methods to assess mode choice decisions and mode shifting opportunities. The well-established methods for analyzing and projecting changes in modal shares as a result of changes in price and service characteristics include market-segmentation methods, modal elasticity models, and mode-choice models. In addition, statistical approaches have been used to summarize and analyze data about to today's freight markets and modal shares.

This report identifies opportunities for further research and development on commodity-level modechoice factors, freight demand elasticities, and freight mode choice models, interactions between mode choice and supply chain, and performance measures.

The remainder of this report is structured as follows:

- Freight Modes Today. Section 2 describes the roles of truck, rail, air, and water freight transportation and their respective shares of the national freight transportation market.

- Factors Influencing Mode Choice. Section 3 provides an overview of factors shaping mode choice decisions, focusing on existing and emerging factors considered by shippers in making logistics decisions.

- Opportunities for Modal Shifts. Section 4 discusses opportunities and challenges in shifting freight to more fuel-efficient modes.

- Tools and Techniques Used to Project Freight Modal Shares. Section 5 offers an overview of the methods and tools for measuring modal shares and shifts, including market-segmentation methods, modal elasticity models, and mode choice models.

- Federal Policy Actions. Section 6 outlines federal actions with the potential to change modal shares, reviewing prior and current federal initiatives, and suggesting possible future actions.

The Conclusions section is followed by an appendix describing additional research that could produce better estimates of modal share projections in support of policy and program analysis.

While mode choice is of interest in the personal transportation sector as well, the scope of this report focused on the freight sector alone. The scope does not include examination of factors that shape 
transportation demand, nor does it include future scenarios with diverse freight demand and mode profiles: both topics are covered in other Transportation Energy Futures reports.

Finally, there is a lack of current, sufficiently detailed data that takes into account the significant differences among commodities and the increasingly complex nature of national and international supply chains. These data shortcomings have influenced the Transportation Energy Futures analysis, and the development of improved data should be identified as an area for future analytic improvement.

Although mode choice alone is unlikely to offer deep reductions in freight energy use or GHG emissions, this report confirms that encouraging the use of energy-efficient modes through carefully chosen policies can be a meaningful component of any overall transportation energy-reduction strategy. 


\section{FREIGHT MODES TODAY}

The tonnage and number of freight shipments within the United States are increasing steadily as demand for consumer goods and other products grows and as manufacturers and retailers move from inventorybased to just-in-time supply chain and distribution systems (Grenzeback et al. 2013). Freight transportation demand is typically measured in tons, ton-miles, and value (dollars) of goods moved by the freight sector. ${ }^{1}$ The Federal Highway Administration's (FHWA) Freight Analysis Framework (FAF) estimates that 18.5 billion tons of goods were moved in the United States in 2007, generating 5.4 trillion ton-miles of travel and with a value approaching $\$ 16.7$ trillion (FHWA 2012). ${ }^{2}$

The ton, ton-mile, and value data can be broken down by mode, as shown in Figure 2.1. In 2007, trucks moved about $72 \%$ of all freight tonnage, accounting for $42 \%$ of all ton-miles and $70 \%$ of freight commodity value. Rail accounted for only $11 \%$ of tons moved, but $28 \%$ of ton-miles and $3.5 \%$ of total value-reflecting rail's cost-effectiveness in hauling heavier, but generally lower-value, commodities, such as coal and grain, over long distances. Excluding international maritime shipments, waterborne transportation accounted for a smaller percentage of tons and ton-miles. Air freight transportation constituted an even smaller share, except when measured by value.

The freight transportation systems-truck, rail, water, pipeline, and air-provide both competitive and cooperative freight transportation services with each mode offering advantages and disadvantages in terms of price, speed, reliability, accessibility, visibility, security, and safety. ${ }^{3}$ Shippers try to use each mode to their best advantage in selecting freight transportation services to support their supply chains and distribution networks.

One way to visualize these advantages and disadvantages is as a spectrum of freight transportation services (Figure 2.2). On one end of the spectrum is water transportation, which tends to be the lowestcost carrier, but also provides the slowest service and is not universally available, as is truck service. At the other end of the spectrum is air freight service, which offers fast and reliable shipment, but at much higher prices. Between these extremes are truck, intermodal, and rail services. And within each mode, there are different types and levels of service available (e.g., single-customer truckload versus multicustomer less-than-truckload common carrier service, and container- or trailer-on-flatcar rail service versus carload rail service). As a general rule of thumb, higher-value, lower-weight, and more timesensitive freight is shipped by truck and air, while lower-value, heavier weight, and less time-sensitive freight moves by rail and water. ${ }^{4}$

\footnotetext{
${ }^{1}$ A ton of goods moved one mile is counted as one ton-mile. There is double-counting in the reporting of aggregate national freight transportation statistics because data are compiled by mode, not specific shipment. A ton of goods transported two miles by truck is counted as one ton of freight and two ton-miles of freight movement; however, a ton of goods transported the one mile by truck, transferred to rail, and transported one more mile by rail is counted as two tons of freight (one by truck, one by rail) and two ton-miles of freight movement.

${ }^{2}$ Unless otherwise noted, most of the freight demand statistics are based on FAF versions 3.1 and 3.2.

${ }^{3}$ This paper reports data on truck, rail, water, pipeline, and air freight transportation, but the discussions focus on truck, rail, and, to a lesser extent, water transportation. Pipeline and air are critically important freight services, but both are highly specialized. Pipeline competes with water for certain commodities, and air competes with truck for high-value, time-sensitive commodities, but the opportunities for major modal shifts between these modes that would substantially change energy consumption and GHG emissions are limited, and therefore are given less attention in the text discussions.

4 "Visibility," as used in the figure, refers to the ability to track and communicate the location, condition, and estimated time of arrival of a shipment and its vehicle. Visibility is particularly important and valuable to businesses engaged in just-in-time manufacturing and retailing. These businesses depend on predictable replenishment of materials, parts and finished products as current stock is used or sold.
} 


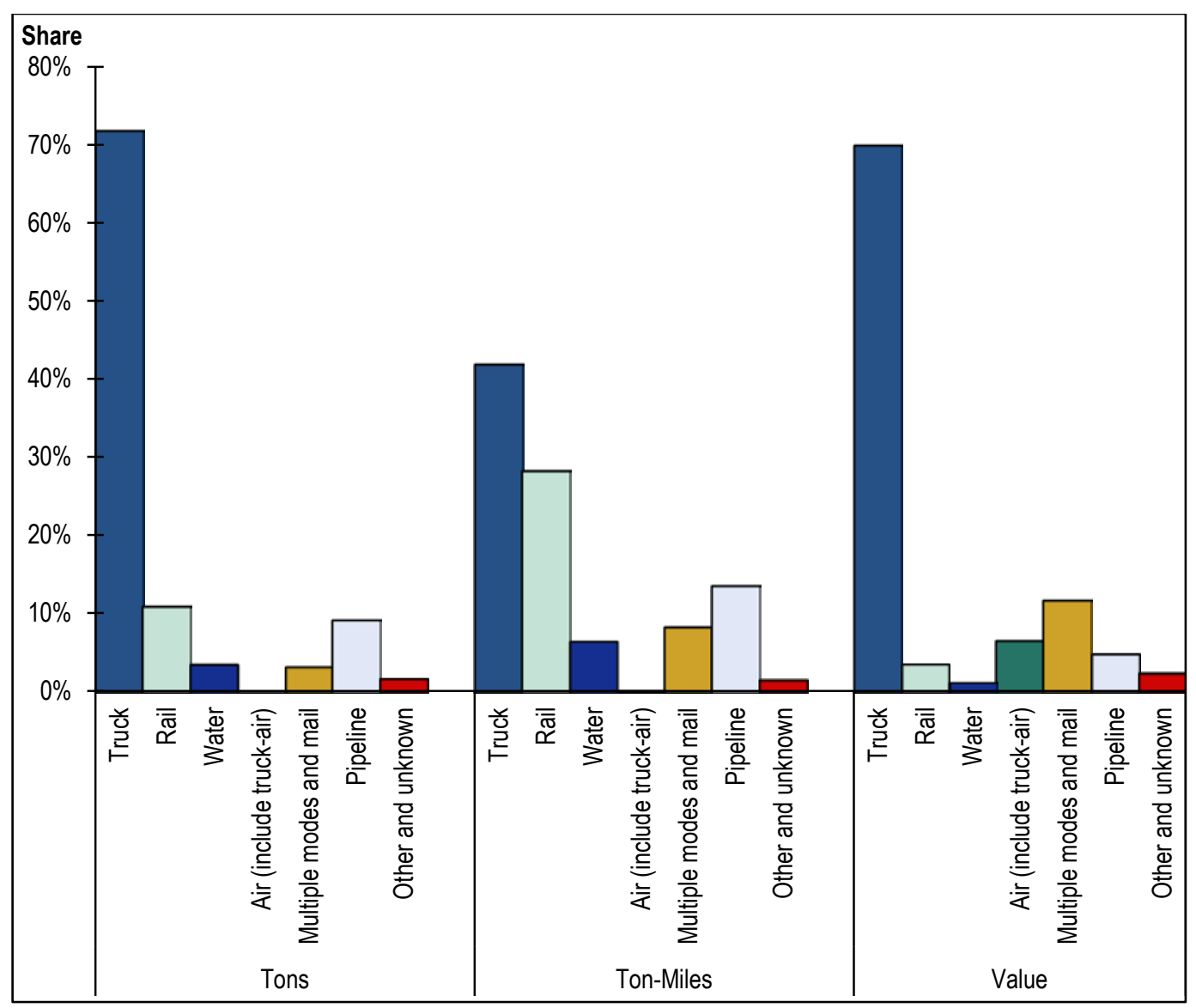

Figure 2.1. Freight transportation demand in tons, ton-miles, and value by mode, $\mathbf{2 0 1 0}$ (Source: Cambridge Systematics, Inc., NREL Freight Energy Analysis Tool, FAF 3.2)

\section{Service Cost Continuum}

$$
\text { Higher }
$$

Lower

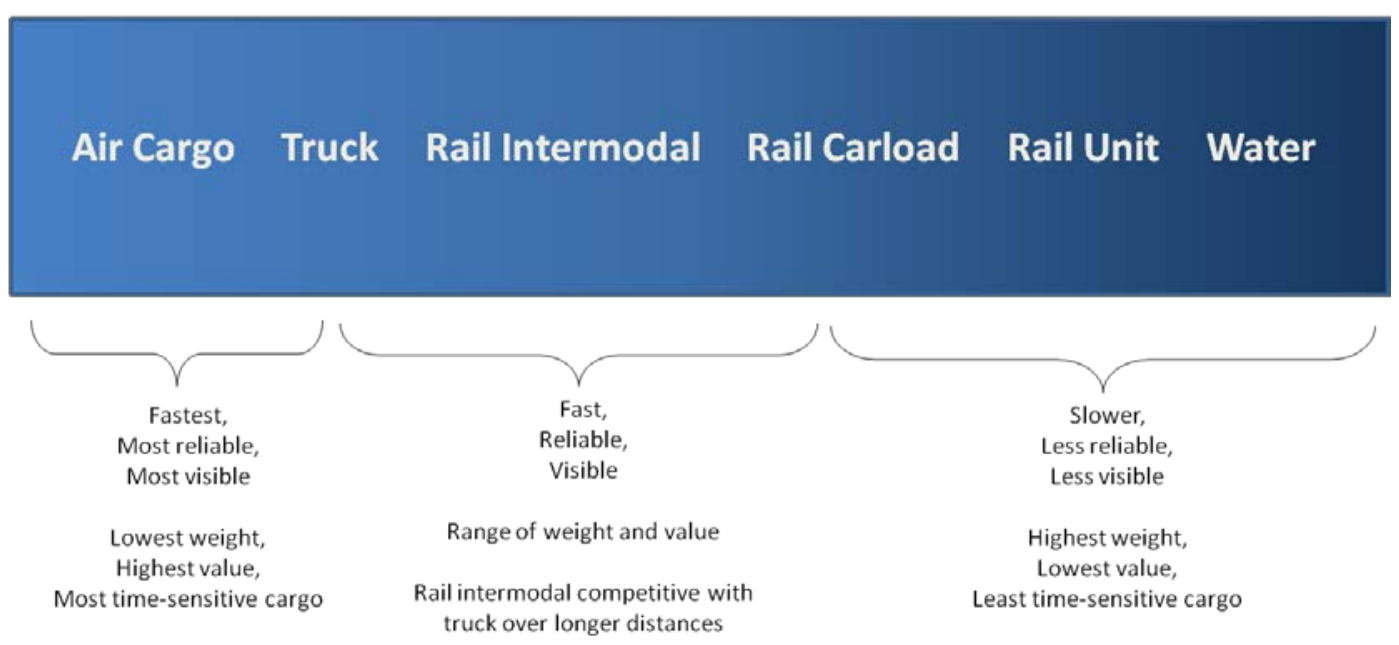

Figure 2.2. Freight transportation service spectrum 
The technology, capacity, and performance of freight transportation systems have changed radically over the past 200 years. For additional discussion of the changes to freight transportation, see American Association of State Highway and Transportation Officials (2003). The colonial economies of the $18^{\text {th }}$ century were built on water transport. Businesses clustered close to sea and river ports to minimize the cost of freight transportation. At the time of the American Revolution, it cost as much to move a ton of goods 30 miles inland as to move it across the Atlantic (McPherson 1988). Two out of three settlers lived within 50 miles of the Atlantic coast.

The introduction of rail technology in the mid $-19^{\text {th }}$ century freed business and industry from the need to locate near sea, river, and canal ports. Within a matter of decades, railroads opened much of the interior of the country and freight transportation costs dropped. East-west rail routes were built to follow development of the Midwest and solidify political and military control of the West after the Civil War.

The development of truck and highway technologies in the early $20^{\text {th }}$ century freed business and industry again, this time from the need to locate near rail lines and terminals. A grid of east-west and north-south Interstate highways was built to connect cities and regional economies. Businesses and communities migrated outward from city centers, taking advantage of inexpensive land made newly accessible by the trucking and highway systems. Long-haul trucking captured a large share of east-west freight traffic from the railroads and much of the north-south freight traffic from coastal steamers and river barges. While rail and water continued to serve some traditional markets, trucks were the only way to serve the new suburban and ex-urban markets. Trucking became the dominant mode of freight transportation, and much of the railroad industry shrank into bankruptcy.

In the 1980s, after long debates about economic regulation, Congress deregulated the private-sector freight transportation industry. Deregulation triggered a massive restructuring of the airline, railroad, motor carrier, and marine shipping industries. Firms were consolidated, routes and services were redesigned, and prices slashed. The changes were accelerated by a rapid increase in international trade, driven by imports of consumer goods through Pacific Coast ports and trade agreements with Canada and Mexico. The introduction of containerization (which markedly reduced damage, theft, and handling costs) helped to revitalize the rail industry as shippers began using intermodal truck/rail service to reach inland markets.

Today, the freight industry is in the midst of another technological revolution. This one is not driven by the introduction of a new mode of freight transportation but by the adoption of computers, electronic sensors, and digital radio and satellite communications. This information technology and communications revolution has given manufacturers, retailers, and their carriers the ability to closely monitor and coordinate production, supply chain, and transportation operations worldwide and locally, substantially improving the cost-effectiveness of freight transportation. ${ }^{5}$

Deregulation and technology have greatly reduced the barriers between freight transportation modes, refocusing attention on overall trip performance and forcing each mode to target the commodities and markets that it serves best and most economically. There is still considerable competition between modes, but also more effective cooperation. Railroads haul export grain and coal to the Mississippi River where these commodities are transported by barge to Gulf Coast ports. Railroads use trucks to perform collection and distribution services (also known as drayage) at transflow and transload facilities, where

\footnotetext{
${ }^{5}$ For the purposes of this paper, the terms "cost effective" and "cost effectiveness" are used in the sense of cost-per-ton or costper-ton-mile of freight delivered from a shipper's or consumer's perspective. Cost effectiveness is usually measured by dollars spent on transportation as part of the total logistics cost of delivered products or more directly as the cost per ton, truckload, or container for delivery along a specific freight lane (e.g., delivery of an intermodal container between Los Angeles and Chicago).
} 
bulk products are transferred in a seamless operation. ${ }^{6}$ Trucking companies regularly use the railroads for long-haul container and trailer shipments to save on labor and fuel expenses.

At issue in the discussion of modal roles and shares is the question whether it is feasible - through federal government policy, regulatory, or investment actions - to shift freight from less fuel-efficient modes (such as truck and air) to more fuel-efficient modes (such as rail and water), thereby reducing energy use (especially petroleum-fuel use) and GHG emissions.

Freight transportation accounts for about $26 \%$ of all petroleum-based fuels (gasoline, diesel, etc.) consumed by the transportation sector, which itself is $97 \%$ dependent on petroleum-based fuels. Figure 2.3 shows the approximate shares of petroleum fuel used by each transportation mode.

Petroleum fuel consumption correlates closely with GHG emissions. Transportation GHG emissions account for $27 \%$ of total U.S. GHG emissions and have been the source of the largest absolute increases in U.S. GHGs since 1990. Figure 2.4 shows the estimated contribution of each transportation mode to GHG emissions. In 2009, emissions from on-road vehicles accounted for $86 \%$ of transportation GHG emissions. Emissions from light-duty vehicles, which include passenger cars and light-duty trucks (e.g., sport utility vehicles, pickup trucks, and minivans), accounted for about $65 \%$ of emissions. Emissions from freight trucks accounted for $20 \%$, and emissions from commercial aircraft (domestic and international) for $6 \%$. Emissions from rail (freight and passenger) accounted for $2.5 \%$. Emissions from all other modes accounted for less than 10\% of total emissions (EPA 2011b).

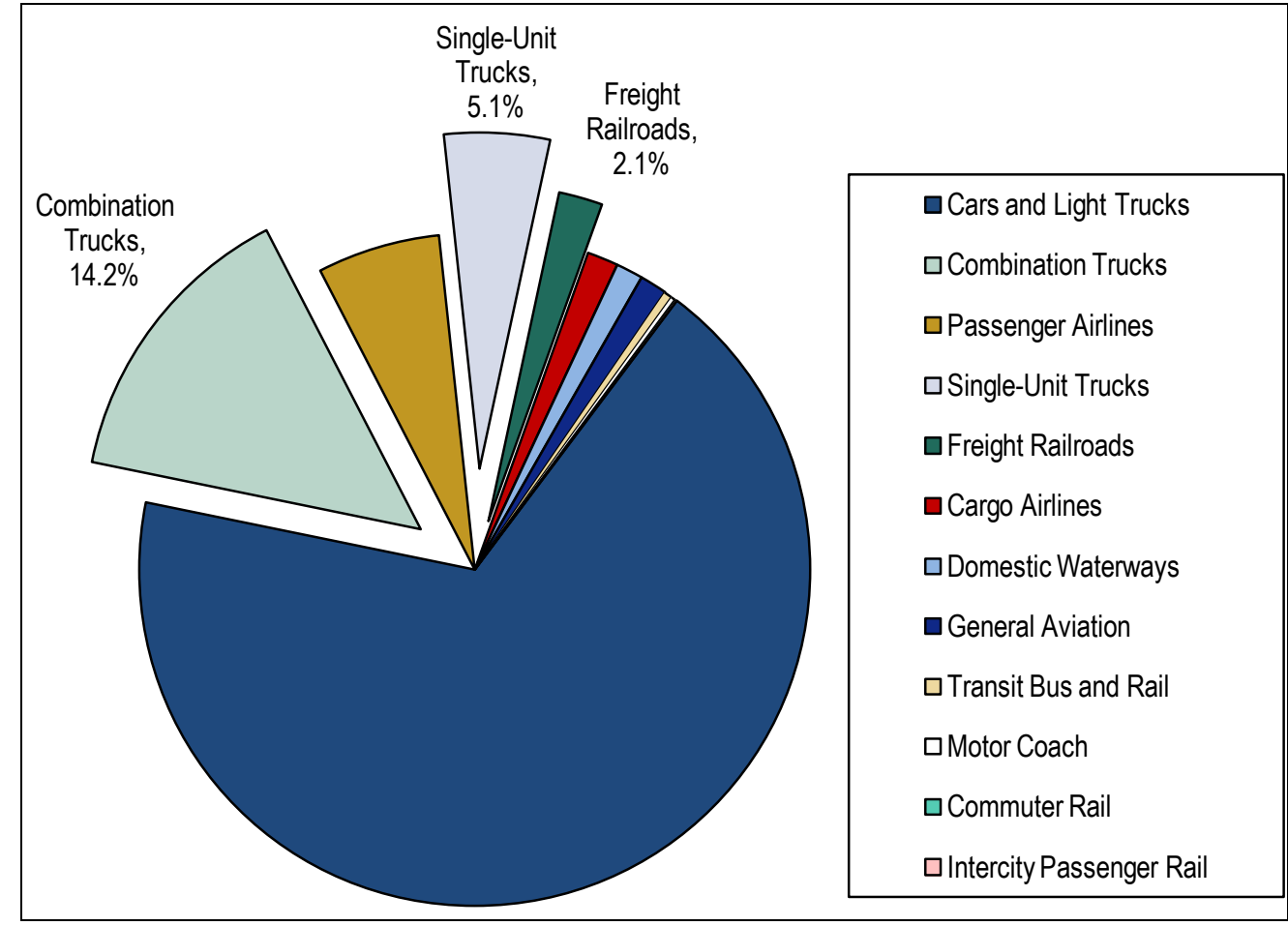

Figure 2.3. Petroleum fuel consumption by U.S. domestic transportation mode, 2005/2007

(Source: TRB 2011b, Figure 1.1)

Note: The total represents consumed gallons of gasoline, diesel, and jet fuel, irrespective of energy density. Mode totals were calculated through various government and industry sources for the most recent year in the period covered. Fuel used by pipelines, international aviation, and international maritime are excluded.

\footnotetext{
${ }^{6}$ Transflow services are where flowing commodities, such as corn syrup, petroleum products, or plastic pellets, are transferred between railcars and trucks for customers without direct rail service. Transload services are where nonflowing commodities, such as steel, lumber, or paper, are transferred between railcars and trucks for customers without direct rail service.
} 


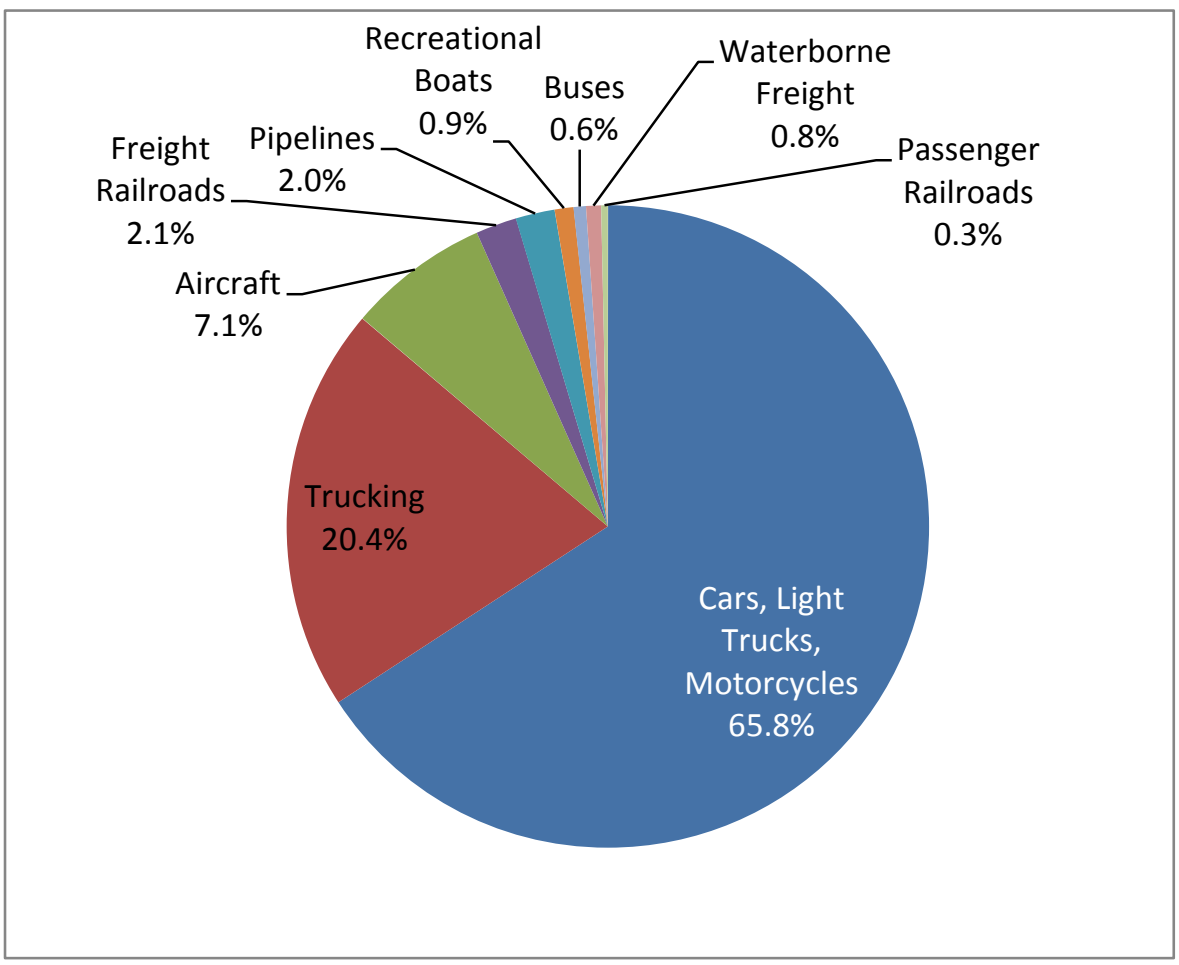

Figure 2.4. U.S. GHG emissions by U.S. domestic transportation mode, 2009

(Source: EPA 2011b)

Figure 2.5 shows the modal shares of freight transportation at different shipment distances in 2007 . Truck shares are plotted using the reported value for each distance band (of 100 miles) and a smoothed, leastsquares fitted curve. The shares are measured as percentages against the left-hand scale. The modal share for rail and all other modes, which includes domestic water shipping and pipelines, is calculated as 100 minus the observed truck modal share and then plotted as a smoothed, least-squares fitted curve - the mirror image of the truck modal share curve. The modal shares are based on the total tonnage of all commodities reported in the FHWA FAF Version 3 (FAF3) database (FHWA 2012). ${ }^{7}$ The tonnage moved in each distance band is shown by the height of the column and measured in thousands of tons on the right-hand scale.

\footnotetext{
${ }^{7}$ The FAF integrates data from a variety of sources to create a comprehensive picture of freight movement among states and major metropolitan areas by all modes of transportation. With data from the 2007 Commodity Flow Survey and additional sources, FAF3 provides estimates for tonnage, value, and domestic ton-miles by region of origin and destination, commodity type, and mode for 2007, the most recent year, and forecasts through 2040. Also included are state-to-state flows for these years plus 1997 and 2002, summary statistics, and flows by truck assigned to the highway network for 2007 and 2040.
} 


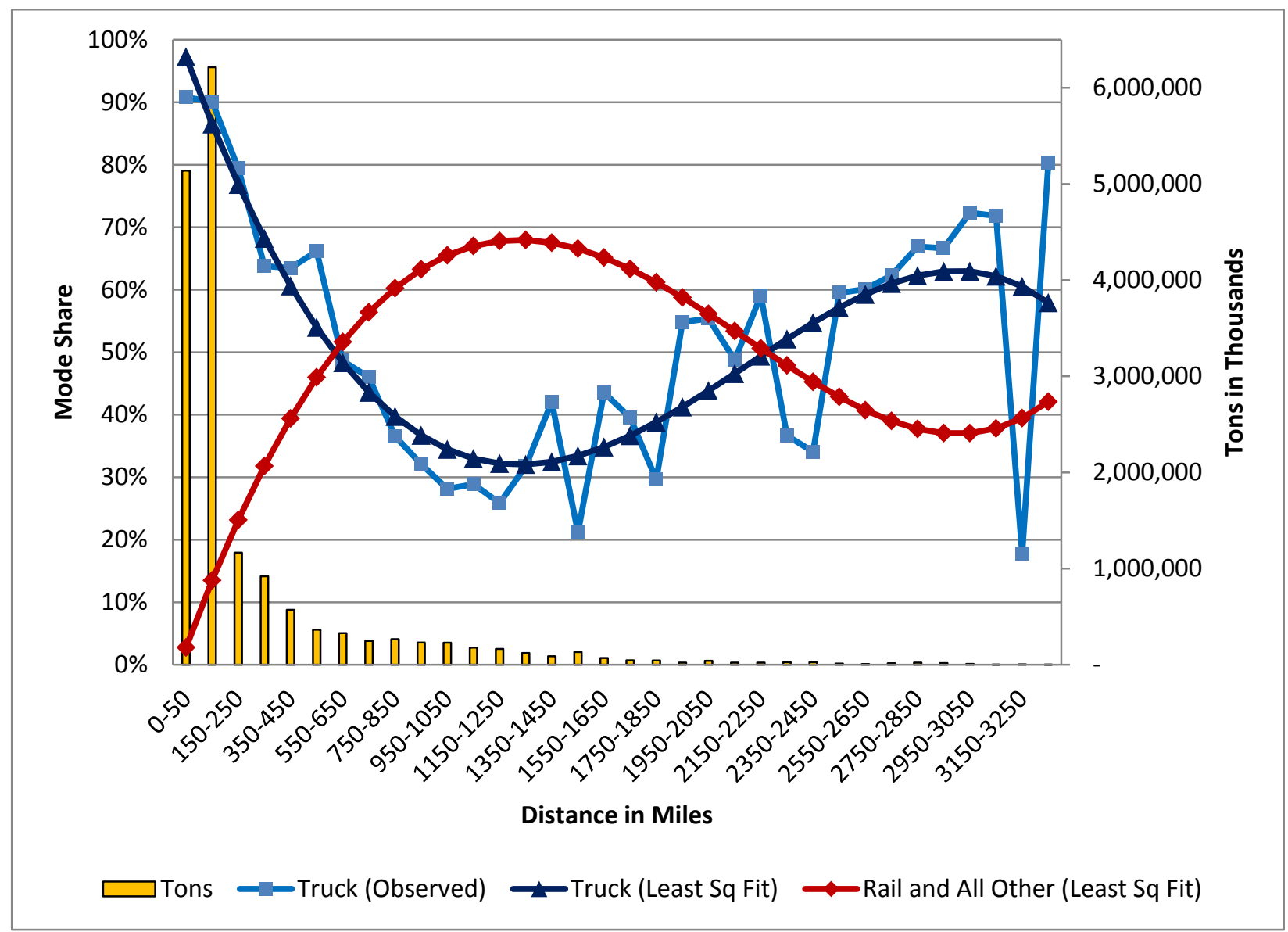

Figure 2.5. Freight modal shares and tons by distance for all commodities, 2007

(Source: Cambridge Systematics, Inc., NREL Freight Energy Analysis Tool, FAF 3.2)

Note: Least squares fit is a mathematical procedure for finding the best-fitting curve to a given set of points by minimizing the sum of the squares of the offsets ("the residuals") of the points from the curve.

The FAF 3.2 data show that trucks dominate the market today for freight shipments under 500 miles, which account for almost $80 \%$ of all domestic freight tonnage. Rail, barge, and pipeline command the market for freight shipments between 500 and 2,000 miles, reflecting the lower cost and greater fuel efficiencies possible with rail, water, and pipeline technology. Trucks and air freighters have the larger share of the market between 2,000 and 3,000 miles where the tonnage of very long-distance shipments (and, by implication, the size of individual shipments) is small and the lack of direct rail and water service makes truck and air more attractive to shippers.

The figure also shows that the amount of tonnage moving in the over 500-mile range is much smaller than the amount being moved in the under 500-mile range. While there are opportunities to shift some of this tonnage from truck to rail or water, the potential for a major shift of tonnage is limited by the size of the market.

Figure 2.6 compares modal shares and ton-miles, where a ton of freight moved one mile constitutes a tonmile of freight movement. The modal shares for truck and rail-and-all-other modes are calculated and plotted the same way as in the preceding figure, but the columns show ton-miles, not tons. 


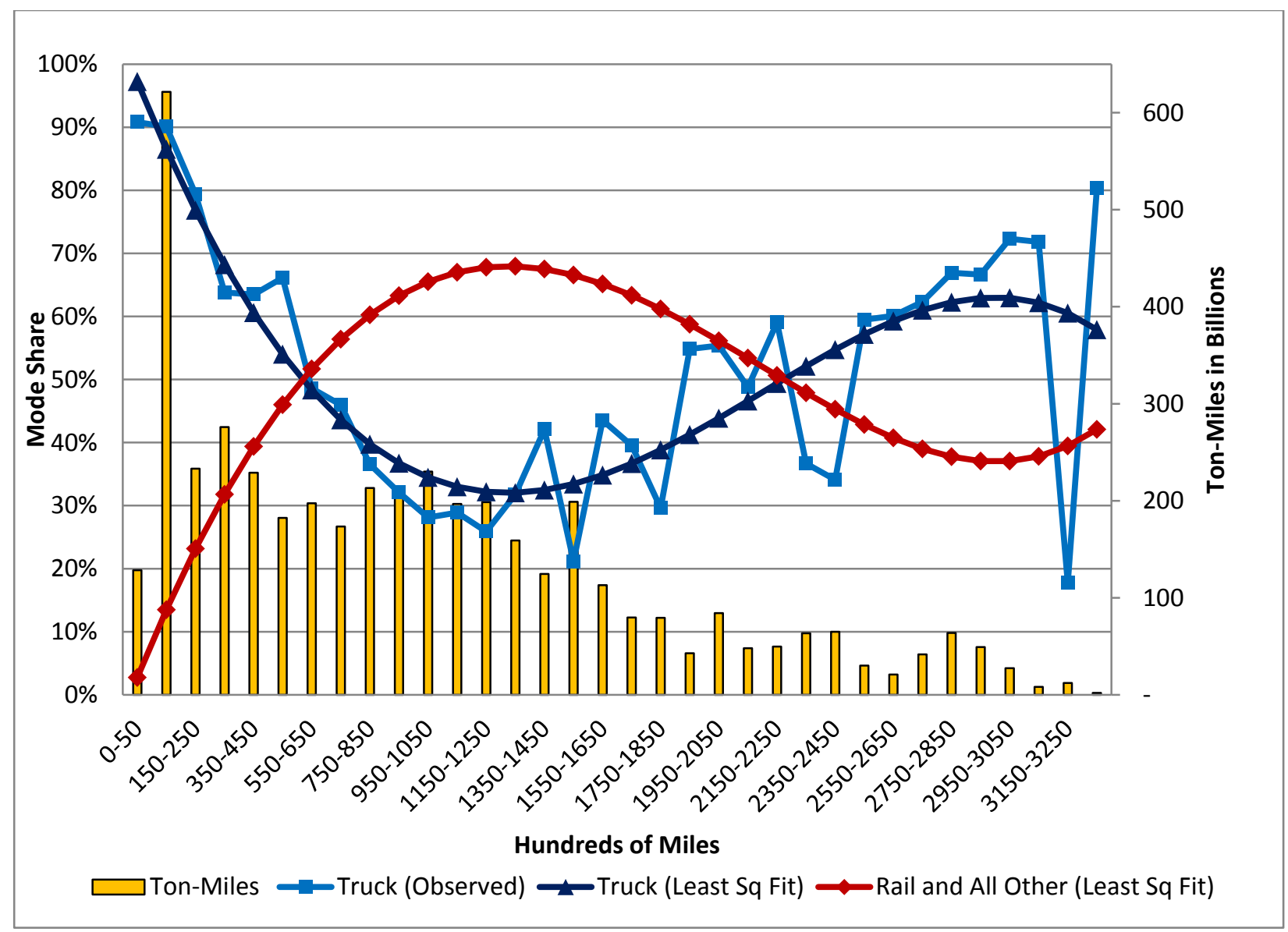

Figure 2.6. Freight modal shares and ton-miles by distance for all commodities, 2007

(Source: Cambridge Systematics, Inc., NREL Freight Energy Analysis Tool, FAF 3.2)

Note: Least squares fit is a mathematical procedure for finding the best-fitting curve to a given set of points by minimizing the sum of the squares of the offsets ["the residuals"] of the points from the curve.)

Relatively few ton-miles are accrued in the 0- to 50-mile distance band because the shipment distances are short and the FAF (and the Commodity Flow Survey upon which the FAF is based) does not capture all local freight movement within cities and counties, especially freight carried in light- and medium-duty straight and small tractor-semitrailer trucks. As a result, ton-miles of travel at the local level are underrepresented. The FAF does a better job of capturing the intercounty and intraregional freight moves in the 50- to 150-mile distance band, about $85 \%$ of which moves by truck. Many of the ton-miles in this band are accounted for by shipments generated by regional distribution centers, petroleum distribution from terminals, and inter-manufacturing plant shipments.

Unlike the distribution of tonnage, the distribution by ton-miles shows substantial ton-miles accruing to truck, rail, and other modes in the 250- to 1,500-mile distance bands. This suggests opportunities to reduce energy use and GHG emissions by improving the energy efficiency of truck, rail, and water freight operations and by shifting freight tons and ton-miles from truck to rail at the lower end of this range, especially freight moving in 250- to 750 -mile range.

The total amount of freight that can be shifted from truck to rail in the 250- to 750-mile range depends on the widely differing service requirements and economics of individual commodities being moved at these distances. As an example, Figure 2.7 compares modal shares and cumulative ton-miles for mixed freight (commodity group 43) shipments, which are a broad assortment of consumer merchandise, semi-finished parts, and other retail goods. Almost $60 \%$ of the ton-miles are under 750 miles, but rail captures less than 
$10 \%$ of these ton-miles, reflecting the fact that mixed freight shipments are relatively high-value and time-sensitive shipments. Rail could capture more mixed freight, but can only do so by providing service that is very competitive with truck service.

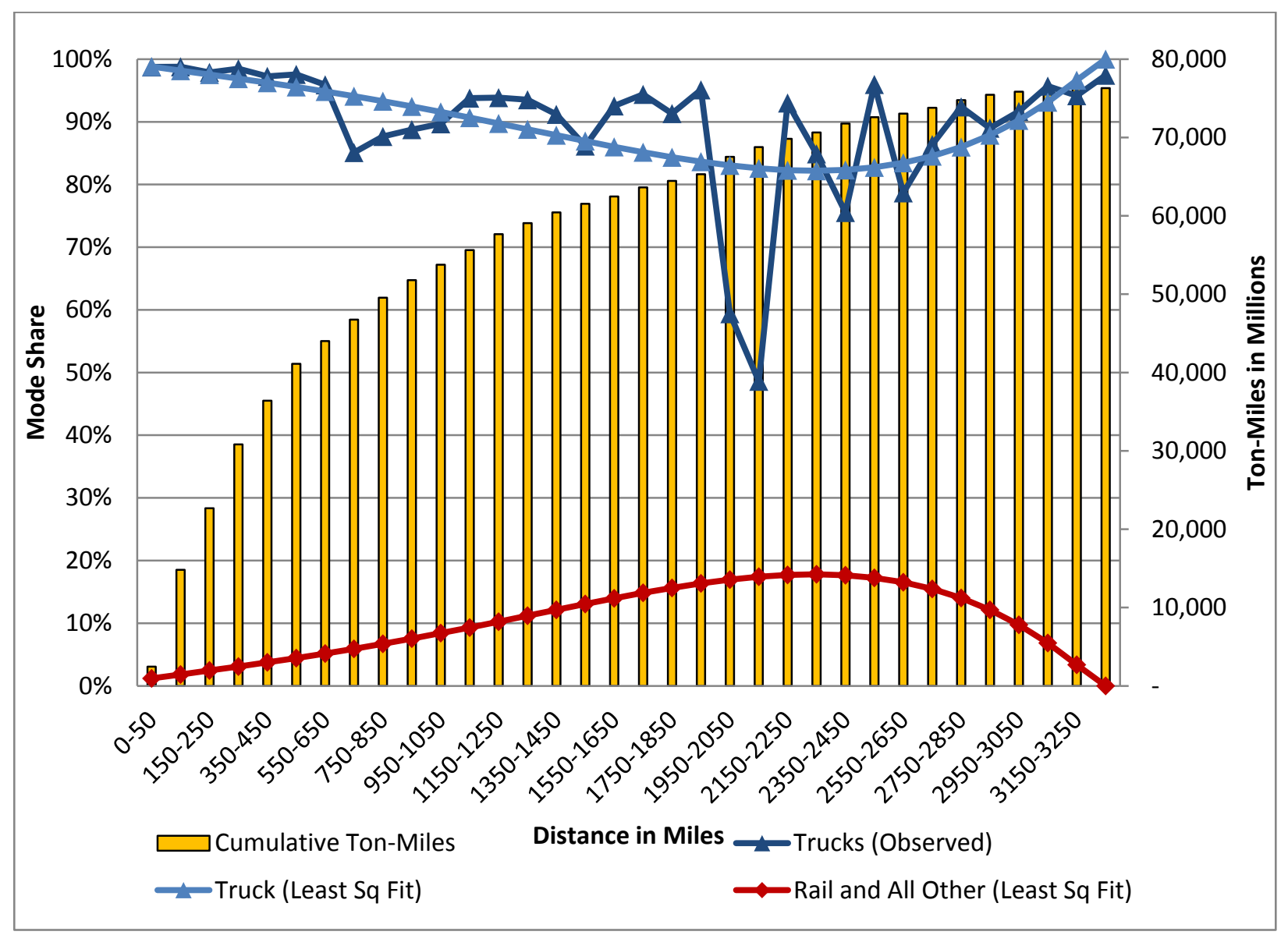

Figure 2.7. Freight modal shares and cumulative ton-miles by distance for mixed freight (commodity group 43), 2007

(Source: Cambridge Systematics, Inc., NREL Freight Energy Analysis Tool, FAF 3.2)

Note: Least squares fit is a mathematical procedure for finding the best-fitting curve to a given set of points by minimizing the sum of the squares of the offsets ("the residuals") of the points from the curve.

Figure 2.8 shows a different pattern, this one of the modal shares and distribution of ton-miles for shipments of machinery (commodity group 34). On average, machinery is shipped longer distances, with only $35 \%$ of cumulative ton-miles accruing with 750 miles. But because machinery is moving longer distances and the shipments tend to be heavier than mixed freight shipments, rail captures a large portion of this market, approaching $15 \%$ at 750 miles. Rail could capture a larger share of the market -in both the mid- and longer-distance markets - but again, must provide services that are price- and qualitycompetitive with trucking. 


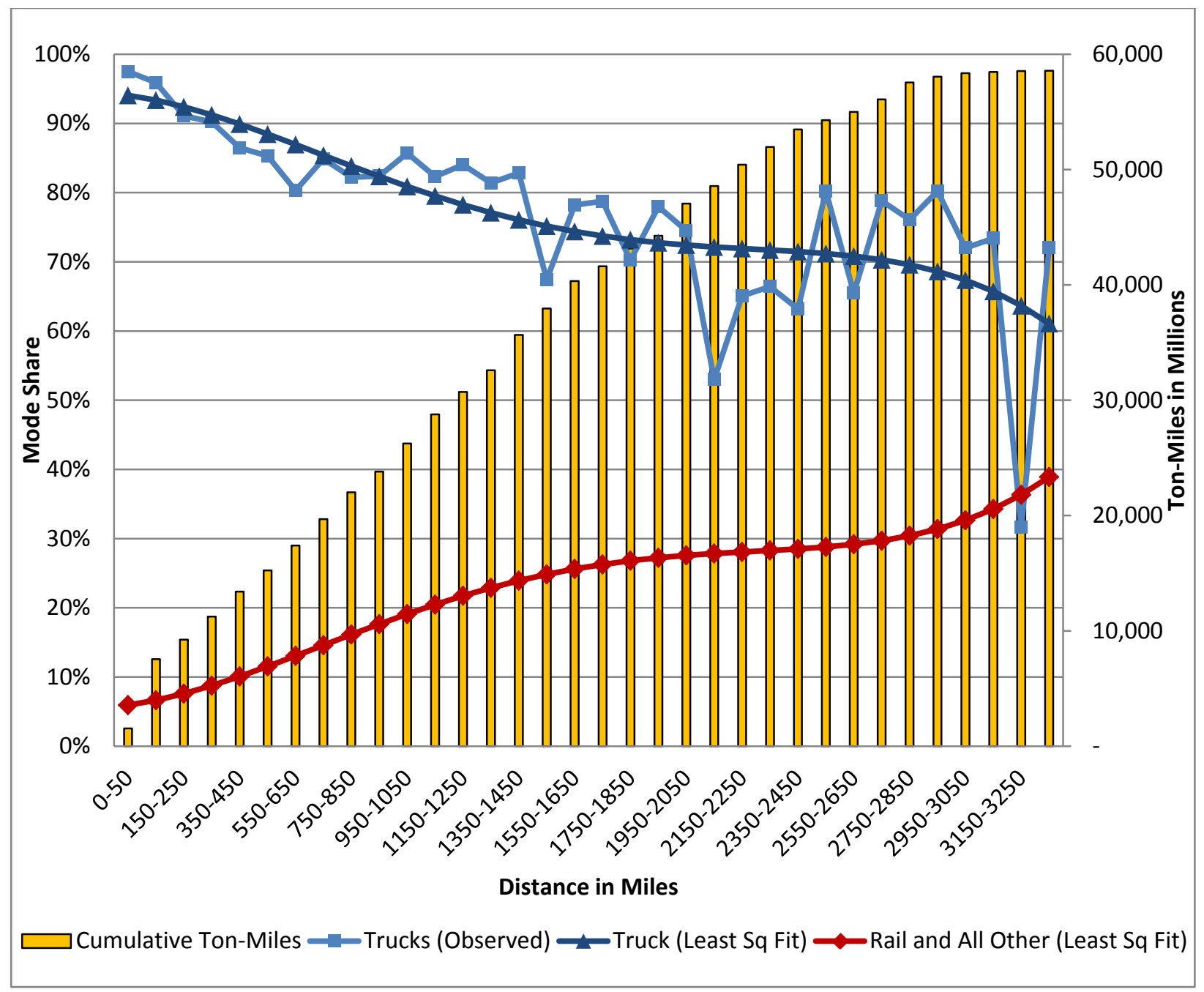

Figure 2.8. Freight modal shares and ton-miles by distance for machinery (commodity group 34), 2007

(Source: Cambridge Systematics, Inc., NREL Freight Energy Analysis Tool, FAF 3.2)

Note: Least squares fit is a mathematical procedure for finding the best-fitting curve to a given set of points by minimizing the sum of the squares of the offsets ["the residuals"] of the points from the curve.

The next section describes each of the freight transportation modes. Section 3.0 outlines the key factors that influence mode choice and explain the current modal shares, and Section 4.0 explores opportunities to change the modal share of tons and ton-miles among the modes.

\subsection{Truck}

As shown in Figure 2.9, trucks are the dominant mode of domestic freight transportation in the United States, handling approximately $81 \%$ of total weight and nearly $86 \%$ of the total value of freight shipments in 2009 (FHWA 2012). ${ }^{8}$ As shown in Figures 2.3 and 2.4, freight trucks are responsible for almost $20 \%$ of all transportation-related fuel consumption and GHG in the United States. According to the Bureau of

\footnotetext{
${ }^{8}$ The source for all of the freight projections within this report is FAF3 data released by FHWA in 2010. FAF3 is a comprehensive database of freight flows by all modes to, from, and within the United States. FAF3 provides estimates for tonnage and value, by commodity type, mode, origin, and destination for 2007 and forecasts through 2040. FAF3 provides data for 43 commodity classes.
} 
Transportation Statistics in 2011, trucks had an average fuel economy of 5.9 miles per gallon (mpg) in 2007, and traveled over 225 billion vehicle miles in 2007.

Understanding the role of trucks in the freight system and the various components of truck activity helps identify which components are candidates for modal shift. Because of its flexibility, cost-effectiveness, and high level of service, truck is the mode of choice for many shippers and manufacturers. And because trucks have the flexibility to provide last-mile service, they often work closely with other modes to transport goods between the shipper or customer and ports, airports, distribution, transload, or intermodal facilities. The past several decades have seen increased integration of the truck and rail portion of intermodal service by carriers, such as J.B. Hunt and Schneider. Truck trips also are an important part of the services provided by integrated carriers such as FedEx and UPS.

The definition of freight trucks in the Energy Information Administration's (EIA) National Energy Modeling System Transportation Demand Module is any truck with a gross vehicle weight rating of more than 10,000 pounds (EIA 2010). This includes not only long-haul freight movement but also a substantial amount of short-haul distribution and urban goods movement traffic, construction trucking, and service trucking. Freight trucking activity as represented by the FAF data describes primarily long-haul intercity freight movement. The estimates of vehicle miles traveled (VMT) associated with long-haul intercity freight are imprecise owing to the inability to isolate these from all trucking in road counts and imprecise data on average truck payloads. As a result, the trucking activity accounted for in the FAF represents anywhere from $40 \%$ to $60 \%$ of the total freight truck VMT reported by EIA. There will be relatively few opportunities so shift freight from short-haul trucking to short-haul rail. Many of the rail lines that served local rail pick-up and delivery have been removed; few businesses and industries - except at major distribution centers - are designed or operated to absorb railcar-size deliveries; and the labor and energy cost to move a locomotive and a dozen rail cars is prohibitively high for all but the heaviest, bulkiest, or most hazardous of commodities.

\subsection{Rail}

Rail falls on the lower end of the freight service spectrum, providing lower-cost transportation for longdistance shipments and bulk goods. Even within rail, though, there are different levels of service and price. Bulk unit trains of coal moving from mines to power plants or grains moving from farms to ports represent the lower-price end of rail service, and rail often competes with water transport for these types of goods. Premium rail and intermodal service is targeted at international containers and domestic containers and trailers. This business, which is in direct competition with the trucking industry, represents the fastest growing segment of rail service. Carload service (boxcars, gondolas, tank cars, etc.) falls between the slow bulk unit trains and the faster intermodal services in terms of price and service levels.

Freight locomotives are responsible for approximately $2.1 \%$ of transportation-related fuel consumption ${ }^{9}$ and GHG emissions (AAR 2012b) in the United States. Freight trains traveled over 435 million miles in 2009, with an average fuel economy of 10 mpg per railcar (Beningo et al. 2011; AAR 2009).

\subsection{Air}

Air cargo serves primarily high-value, time-sensitive commodities. As shown in Figures 2.9 and 2.10, the total volume of air cargo is much lower than other modes, although the average shipment value and trip length are both higher.

Air cargo generally moves one of two ways: on dedicated cargo planes, or as belly cargo in the holds of regularly scheduled passenger planes. Air cargo provides the fastest service to certain markets, yet is limited in the types of commodities that can be economically transported. The use of passenger airplanes

\footnotetext{
${ }^{9}$ Class I railroads only. In 2009, according to the Bureau of Transportation Statistics, National Transportation Statistics, 2011, Class I railroads consumed 3,192 million gallons of diesel fuel (Table 4.5) and the entire U.S. transportation sector consumed 152,861 million gallons (4,931 barrels) of diesel fuel (Table 4.4) (Beningo et al. 2011).
} 
carrying freight as belly cargo limits the potential to shift freight from truck to air because of capacity and schedules, especially as the passenger airlines have cut back on less profitable routes and substituted regional jets for large jets. In addition, tighter security measures and increasing passenger load factors (from $65 \%$ on domestic flights in 1995 to $78 \%$ in 2010 ) have increased costs and further decreased capacity (International Air Transport Association, undated).

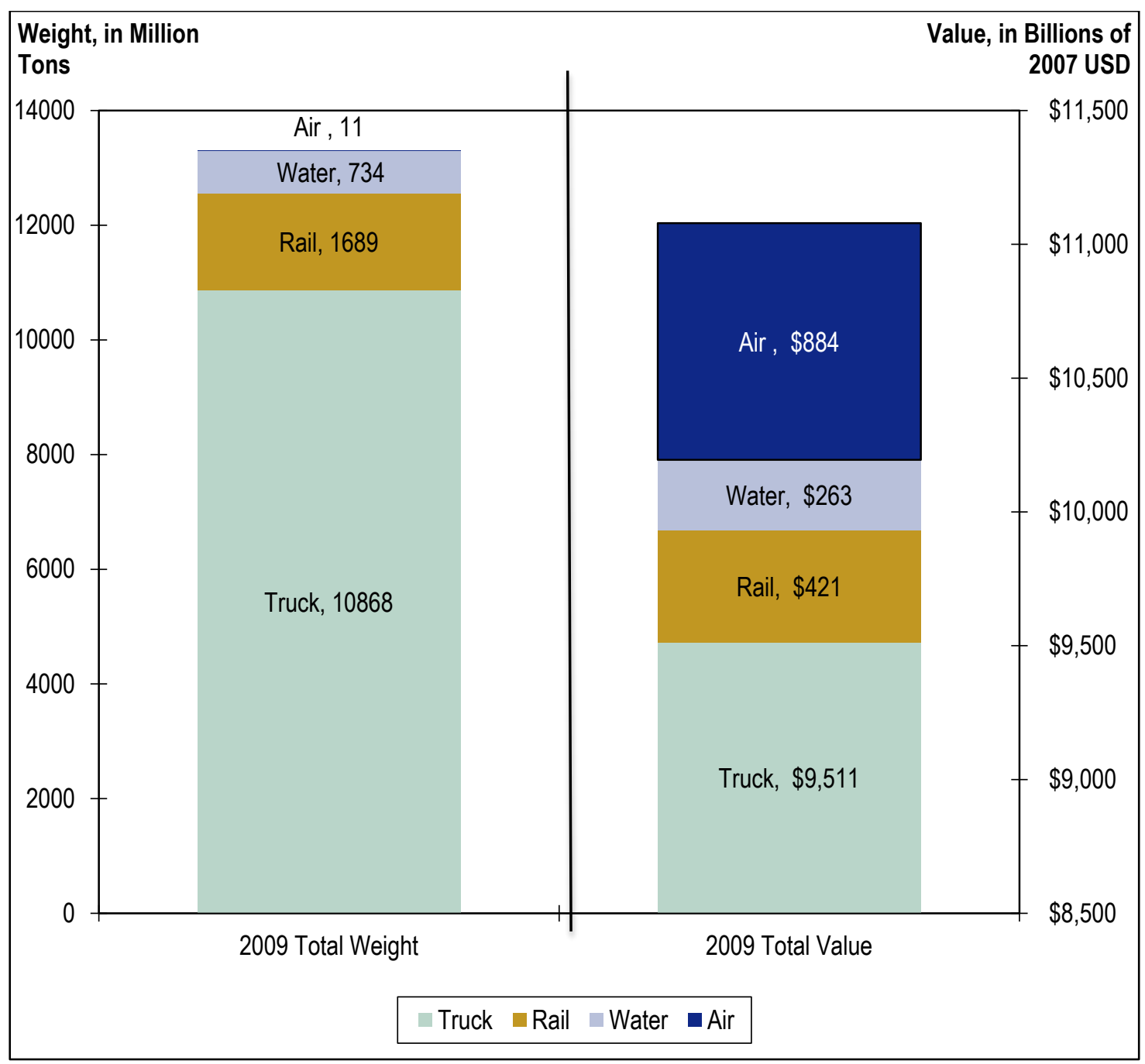

Figure 2.9. Freight tonnage and value, 2009

(FHWA 2012) 


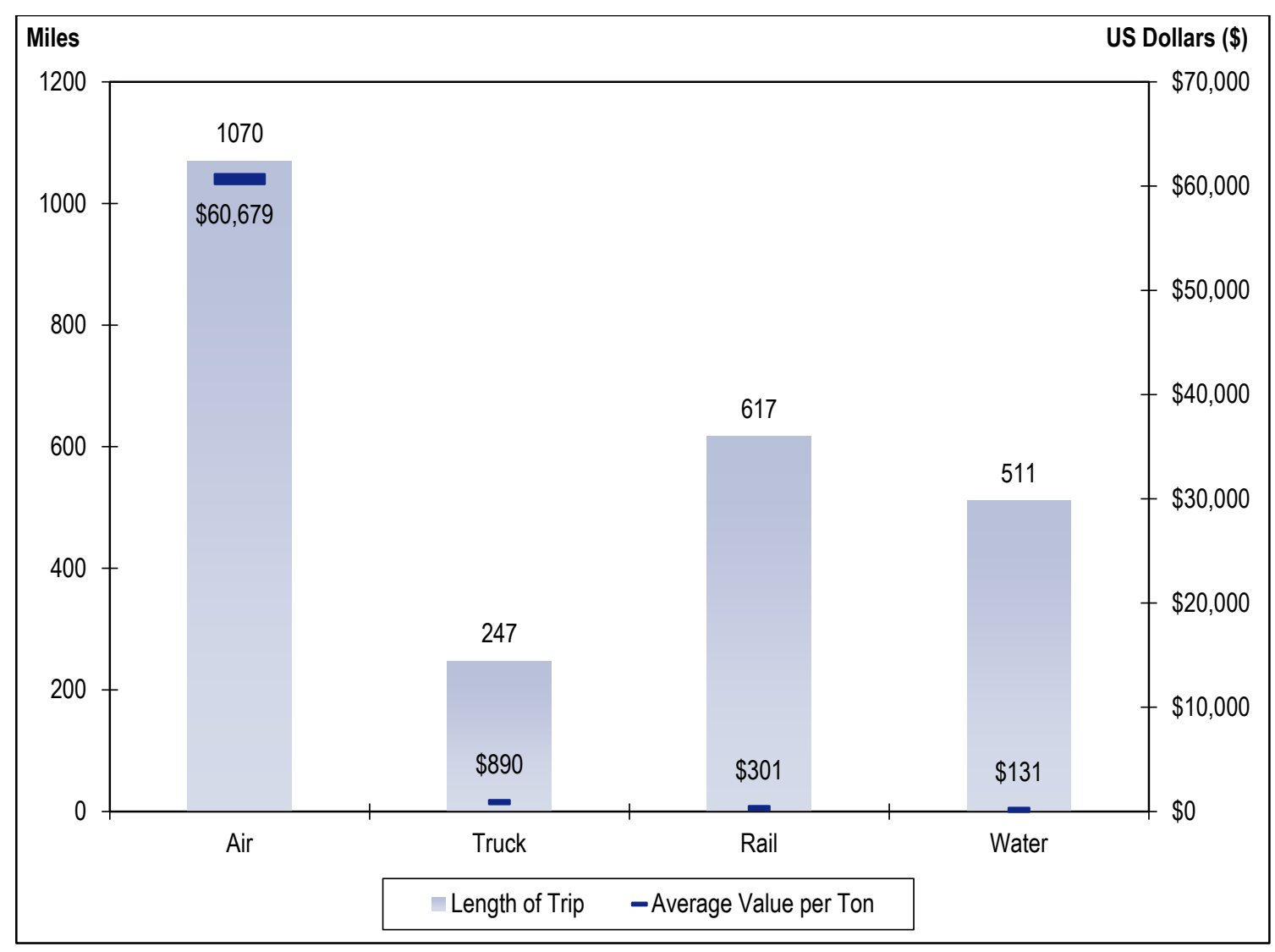

Figure 2.10. Average length of trip and value per ton of cargo, 2010

[Source: AASHTO Freight Rail Bottom Line Report (adapted) (AASHTO 2003)]

Almost 40 billion ton-miles of freight were moved by air carriers in 2006: 16 billion ton-miles by domestic carriers, and 24 billion ton-miles by international carriers to or from the Unites States [U.S. Department of Transportation, Bureau of Transportation Statistics, U.S. Air Carrier Traffic and Capacity Summary by Service Class (2007) as cited in Beningo et al. (2011)]. Fuel efficiency of air freight is difficult to calculate because of the mix between passenger and freight service on many airlines.

\subsection{Water}

Coastal and inland waterway movements are generally the slowest but least expensive shipment method. Inland or coastal waterways are used primarily to transport bulk commodities, such as grain or sand. As shown in Figure 2.11, a typical inland barge has a capacity 15 times greater than one rail car and 60 times greater than one semi-trailer truck for dry cargo and even more capacity for liquid cargo.

Shipments by water often start and finish with rail or truck modes. In 2005, barges and other ships carried over 1 billion tons of domestic freight over average haul distances of 450 miles for internal waterway shipments to 1,200 miles for coastal shipments. Another 1.5 billion tons were hauled as imports and exports to coastal and inland ports [U.S. Army Corps of Engineers, Waterborne Commerce of the United States, as cited in Beningo et al. (2011)]. 

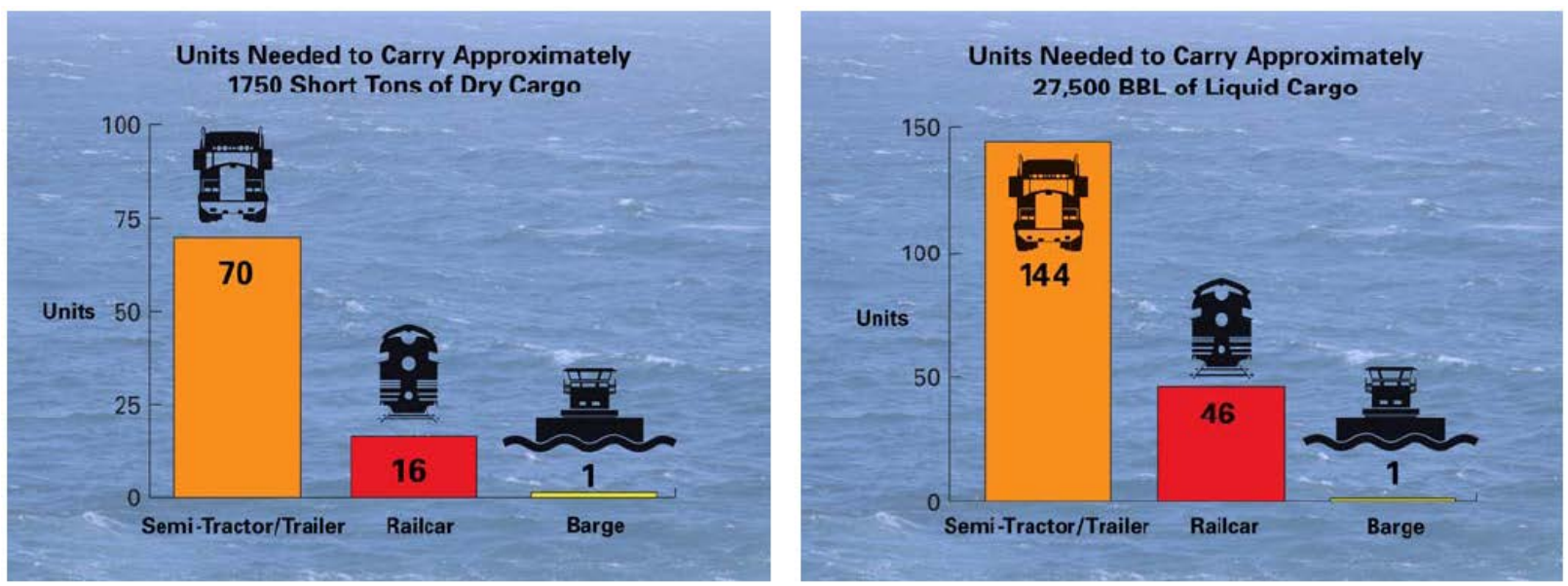

Figure 2.11. Modal capacity comparisons

(Kruse et al. 2009) 


\section{FACtors Influencing Mode Choice}

Freight transportation is a service purchased by shippers and receivers, and hence the freight transportation market operates in response to shippers' needs. Shippers and receivers, and their third-party logistics providers, typically make their purchasing decisions based on multiple factors, including modal characteristics, commodity characteristics, shipper/receiver characteristics, total costs, and other factors. The critical factors are listed in Table 3.1, but the importance of these and other factors is highly dependent on the individual agents who make the decisions. The service that a particular shipper chooses depends on the commodity, trade lane, ${ }^{10}$ and competitive advantage offered by the different modes. A discussion of some of the critical factors is provided below. Selection and discussion of these factors is based on authors' expertise with the freight transportation industry and assessment of the literature.

Table 3.1. Factors that Affect Freight Modal Choice

\begin{tabular}{ll}
\hline Factor Category & Factor \\
\hline Modal Characteristics & Capacity \\
& Trip Time \\
& Reliability \\
& Equipment Availability \\
& Customer Service and Handling Quality \\
\hline Commodity Characteristics & Shipment Size \\
& Package Characteristics \\
& Shipment Shelf Life \\
& Shipment Value \\
& Shipment Density \\
\hline Shipper and Receiver Characteristics & Access to modes \\
\hline Logistics Costs & Order and Handling Costs \\
& Transportation Charges \\
& Capital Carrying Cost in Transit \\
Intangible Service Costs, i.e., Billing Processes \\
Inventory Costs \\
Loss and Damage Costs \\
Service Reliability Costs \\
\hline Additional Factors & Length of Haul \\
& Shipment Frequency \\
& Environmental/Sustainability \\
\hline
\end{tabular}

(Sources: TRB 2010, Table 3.6; Florida Department of Transportation 2008 Table 4.1)

\subsection{Modal Characteristics}

Price, capacity, transit speed, and equipment availability are among the most obvious and important considerations for shippers when buying freight transportation services. Reliability, or the degree of certainty and predictability in travel times on a system, is also a critical factor, particularly for just-in-time logistics processes, which rely on timely and predictable shipments to reduce inventory costs.

The capacity of a system provides an upper bound on the amount of traffic that can use a particular mode or route. Congestion or other increased costs are often the result of systems near capacity, which can lead to increased travel cost and time and are reflected in higher prices offered to shippers by carriers. Time in transit is often a consideration for shippers' mode choice, from a cross-town shipper who sees travel time variability of a few minutes or hours, to long-haul shippers who see variability from a few hours to weeks. In addition to travel time, additional time may be needed for drayage operations, intermodal interchanges,

\footnotetext{
10 "Trade lane" typically refers to a route between to two cities. A lane can be served by one or modes; for example, the trade lane between Los Angles and Chicago is served by both highway and rail.
} 
container loading, or local pickup/delivery. Particularly for specialized shipments (i.e., chemicals or live animals), the availability of specialized equipment can further limit shippers' mode choice.

Increased use of just-in-time logistics practices has contributed to reduced warehousing and production costs for businesses, but at the same time has increased the pressure on freight transportation providers to provide consistent, reliable, and predictable transportation service. Reliability is of particular concern for intermodal shipments, as precisely scheduling intermodal transfers are a key component to efficient and successful intermodal freight transportation operations. The inability to confidently schedule these modal transfers often leads to one of two things. If precise transfer schedules are maintained, many intermodal transfers are missed, affecting operations further down the logistics chain. The other, more common, result is that intermodal schedules have built-in slack time to account for unreliable travel times. While this can prevent intermodal connections from being missed, it introduces inefficiencies in the process and drives up total costs for both shippers and carriers.

Trucking is generally regarded by shippers as the most reliable mode because of its ability to provide tailored door-to-door service and plan alternative routes to avoid roadway delays. However, recent years have seen significant increases in rail and intermodal reliability, and in some markets and some commodity types, these services compete effectively with trucks.

\subsection{Commodity Characteristics}

Another consideration in modal selection is the characteristics of the commodities being shipped, as some commodities - due to size, weight, perishability, or other factors - are more cost-effectively transported by one specific mode. Shippers typically consider:

Shipment Weight and Density. Shipment weight is a critical consideration, given state and federal regulations on allowable truck weights. Some elements of the rail system - particularly on the smaller (regional or short line) railroads - are also weight-restricted because of the limited weight-bearing capacity of older rail track and bridges. Higher-weight shipments tend to be low in value (e.g., grain, coal) and will be shipped by rail or water. However, the density of shipments is also an important factor in modal selection. For low-density freight, such as computer equipment or snack foods, vehicle sizedefined by the cubic capacity of the trailer, railcar, or container - limits the amount of payload freight that can be carried, not vehicle weight limits (FHWA 2000). Shipments of these commodities are said to cube out before they weigh out; that is, the truck trailer is filled well before the maximum payload weight is reached. The FHWA's Comprehensive Truck Size and Weight Study estimated that $80 \%$ of low-density but higher-value shipments cube out prior to weighing out (FHWA 2000). Increasing the cubic capacity of truck (as is done by permitting one truck tractor to haul two or three trailers) increases the costeffectiveness of trucking; likewise, moving from single-stack to double-stack rail cars (stacking containers two deep on a rail flat car) increases the cost-effectiveness of rail intermodal operations. However, shifting low-density freight from truckload to rail carload generally does not generate significant cost savings unless the freight is moving very long distances.

Package Characteristics (i.e., the qualities of a shipment that may require special handling or transport operations). Certain commodities may have characteristics requiring a certain type of handling, packaging, or transport. Shipments that have special requirements (e.g., hazardous materials, oversize/ overweight) are often carried by a particular mode because of these considerations and are unlikely candidates for modal shift.

Shipment Shelf Life or Value. Shipments with a short shelf life or that are highly valuable require faster transport than those that are nonperishable, not urgent, and/or low value. High-value shipments may require guarantees of timeliness or special handling by the shipper, and can also incur high-insurance or incidental costs. Some shippers of goods, such as perishable food and high-end autos, choose to employ a limited number of carriers (mainly truck) to ensure their additional specifications. 


\subsection{Logistics Costs and Characteristics}

The most important factor in many mode choice decisions is the total logistics cost, which includes transportation and logistics costs, inventory costs, risk mitigation/compliance costs, and other factors. The key components include:

Transportation Costs. The cost of transportation is a part of the overall logistics cost and includes the shipping cost, handling cost, and other costs (i.e., insurance) paid to the carrier. Studies on price elasticity (which estimate the likelihood that a change in price will cause a shift in demand) are limited and usually case dependent. However, one study showed that rail is the most sensitive to cost variation (Beuthe et al. 2001). Some opportunities for modal shift involve influencing the cost of transportation through pricing, fee, and tax strategies.

Length of Haul/In-Transit Carrying Cost. Length of haul and in-transit carrying cost are factors that describe the distance that a commodity is shipped and the costs to have the commodity in transit over this distance. When carrying costs are high, shippers may choose faster modes, such as truck. The cost structure of trucking can be more favorable to short-haul shipments because they use roads and do not require additional infrastructure, such as rails or ports, making trucking more cost effective for over a short distance. As a general rule of thumb, trucking is more cost-effective for trips of up to 500 miles and rail for shipments 500 to 1,500 miles. The exceptions include very heavy dense shipments, such as gravel, that will move short distances by rail and very light, high-value shipments that will move long distances by truck or air.

Inventory Cost/Shipment Frequency. Inventory costs and shipment frequency are factors that describe the strategy to have goods ready at hand (i.e., in inventory) or have goods shipped as needed. As firms have shifted to a pull-based system, where goods are delivered just in time, overall inventory costs have significantly decreased, and shipment frequency has increased. Shippers employing these systems often place a high value on fast, frequent, and flexible service.

Loss and Damage Costs. Loss and damage costs include payments for lost or damaged inventory or delayed shipments. These costs can vary significantly by carrier and mode, depending on their reliability and business practices.

Scheduling and Frequency. Availability of scheduled service and the frequency of service in general are important considerations, particularly for high-demand or high-value shipments. Recently, rail carriers have begun to offer more scheduled service in order to meet their customers' needs and to compete more closely with the service provided by trucks.

\subsection{Emerging Trends in Mode Choice}

In recent years, the increased focus on environmental sustainability, fluctuating fuel prices, and the global economic downturn have led many shippers to rethink their business practices. In addition to the factors discussed above, there are a number of emerging trends and issues that are beginning to influence both freight demand and mode choice decisions.

\subsubsection{Greening of the Supply Chain}

Current trends in environmental and economic efficiency have led many shippers to rethink or redesign their supply chains. Sustainability metrics, including GHG emissions, fuel use, and pollution emissions are being incorporated in supply chain and transportation purchase decisions. The effects on individual shippers' mode selections are not well documented, but the rise in programs and certifications, such as the U.S. Environmental Protection Agency's (EPA's) SmartWay, suggest that more companies are considering sustainability (EPA undated). A recent stated-preference survey found that GHG emissions were identified as one of five potentially relevant characteristics that a shipper may use to make transport decisions (Fries and Patterson 2008). 
Oftentimes, changes implemented in order to increase environmental sustainability yield economic benefits as well. Businesses have made changes to everything from the way they package their products, to the trucks and warehouses that they use and to the countries from which they source their products. In the computer industry, for example, both Dell and Hewlett-Packard have realized economic benefits by adjusting their packing in order to reduce its costs and environmental impact. Hewlett-Packard committed to reduce the amount of plastic used in printer packaging by $50 \%$, utilize at least $35 \%$ recycled paper in cardboard packaging material, and reduce the overall weight of printer packaging by $50 \%$ by 2011 (HP 2012). Dell has found that reducing its use of cardboard by designing smart packages has saved it money because it can now fill its trucks with more product, increasing the average truck load from 18,000 to 20,000 pounds (Esty and Winston 2006). 3M has developed a system to install adjustable decks in its trucks, allowing it to place pallets on two levels. Using this system has allowed one $3 \mathrm{M}$ facility to reduce its daily truck loads by $40 \%$ and save $\$ 110,000$ annually (3M 2012).

The increased emphasis on green supply chains could induce shippers to investigate the use of more environmentally friendly modes, like rail or waterway shipments, that can handle larger volumes of goods with less energy and fewer GHG emissions. However, because many of these modes cannot effectively compete on cost, speed, and reliability, the focus of many initiatives is on retrofitting existing vehicles to become more environmentally friendly or addressing other elements of the supply chain (e.g., packaging, warehousing).

\subsubsection{Fluctuating Fuel Prices}

Fuel prices have an impact on sourcing and mode choice decisions. While cheap petroleum-based fuels helped drive globalization over the past few decades, fuel prices doubled between 2006 and 2008, increasing the portion of carriers' operating costs devoted to fuel from a historic average of approximately $15 \%$ to over $40 \%$ (Gordon 2009). For importers, fuel prices in the fall of 2008 , when oil prices were around $\$ 100$ per barrel, were equivalent to an $11 \%$ tariff on containerized goods, up from the equivalent of 3\% in 2006 when oil was $\$ 20$ per barrel (Solomon 2009).

While fuel prices have moderated since their peak, the movement towards shorter supply chains may accelerate as the global economy begins to recover and fuel prices are driven higher by increasing and more volatile demand. One early example of this trend is Tesla motors, based in California, which recently canceled plans to produce its 1,000-pound batteries in Thailand, opting for a closer source, thereby reducing the shipping distance of each battery by approximately 5,000 miles (Gordon 2009).

Fluctuating fuel prices make higher-fuel-consuming modes, such as truck, less cost-effective and more volatile and may lead some shippers to investigate the use of alternative modes, particularly rail, for some commodities and trade lanes.

\subsubsection{Railroad Operational Strategies}

Freight railroads are increasingly utilizing hook-and-haul strategies, moving connections off of main lines and running longer and heavier trains. Hook-and-haul strategies involve the railroads picking up and dropping off large blocks of railcars, leaving the assembly and disassembly of these blocks to the industries or to short line railroads. This strategy, which increases train velocity by reducing the number of stops the railroads make for individual railcars, is generally performed off of the main lines on track owned by shippers/industries or short lines, thus freeing the main lines for through trains.

Longer and heavier trains are also being used by the railroads to maximize existing capacity and improve efficiency. For example, BNSF prefers that all its international intermodal shipments be handled in 40foot well cars and all its intermodal trains reach 8,000 feet in length. These requirements allow BNSF to increase the amount of freight that can be handled over its main lines without increasing the number of trains. However, the longer trains cannot be handled without lengthening sidings to permit trains to meet and pass and without providing the corresponding yard capacity to assemble and hold the longer trains. Adding sidings and expanding terminals are major challenges in densely developed urban areas. Railcar 
weights also are increasing with some Class I main lines now capable of handling 315,000-pound railcars. $^{11}$

One result of these and other operational strategies is that some rail-competitive traffic is no longer attractive to large railroads because sufficient volumes cannot be generated. Shippers that cannot guarantee large, consistent blocks of traffic that correspond to the operational needs of the railroads are increasingly forced to investigate alternative modes, usually truck.

\subsubsection{Improved Energy Efficiency}

Modal efficiencies have increased significantly since the 1960s. In particular, the fuel efficiencies of rail have increased over $20 \%$ since deregulation in the 1980s (see Figure 3.1). Increases in rail fuel efficiency are even more striking when examined on a ton-mile basis (see Figure 3.2). At the same time, however, the number of miles traveled by truck has increased eight-fold (Figure 3.1); even as both truck traffic and Class I railroads have seen almost proportional growth in ton-miles (Figure 3.2). Nevertheless, the combination of improved freight rail efficiency and fluctuating fuel prices could lead shippers to investigate the use of freight rail as an alternative to trucking for some shipments.

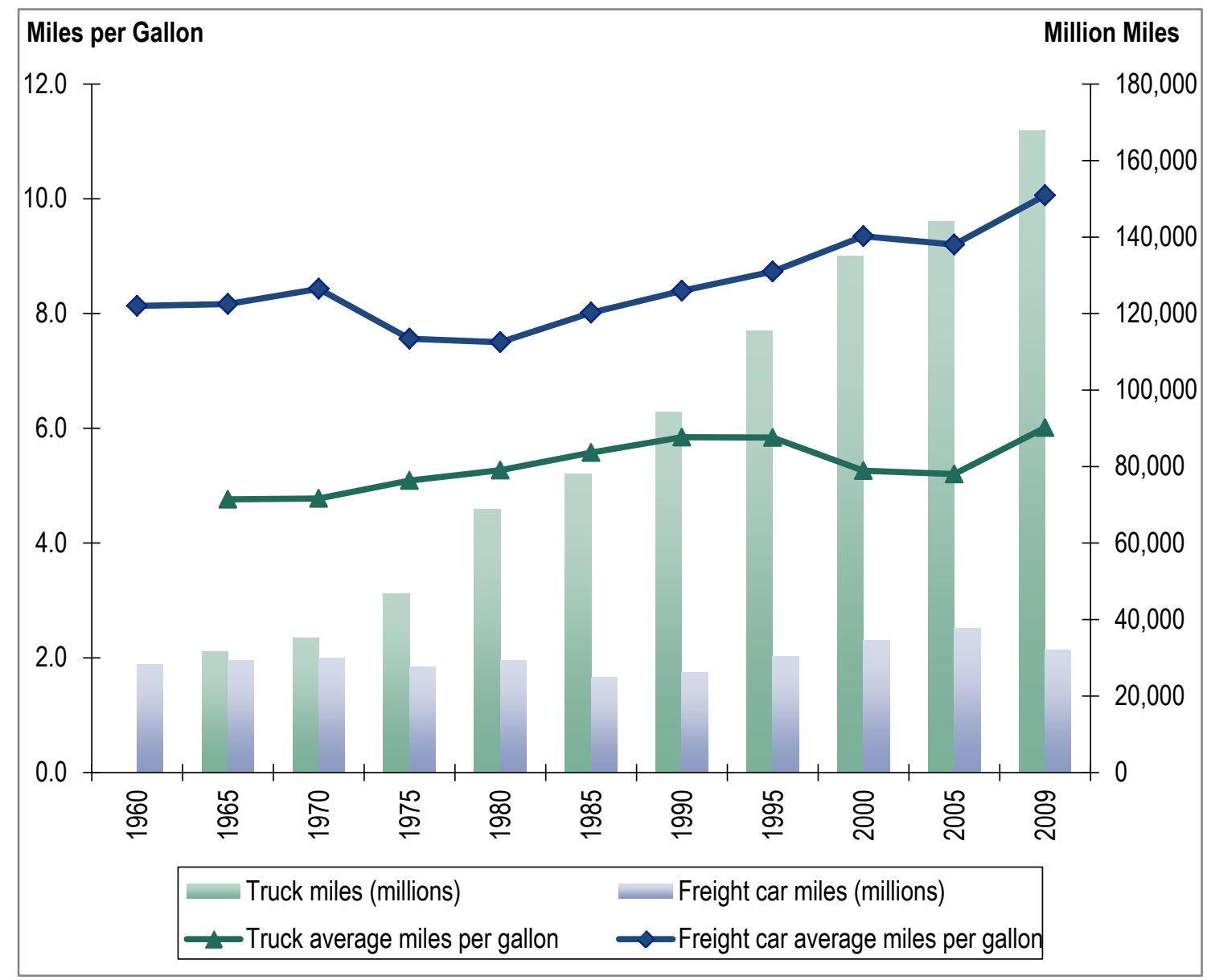

Figure 3.1. Freight truck and rail miles per gallon and miles traveled, 1960 to 2009

[Source: Tables 4-14 and 4-17 (Beningo et al. 2011)]

\footnotetext{
${ }^{11}$ See for example, Washington State Statewide Rail Capacity and System Needs Study (Cambridge Systematics, Inc. 2006).
} 


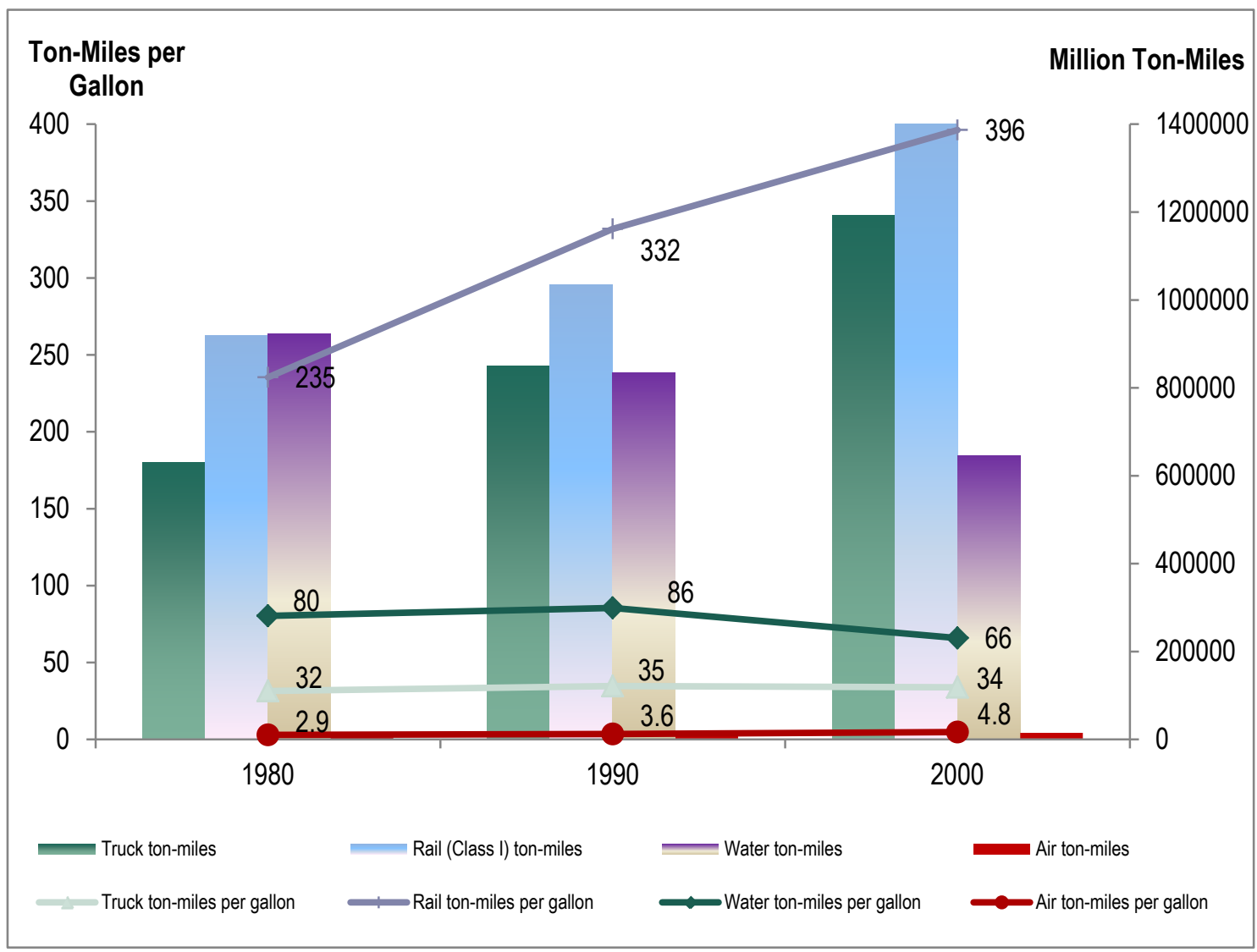

Figure 3.2. Freight ton-miles per gallon and ton-miles traveled, 1980 to 2000

[Source: Tables 4-5 and Modal Profiles (Beningo et al. 2011)]

Along with rail, air freight has also seen almost doubled fuel efficiency since 1980, although at five tonmiles per gallon, even the most efficient air freight movements cannot compete with land- or water-based modes (see Figure 3.2). Water remains the second most fuel efficient mode at over 60 ton-miles traveled per gallon, but the mode has seen decreases both in utilization and fuel efficiency over the past decades.

Figure 3.3 shows the marginal cost per mile of operating a truck in early 2010 (American Transportation Research Institute 2011). Figure 3.4 shows the industry-wide estimate of railroad operating costs in early 2012 (AAR 2012c). ${ }^{12}$ The data are not directly comparable because of the differences in the dates and the underlying accounting and reporting procedures. However, the data provide a general indication of the relative importance of fuel costs in the operation of truck and rail services (Grenzeback et al. 2013).

\footnotetext{
12 The category "Other" in the "Rail Cost Adjustment Factor All-Inclusive Index, 2012" includes purchased services, portions of administrative expenses, and property taxes.
} 


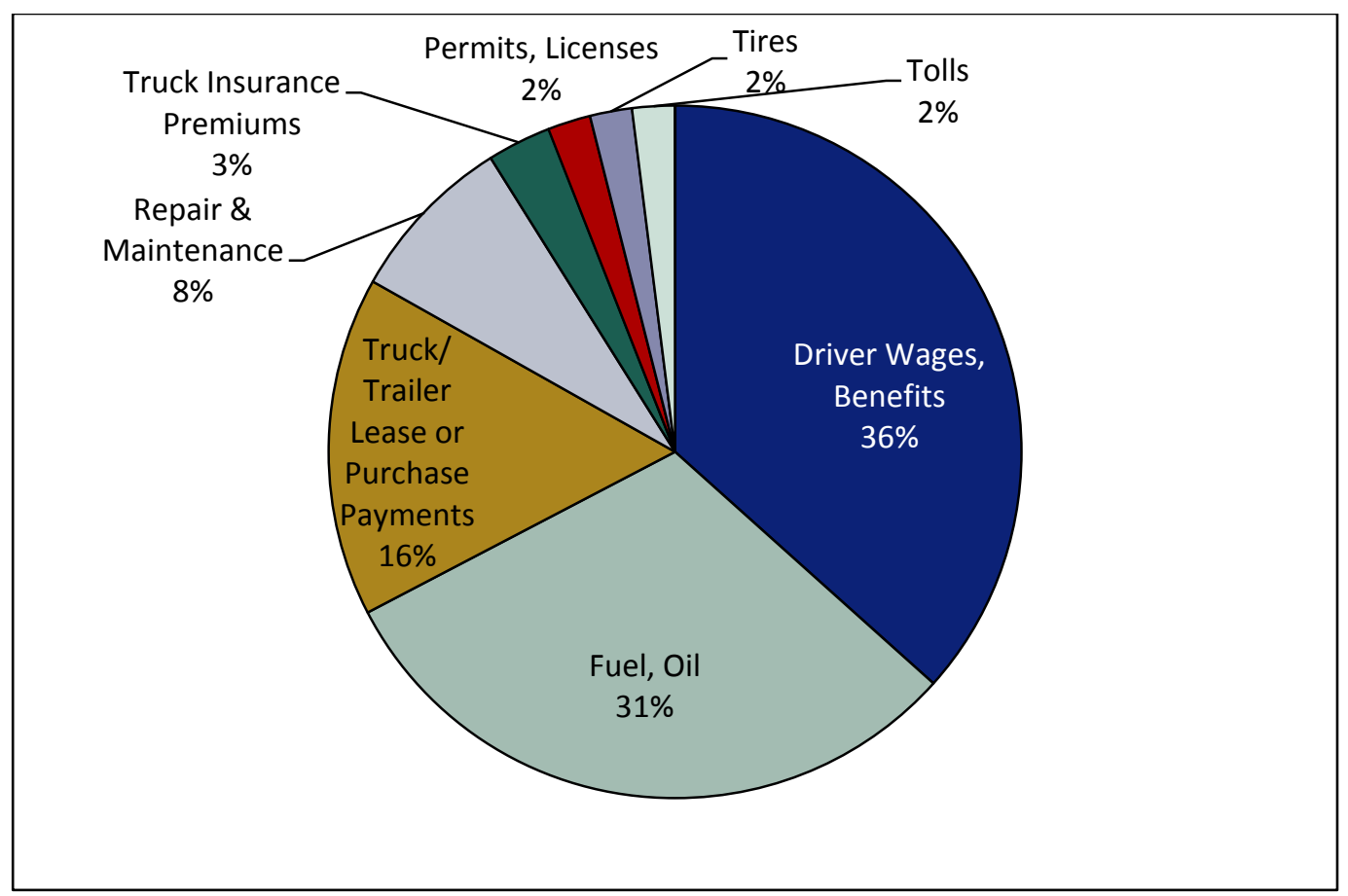

Figure 3.3. Trucking marginal operating costs per mile, 1Q 2010

(Source: American Transportation Research Institute 2011)

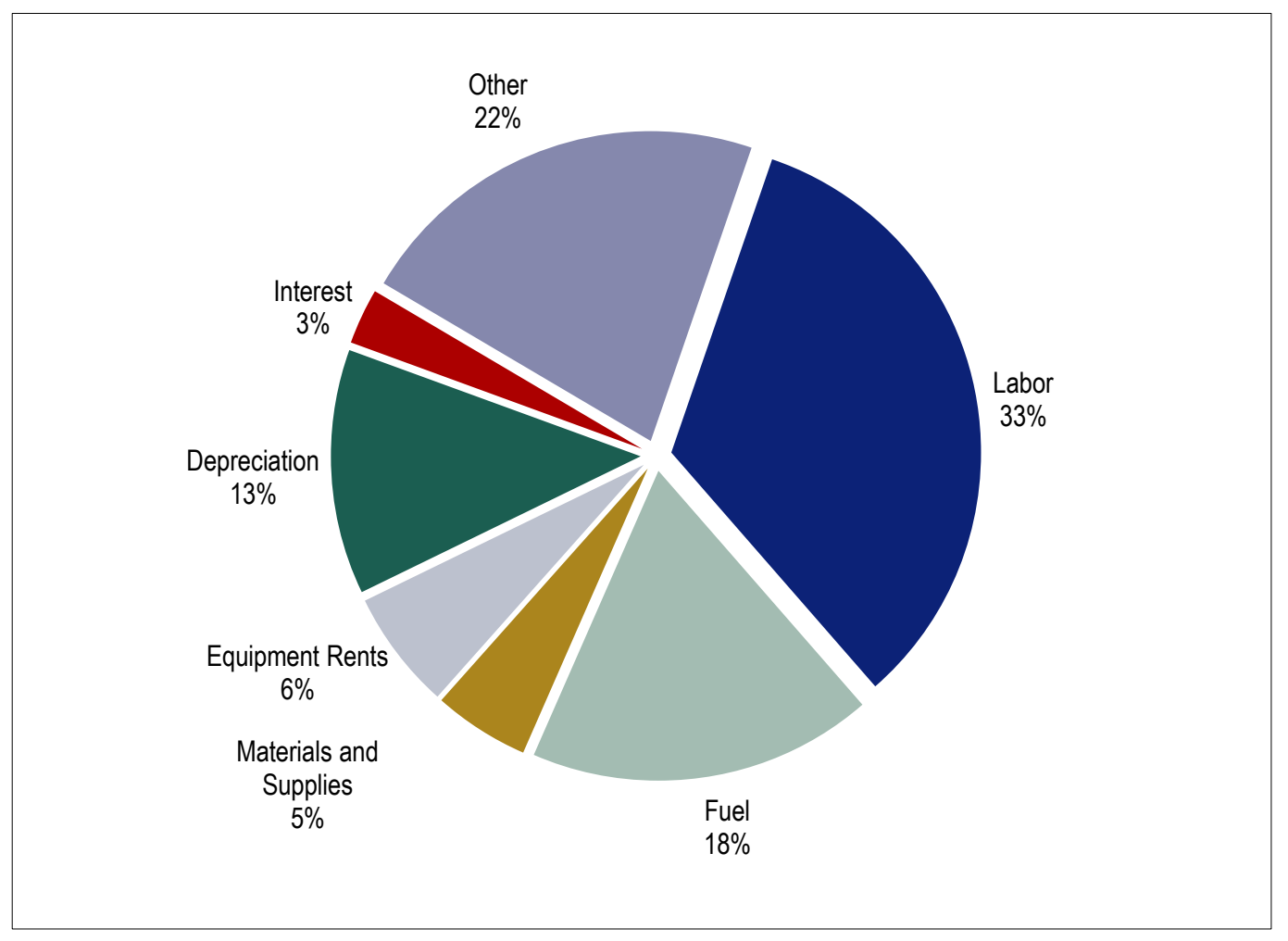

Figure 3.4. Rail weighted industry operating costs

[Source: Rail Cost Adjustment Factor All-Inclusive Index, 1Q 2012. (AAR 2012c)] 
For trucking, fuel costs in early 2010 accounted for $31 \%$ of marginal operating costs per mile; driver labor costs for $36 \%$. These proportions have varied considerably in recent years with fuel accounting for $38 \%$ in 2008 and 28\% in 2009 (American Transportation Research Institute 2011). The cost and volatility of fuel prices in the past decade has been a major factor pushing the motor carrier industry to search for more fuel-efficient engines and transmissions, more aerodynamically clean truck shapes, and more efficient head-haul and back-haul routing and dispatching.

Railroads spend relatively less on fuel, reflecting the economies of scale and corresponding fuel savings that are achieved by hauling very large volumes of freight over long distances. In 2008, railroads consumed approximately 320 Btu per ton-mile compared to trucking, which used approximately 1,390 Btu per ton-mile for heavy-duty truck operations (Davis, Boundy and Diegel 2012; Davis, Diegel, and Boundy 2008; Davis, Diegel, and Boundy 2012). ${ }^{13}$ The difference in fuel use is reflected in the higher price of trucking services and the lower price of rail services.

\footnotetext{
${ }^{13} \mathrm{Btu}$ (British thermal units) per ton mile is a measure of energy intensity. Energy and Environmental Research Associates estimated Btu for rail based on data reported in Bureau of Transportation Statistics, Table 4-25 (S.C. Davis, R. Boundy, S. Diegel 2012) and for truck based on data reported in Transportation Energy Data Book, Table 2.16 (Davis, Diegel, and Boundy 2008). The truck estimates assume 16 tons payload per truck (FHWA) and average payload (pounds) by Gross Vehicle Weight Group VIUS - by State (Davis, Diegel, and Boundy 2012).
} 


\section{OPPORTUNITIES FOR MODAL SHIFTS}

State departments of transportation (DOTs), metropolitan planning organizations (MPOs), and other entities have investigated ways to use investment strategies, public policies, and incentives to more effectively utilize all the components of the freight transportation system. Examples are provided in this section. Particular attention has been given to shifting truck traffic to the freight rail and inland/coastal waterway systems. As the cost of highway congestion has increased, public policy-makers at all levels of government have started looking to these modes to relieve truck and highway congestion and help conserve energy, reduce engine emissions, and improve safety. Shippers, too, have started looking at options - particularly rail options - to carry more longer-distance shipments, especially as the costs of truck fuel and labor have increased.

Many factors will affect whether traffic shifts: some commodities are not suited to alternative modes, and some trade lanes do not generate sufficient demand to warrant changes in mode selection or to encourage investments designed to attract additional traffic. Existing research shows that price and service elasticities of demand are highly commodity-dependent. The next sections review the currently available estimates of the opportunities for modal shifts.

\subsection{Prices and Modal Shifts}

Price is a major factor in mode choice. Economists measure the change in modal demand as a function of change in freight transportation price as elasticities. Three types of elasticities can be calculated for freight modes: 1) own-price elasticity, ${ }^{14}$ which reflects the change in demand due to changes in price within the mode; 2) cross-price elasticity, which reflects the change in demand (and potential for modal shift) due to change in price between modes; and, 3) substitution elasticity, which is less commonly used and measures how easy it is to substitute one mode for another. Cross-price elasticity is most commonly used to examine mode shift and typically focuses on the change in demand for rail given a change in the price (i.e., cost, rate, or other measure) of trucking.

In a 2005 U.S. Army Corps of Engineers (USACE) Navigation Economic Technologies Program report (Clark et al. 2005), elasticity of demand was compiled from several survey articles (Oum, Waters, and Yong 1992; Goodwin 1992). Figure 4.1 shows the most likely range of the own-price elasticity ${ }^{15}$ of demand for each commodity and mode. As expected, the elasticities are all negative (i.e., a 1\% increase in price for a mode decreases demand for that mode). Overall, commodities are somewhat inelastic for rail and truck and more so for air. ${ }^{16}$ However, the study showed a significant variation in elasticity when the results were broken out by commodity and mode, which can be partially attributed to issues in study design, such as geographic scope, temporal scope, model construct, and data availability, and to variations between firms and shipments. What is clear is that firms shipping commodities respond differently to price changes, depending on the size and characteristics of both the firm as a whole and the individual shipments.

\footnotetext{
${ }^{14}$ The terms own-price and cross-price are used because - in the literature cited in this paper - price is the most commonly studied mode-choice variable. The concept of own-price versus cross-price elasticity should be understood to refer to any change in a variable that affects mode choice.

${ }^{15}$ Own-price elasticity refers to the relationship between price and demand within a commodity.

${ }^{16}$ Economists generally classify products as being relatively elastic when they have an elasticity of demand that is $>+1$ or $<-1$ (i.e., greater than positive one or less than negative one). Products with an elasticity of demand that is between +1 and -1 are relatively inelastic.
} 


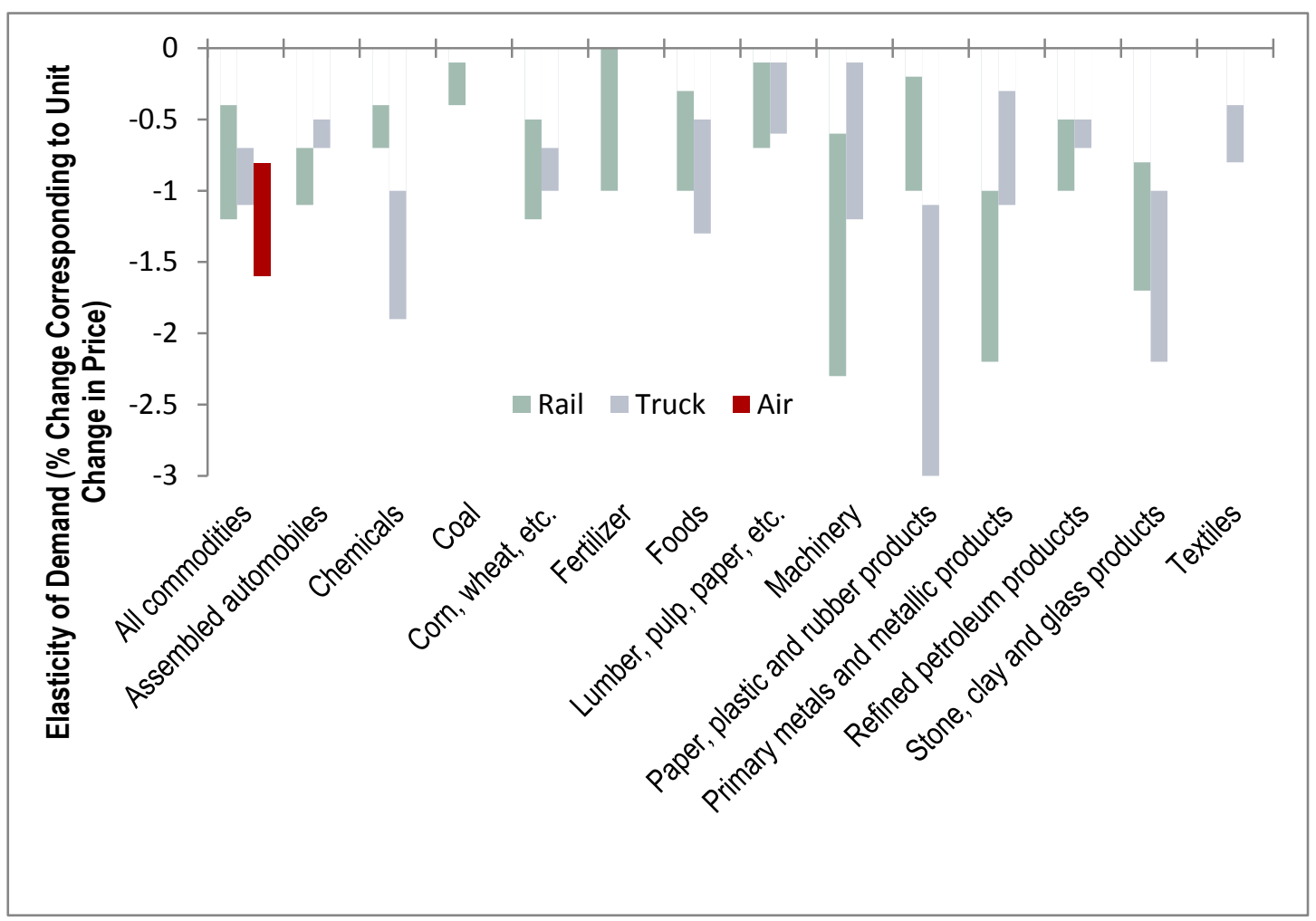

Figure 4.1. Most likely range of elasticities of demand for freight transport

[Source: Clark et al. (2005)]

An additional measure of elasticity, the cross-price elasticity, is used to estimate which of two interchangeable modes will be substituted for the other when there is a price increase in one of the modes, as follows: a cross-price elasticity greater than zero indicates that the two modes are substitutes and there is a potential for mode shift; an elasticity of zero indicates that there is no relationship; and an elasticity less than zero indicates that the modes complement each other and there is a potential for mode shift. Figure 4.2 presents the cross-price elasticities between rail and truck from studies reviewed in the Navigation Economic Technologies Program report (Oum 1989; Friedlaender and Spady 1980; Winston 1981; Abdelwahab 1998). There is some variation, but most commodities and modes are fairly inelastic, supporting the idea that, in many cases, mode shift potential is small based on price changes alone.

Similar to Figure 4.1, variation in elasticities can be attributable to a wide range of factors, such as study design, geographic/temporal scope, and variation among individual firms and shippers. 


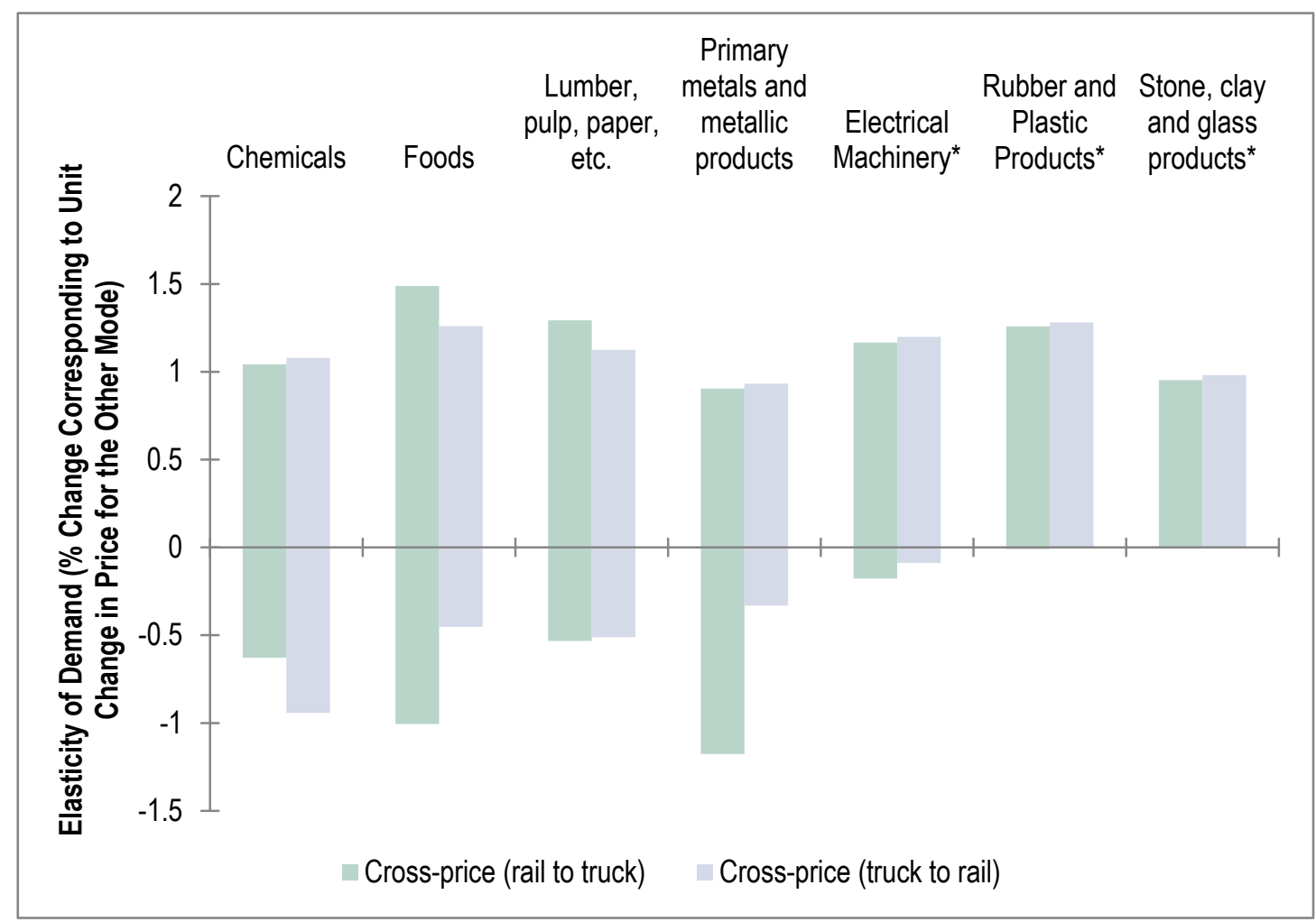

Figure 4.2. Cross-price rail-to-truck and truck-to-rail elasticities

(Source: Clark et al. 2005).

*Cross-price elasticity values were not available for all studies.

The results of the elasticity studies show that elasticity estimates vary significantly from study to study, indicating a high level of uncertainty about actual mode shifting potential in response to price. While policies may not be designed to directly alter prices of modes or price relationships among modes, many policies (i.e., fuel taxes, investments that reduce travel times by modes, and costs of environmental regulation) do impact prices. The elasticity results suggest the effectiveness of these strategies will vary by commodity and by market (since price relationships among modes may vary substantially from trade lane to trade lane). Furthermore, there are limitations in terms of what magnitude of change can be made.

It is clear that, while opportunities for mode shifts exist, not all commodities are effectively served by all modes, placing a natural upper bound on the amount of traffic that could reasonably be expected to shift modes. Plans and studies conducted by states, regions, and other entities - coupled with our own understanding of freight systems, commodity types, and trade lanes-have shown that the best opportunities for mode shifts are between trucks and rail intermodal services with limited opportunities among other modes, as shown in Table 4.1. These findings are generalizations based on overall mode shift potential, but different levels of potential may be possible for certain commodities and trade lanes. 
Table 4.1. Freight Modal Shift Potential

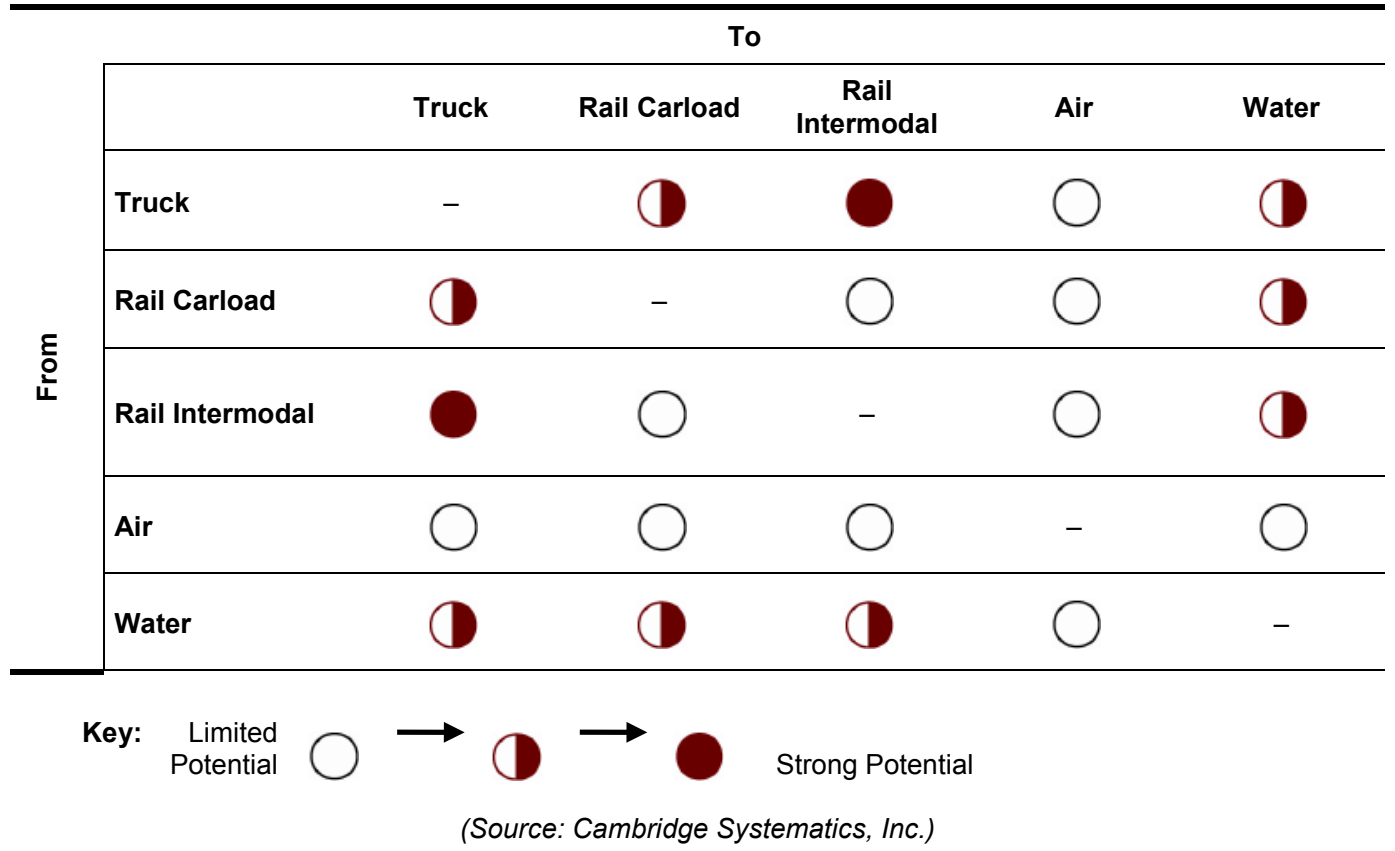

Another factor limiting the potential for large-scale shifts among freight modes is growth in overall demand. Figure 4.3 shows freight projections from FHWA FAF3 data released in November 2010. The FAF3 database includes a comprehensive list of freight flows by all modes to, from, and within the United States, and provides 2007 estimates and forecasts through 2040 on tonnage and value by commodity type, mode, origin, and destination. FAF3 data cover 43 commodity classes. As shown in Figure 4.3, the FAF3 projections show growth in overall freight movements (66\% by weight and 145\% by value between 2009 and 2040), but declining market shares for non-truck modes (FHWA 2012):

- Truck movement share increasing from $82 \%-84 \%$ (by weight) but declining from $86 \%-80 \%$ (by value)

- Rail movement share declining from $12.6 \%-10 \%$ (by weight) and from $3.8 \%-2.7 \%$ (by value)

- Water movement share declining from 5.5\%-5.1\% (by weight) and from $2.4 \%-1.5 \%$ (by value)

- Air movements share increasing from $0.08 \%-0.2 \%$ (by weight) and from $8.0 \%-16.0 \%$ (by value)

These changes in modal share are due primarily to a) changes in the mix of commodities transported in the United States away from lower-value, heavy-weight commodities to higher-value, lighter-weight commodities, and b) shifts in the economic geography of the United States that reduce length of haul of many shipments. The FAF3 projections do not take into account the capacity of the highway or rail systems to accommodate the projected growth. They are demand-driven forecasts instead of supplyconstrained forecasts. Specifically, these projections do not reflect either changing investment patterns in modal capacity or the implementation of policies and programs designed to influence modal share. As a result, modal shifts reflected in the FAF3 forecasts should be considered to be a continuation of existing economic trends. Whether or not these numbers are realized will depend upon changes in factors, such as investments in infrastructure and creation of policies that support or inhibit each mode type. Regardless, the implications for fuel use, GHG emissions, and congestion are striking, because almost $60 \%$ of the freight increase (measured in tons) that is projected would be shipped by trucks. 


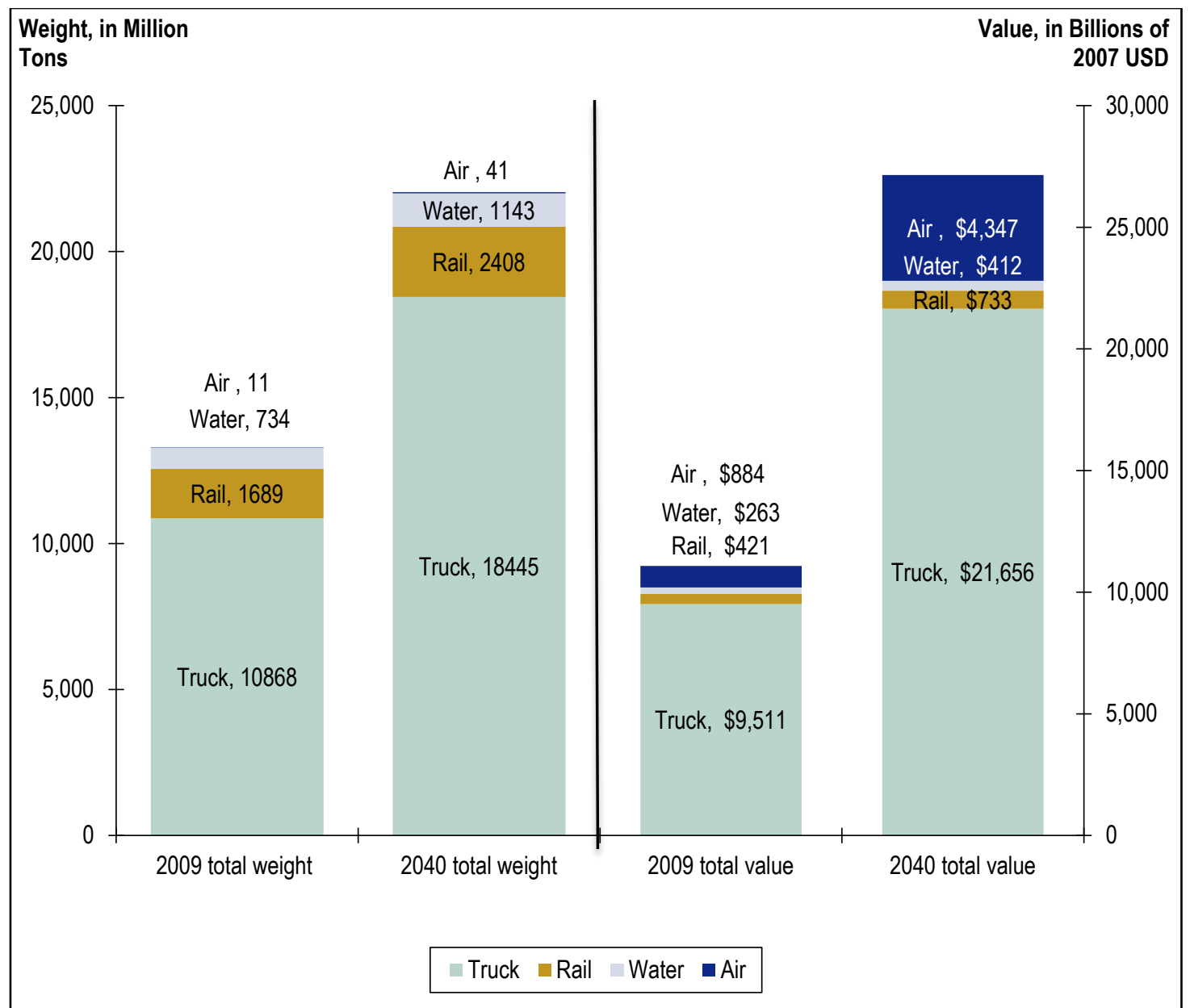

Figure 4.3. Freight demand and modal shares, 2009 and 2040

(Source: FHWA FAF3)

The following sections describe the potential for shifts among freight modes, examples of how and where these shifts have been accomplished, and an assessment of the challenges and opportunities associated with each.

\subsection{Truck-to-Rail Modal Shifts}

Trucking specializes in reliable door-to-door service with high visibility and speed, usually at a higher cost than rail. ${ }^{17}$ Rail specializes in cost-effective terminal-to-terminal service, usually with lower speed and reliability, although the rail industry is working to compete in these areas. Rail's major advantage over truck has historically been its lower costs. A rail service that offers lower costs than trucking, combined with comparable on-time performance and loss/breakage avoidance, can be extremely competitive with trucking, even if transit times are not as fast as trucking.

As discussed earlier, much of the focus on effecting modal shifts has been on shifting truck movements to the rail system. And while truck-to-rail shifts represent an attractive opportunity to reduce overall truck

\footnotetext{
17 "High visibility" refers to the ability of the carrier and, more importantly, the shipper and receiver of freight to track the progress of a shipment and its estimated time of arrival. Bar-coding on products and boxes; radio-frequency transponders on pallets, trailers, containers, and rail cars; and on-board truck and rail GPS units and digital cellular and satellite communication systems make it possible to track shipments from door-to-door across oceans, continents, and cities, in much the same ways that FedEx and UPS provide visibility in tracking small packages to their retail and business customers.
} 
traffic, not all truck movements are suitable for shifting to rail. Among others, a key factor preventing these shifts is shipment distance. Some rail services are competitive with trucking at shorter distances, but these are almost always bulk commodities moving in unit trains (e.g., aggregates). Freight that can be moved in less than a single driving day (11 hours, according to current federal hours-of-service standards) has historically moved by truck. This usually corresponds to a minimum distance of around 500 miles. An exception to this general rule is movements of heavy commodities that can be accomplished exclusively by rail, such as coal or clay moving straight from a mine to a power plant or a port.

Intermodal traffic covering distances greater than 500 miles provides the most attractive market for a truck-to-rail modal shift. Intermodal traffic consists of freight that can be easily transferred between modes-rail, truck, and, in some cases, water or air. Intermodal rail service became established in the 1980s and has become a major part of the railroading business. It allows a shipper to move the freight long distances by rail (without paying for a truck driver) and use truck for shorter legs at either end, without unpacking the box carrying the freight itself. Commodities that can be shipped in containers or conventional truck trailers are best suited to diversion from truck to rail:

- Containers are corrugated metal boxes with special "twist locks" at their corners, allowing them to be lifted and transferred easily. For truck transport, containers are set on a truck trailer chassis (specialized flatbed fame and wheels), as shown in Figure 4.4 (top picture). For rail transport, the container and truck chassis can be carried on a conventional rail flatcar, or the container only can be lifted and stacked on a rail flatcar. Specialized intermodal rail flatcars can carry one (single stack) or two (double stack) layers of containers. Containers are usually marked with the name of a shipping line (e.g., APL, Matson, Hanjin, etc.).

- Dry vans are truck trailers that look similar to containers, except they are typically not corrugated, cannot be lifted from the top, and are integrated with their chassis. Figure 4.4 (bottom picture) shows a typical 53-ft dry van truck trailer. Dry van trailers can be detached from the truck tractor and the entire trailer unit lifted and placed on a rail flatcar. Dry vans are usually marked with the name of a trucking company (e.g., Fed Ex, Schneider, J.B. Hunt, Old Dominion, etc.) or a retailer (Wal-Mart, Giant, McDonalds, Vons, etc.).

While commodities shipped in containers and dry vans represent the most attractive candidates for truck or rail diversion, other types of trucks, such as liquid bulk tankers, dry bulk hoppers, and flatbeds, can be handled by rail using an operation known as roll-on/roll-off, or ro-ro, in which the trucks are driven onto and off of railcar platforms. Different types of terminals, equipment, and services are required to handle different truck types. Ro-ro loading systems can involve splitting the train into several segments to allow multiple points of loading and unloading - a process which is referred to as open technology.

Open technology was originally conceived as a way to make rail more competitive with trucking over short distances by reducing load and unload times and offering competitive end-to-end speeds. Ro-ro rail operations are more established in Europe than they are in North America. The three most frequently cited reasons for this are: shorter shipment distances and greater highway congestion in Europe; longer distances and more competitive trucking services in the United States; and much more efficient and costeffective long-haul, double-stack intermodal rail service in the United States. In North America, open technology was first introduced by CSX in the mid-1990s under the trade name "Iron Highway."

Iron Highway technology involves a train comprised of flatcars and multiple power units at different locations, so that the train can be separated into multiple parts; loading ramps are positioned at breaks in the train, and trucks and trailers are driven on and off. The Canada Pacific Railway subsequently acquired the CSX equipment and started the ExpressWay service between Montreal and Toronto (340 miles) in 2006. The Canada Pacific Railway later extended the ExpressWay service to Detroit (adding 230 miles) in 2002. Their service now has five terminals (Montreal, two in Toronto, Windsor, and Detroit) and runs two trains per day in each direction, six days a week, with up to 90 platforms per train. The Canada 
Pacific Railway has reported typical loading times of less than one hour for a 90-car unit. ExpressWay carries only the truck trailers and no drivers, as there are no passenger accommodations. ${ }^{18}$
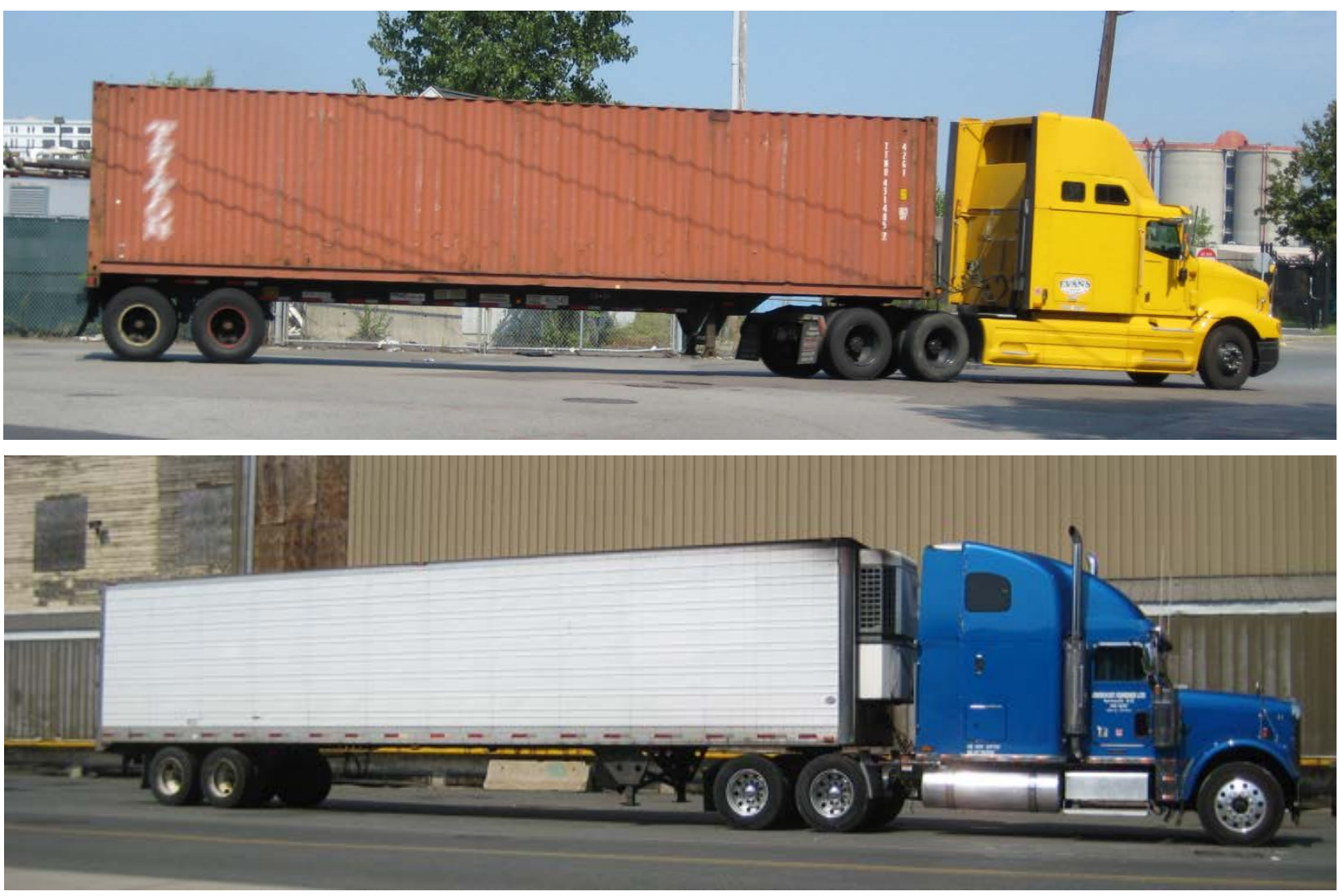

Figure 4.4. Truck hauling intermodal container on a trailer chassis (top), and truck hauling conventional dry van (bottom)

(Photos from Cambridge Systematics, Inc.)

\subsubsection{Issues and Challenges}

Regardless of distance, service, or rail technology, there are certain types of commodities for which the railroads are not competitive. Certain automakers, for example, insist on trucking because of special handling requirements; shippers of time-sensitive freight require the flexibility that trucking provides; and bulk commodities may need to move in smaller quantities than can be handled efficiently by rail or to places not served by rail.

In addition, infrastructure improvements might be necessary to make rail more competitive with truck movements along some corridors. Many rail lines have significant speed restrictions and without improvements will not be capable of competing with trucks for short- or medium-haul traffic. One of the largest challenges is removing height clearance obstructions that prevent double-stack intermodal service. The railroads are investing in these network improvements, most notably Norfolk Southern's Heartland Corridor and CSX's National Gateway projects, but these can be expensive (between \$200 million and $\$ 300$ million for these corridors) and time-consuming. Figure 4.5 shows the general location of Norfolk Southern's Crescent and Heartland corridors.

\footnotetext{
${ }^{18}$ Observations based on the authors' consulting assignments for the railroad industry.
} 


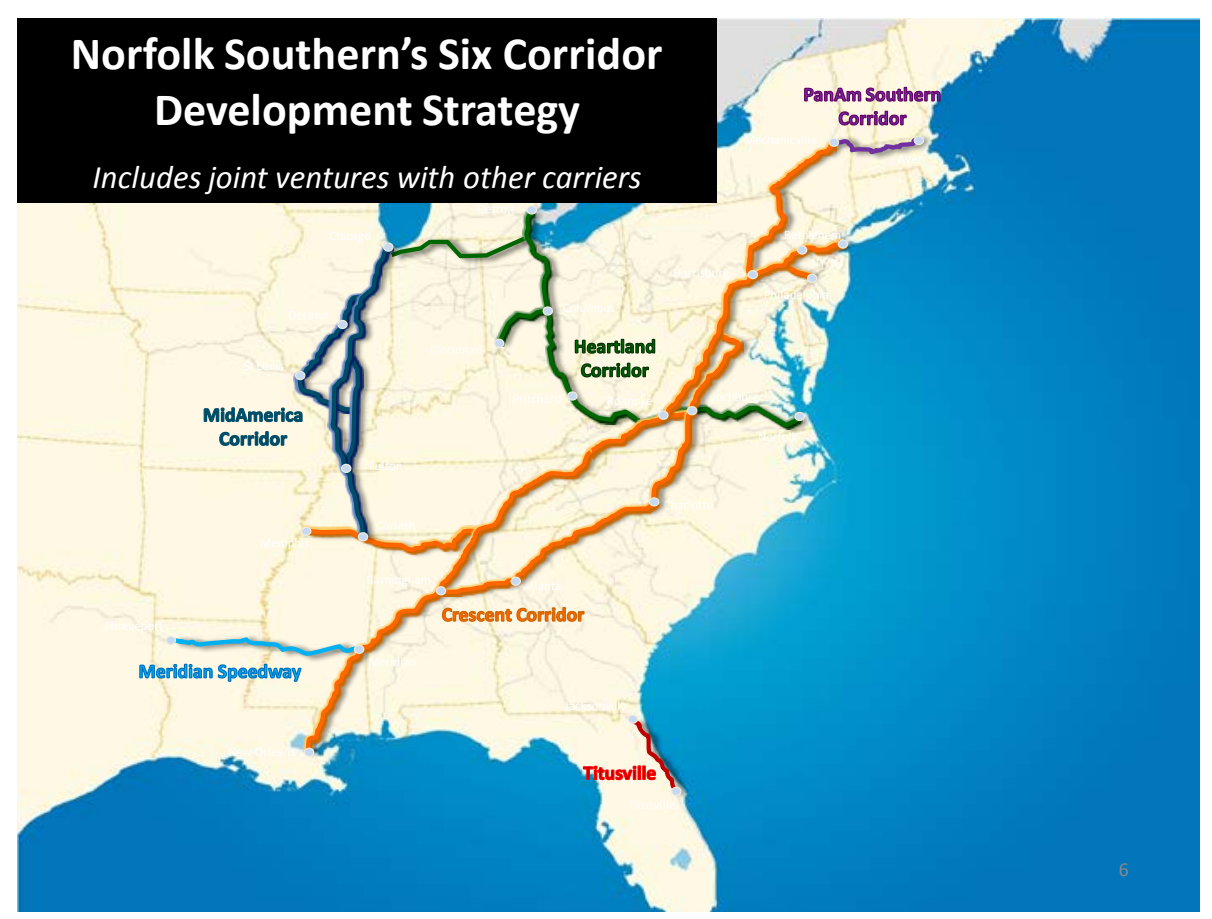

Figure 4.5. Major Norfolk Southern Rail Investment Corridors

(Source: Smith 2010)

Other nations are also working to develop agendas and strategies to shift truck traffic to more energyefficient modes, particularly rail. European Transport Policy papers, published by the European Commission, set the goal of shifting $30 \%$ of the road freight moving over $300 \mathrm{~km}$ to rail or water transport by 2030. ${ }^{19}$ In order to do so, the European Transport Policy papers conclude that an appropriate infrastructure will have to be developed through innovation and investment; however, they do not specify what investments (European Commission 2011). Through the Marco Polo I and II programs, Europe also provides grants to private firms who are able to provide transportation solutions that cause a modal shift, where a significant portion of the funding is going to truck-rail shifts (European Commission).

\subsection{Truck and Rail to Water Modal Shifts}

Water transportation can be used to move goods inexpensively and typically generates fewer GHG emissions than other modes of freight transportation. There has been increasing interest in diverting truck or rail movements to the inland or coastal waterway systems through improved coastal, short-sea, or inland shipping services. Coastal, short-sea, and inland shipping describe marine shipping operations between ports along a single coast, involving a short-sea crossing or movement along an inland waterway. Examples of existing networks and routes include the Gulf Intracoastal Waterway; the Mississippi River System; the Snake River System; Jacksonville to San Juan; Tacoma to Anchorage; Halifax to Boston; Los Angeles to Seattle; Pittsburgh to Monterrey, Mexico; and St. Louis to New Orleans. These shipments can be domestic or international, although short-sea shipping operations in the United States typically consist of domestic cargo.

Short-sea, coastal, and inland shipping services have existed for hundreds of years and provide a variety of freight transportation, salvage, towing, and other maritime services. For some commodities and some

\footnotetext{
${ }^{19}$ See for example http://ec.europa.eu/transport/themes/strategies/2011 white paper en.htm and http:/ec.europa.eu/dgs/jrc/downloads/events/20110707-warsaw/jrc 20110707 verhoef.pdf
} 
trade lanes (i.e., grain movements down the Mississippi River system), inland waterway movements are the dominant mode. And over the past decade, the U.S. Maritime Administration, state DOTs, and even some ports have undertaken short-sea shipping initiatives designed to increase the volume of freight handled by this mode. Of particular note is the Port Inland Distribution Network, which operated between the Port of New York and New Jersey and the Ports of Albany and Boston. The Ports of Bridgeport, Fall River, Canaveral, and others studied inland waterway and short-sea initiatives like the Port Inland Distribution Network and implemented their own.

Despite the interest in making better use of short-sea and inland waterway shipping services, achieving a meaningful shift from other modes has proven challenging. In fact the Port Inland Distribution Network program, which was heavily subsidized by the Port Authority of New York and New Jersey, was recently canceled due to lack of sufficient volume. The initial testing of a multimodal regional routing model to increase annual wheat flows from the Pacific Northwest region through the Columbia-Snake river system showed that even a $20 \%$ increase in wheat production only produced a $1 \%$ increase in barge traffic (Center for Economic Development Education and Research 2005).

\subsubsection{Issues and Challenges}

The issues and challenges that impact the viability of short-sea and inland shipping services to effectively compete for additional traffic, include:

Existing infrastructure may not be capable of handling large volumes of short-sea traffic. The U.S. inland and coastal waterway systems have not been maintained effectively. In many locations, the waterway infrastructure (i.e., locks/dams, channel depths, and bridge clearances) is not robust enough to handle commercial traffic. In 2007, the USACE found that delays caused by undersized locks and bottlenecks on the Mississippi waterway system added an average of $\$ 72.6$ million annually to the cost of shipping. It is unlikely that major investments to maintain or improve the coastal/inland waterway infrastructure will be made until there is sufficient commercial traffic; and commercial users are not likely to consider shortsea/coastal shipping as a viable option until the system is improved (and can provide some degree of transit-time reliability).

Frequency and flexibility of service does not meet shipper requirements. In order to compete effectively with trucks, short-sea shipping and inland operations must offer regularly scheduled services. Service flexibility - a key benefit of trucking operations - is something that these services must also attempt to offer to attract traffic.

Cost. Total trip costs for short-sea shipping can include multiple drayage, loading, and unloading fees, which tend to make these movements less cost-competitive versus truck movements. Additionally, shortsea shipping operations that call at some major deepwater seaports often do not receive a high priority for berthing, particularly in comparison to large, ocean-going containerships. As a result, they are unloaded more slowly, further driving up costs and making it more difficult for these operations to match the cost, speed, and reliability characteristics of competing modes.

Reasons for shippers to switch modes/operations have not been effectively demonstrated or communicated. There is interest among federal, state, and metropolitan transportation agencies in making better use of short-sea and coastal shipping operations. The I-95 Corridor Coalition and Transport Canada, for instance, have investigated strategies to improve the viability of coastal shipping services along the U.S. East Coast and the Pacific Northwest, respectively. And the U.S. Maritime Administration has begun to invest in coastal waterway projects as part of its Marine Highway Program. The largest challenge to increasing the use of these services is to encourage shippers to adapt their operations to short-sea shipping, which often entails longer transit times and sometimes less reliable delivery windows. Studies by the I-95 Corridor Coalition (2005) and Transport Canada (2004) have shown that many shippers and carriers feel that this kind of change in operational strategy can only happen if high-visibility demonstration projects and studies prove that short-sea shipping concepts work in practice. Until short- 
sea or inland shipping can demonstrate that it can compete with other modes in cost, speed, and/or reliability, there may be only incremental increases in the use of these services. 


\section{Tools and Techniques to Project Freight Modal Shares}

Methods for projecting freight modal shares generally fall into three categories: market segmentation, modal elasticity, and mode-choice modeling. The scope of this section was selected based on authors' judgment and in consultation with stakeholders on methods of greatest potential interest, and may not be comprehensive of all potentially relevant methods. Similarly, strengths and weaknesses are described based on authors' perspectives for this report's specific purposes. The following sections describe the processes and tools used to assess and project modal shares within these three categories and provide examples of how these methods have been applied at the local, regional, state, and national levels. Table 5.1 provides a summary of the projection tools discussed in this section.

\section{Table 5.1. Summary of Freight Modal Share Projection Tools}

\begin{tabular}{|c|c|c|c|}
\hline Type of Tool & Market Segmentation & Modal Elasticity & Mode-Choice Models \\
\hline Examples & $\begin{array}{l}\text { MAROps Comparable } \\
\text { Markets Method }\end{array}$ & $\begin{array}{l}\text { Truck-Rail Diversion; ITIC; ICM; } \\
\text { Economic Cost Models }\end{array}$ & Discrete Choice; Pivot Point; Mesoscale \\
\hline \multirow{2}{*}{$\begin{array}{l}\text { Geographic } \\
\text { Scope }\end{array}$} & \multirow{2}{*}{$\begin{array}{l}\text { Local to nationwide, based on } \\
\text { data availability }\end{array}$} & Local to nationwide & Local to regional \\
\hline & & $\begin{array}{l}\text { Truck-Rail Diversion developed } \\
\text { for corridor analysis }\end{array}$ & $\begin{array}{l}\text { Substantial data requirements make } \\
\text { multimodal, multijurisdictional } \\
\text { implementation challenging; } \\
\text { mesoscale-type models mitigate some } \\
\text { issues }\end{array}$ \\
\hline Data Sources & $\begin{array}{l}\text { Commodity flows, network } \\
\text { and modal characteristics }\end{array}$ & $\begin{array}{l}\text { Commodity flows, network and } \\
\text { modal characteristics, cost or } \\
\text { pricing information }\end{array}$ & $\begin{array}{l}\text { Commodity flows, network and modal } \\
\text { characteristics, shipper/carrier } \\
\text { preference surveys, employment data }\end{array}$ \\
\hline \multirow[t]{2}{*}{ Applications } & \multirow[t]{2}{*}{$\begin{array}{l}\text { Identifies markets for modal } \\
\text { shift and estimates diversion } \\
\text { potential }\end{array}$} & \multirow{2}{*}{$\begin{array}{l}\text { Estimates sensitivity to price and } \\
\text { potential modal shift in response } \\
\text { to price or level of service } \\
\text { changes }\end{array}$} & $\begin{array}{l}\text { Estimates modal shares based on } \\
\text { transportation and non-transportation } \\
\text { factors }\end{array}$ \\
\hline & & & $\begin{array}{l}\text { Flexible scenario analysis and } \\
\text { forecasting tool }\end{array}$ \\
\hline \multirow[t]{2}{*}{ Strengths } & \multirow{2}{*}{$\begin{array}{l}\text { Least data intensive and can } \\
\text { be implemented on a national } \\
\text { scale }\end{array}$} & \multirow{2}{*}{$\begin{array}{l}\text { Can utilize actual goods } \\
\text { movement data and account for } \\
\text { infrastructure or policy changes }\end{array}$} & $\begin{array}{l}\text { Ability to model individual agent } \\
\text { behavior }\end{array}$ \\
\hline & & & $\begin{array}{l}\text { Models are customizable, can use a } \\
\text { wide variety of data sources, and can } \\
\text { be used in conjunction with destination } \\
\text { or routing models }\end{array}$ \\
\hline \multirow[t]{2}{*}{ Limitations } & \multirow{2}{*}{$\begin{array}{l}\text { Limited by quality of data, } \\
\text { unable to account for } \\
\text { changing modal } \\
\text { characteristics or policy }\end{array}$} & $\begin{array}{l}\text { Proprietary models utilizing data/ } \\
\text { methodology often not publically } \\
\text { available }\end{array}$ & $\begin{array}{l}\text { Significant data requirements reduce } \\
\text { feasibility for large-scale } \\
\text { implementation }\end{array}$ \\
\hline & & $\begin{array}{l}\text { Results can be highly specific and } \\
\text { not generally applicable }\end{array}$ & $\begin{array}{l}\text { Often rely on costly data collection } \\
\text { efforts (e.g., surveys) }\end{array}$ \\
\hline
\end{tabular}

\subsection{Market-Segmentation Methods}

Market segmentation is the simplest and least data-intensive of existing modal-share projection methods. This method identifies markets where changes in modal shares are possible and then estimates the impacts of a modal shift. Generally, the method is performed using a table of commodity flows by origin/destination (O/D) pair. Commodities and O/D pairs that currently are or could potentially be served by alternate modes are identified and diversion potential is calculated. Resulting future modal shares can then be used to estimate overall productivity, environmental, and other societal costs and benefits.

Benefits of market segmentation include simplicity, ease of implementation, and minimal data requirements. In nearly all cases, this method uses existing commodity-flow and transportation networkflow data from national, statewide, or regional sources. 
Generally, market-segmentation methods perform reasonably well along individual and clearly defined corridors or trade lanes where existing modal shares and O/D patterns are well-established. Diversion potential is typically estimated by looking at cases where the same commodity is shipped over similar distances, collecting data on the relative truck and rail shares of that commodity over the lane, and calculating an average or mean share across the cases. To calculate the diversion potential in a specific trade lane, the current modal share is compared to the average or mean share for the set of comparable lanes. If the share of a specific lane is lower than the average, the difference between the actual and the average (or a high percentage) represents the diversion potential. Realizing the truck-to-rail diversion potential depends on the volume of shipments in the lane, capacity of the rail line, and the level of service. Small volumes of infrequent shipments along congested or circuitous rail routes may not justify diversion to rail. Market segmentation is a good tool for first-order and short-term assessment of diversion potential, but it must be checked against actual service conditions. It is generally insensitive to policy impacts on mode choice and implications of large-scale network investment strategies.

While useful in responding to what-if scenarios, this technique relies on input on trends and issues from an analyst, which can skew results. A further limitation of market-segmentation methods is that they do not consider capacity limitations of the network (i.e., they are not capacity-constrained) or the availability of equipment (i.e., specialized rail cars) and infrastructure to handle the increases in demand. As a result, overall modal diversions can be overstated using this technique.

Market-segmentation techniques have been applied as part of a number of plans, studies, and initiatives. The following Mid-Atlantic Rail Operations (MAROps) study is an example of market-segmentation techniques.

\subsubsection{Mid-Atlantic Rail Operations (MAROps) Comparable Markets Study}

Overview: The study estimates how much additional freight traffic might travel by rail if the MAROps rail improvement program were implemented, increasing capacity of the rail system and allowing for both faster travel times and greater travel-time reliability. The model uses a shift-share approach that compares the rail share in freight markets in the Mid-Atlantic region to the rail shares in other U.S. freight markets.

Developer/Owner: Cambridge Systematics, Inc.

Intellectual Property Rights and Transparency: Publically available report describes methodology for market-segmentation analysis. Can be done using publically available data (i.e., FAF3) and/or private data sources (i.e., TRANSEARCH).

Major Inputs: Economic and commodity flow data, rail and truck freight demand in the target area and in other similar markets, data on equipment type, distance between O/D pairs, and directness of service between markets.

Major Outputs: Potential for modal shift by commodity in a particular market (see Table 5.2).

Overview of Calculations: Markets within the Mid-Atlantic area are defined by the U.S. Department of Commerce Bureau of Economic Analysis and include O/D zone pairs and equipment type (i.e., bulk, tank car). Similar zones are identified in other national markets by factors such as volume in each mode by commodity, distance between city pairs, and directness of travel. The possible modal share range is then identified by comparing the modal share in the matched and comparable markets to establish the potential for shift in the Mid-Atlantic market. Decision rules are then used to define potential modal shift.

Scope: Model is used to compare regional modal share to that of other markets in the United States.

Strengths and Weaknesses for Modal Share Analysis: Strengths of this method include simplicity, ease of implementation, and the use of already available data as an alternative to mode choice or other modeling methods. 
Weaknesses include the fact that the method does not explicitly account for policy impacts on mode choice, nor does it account for the implications of network investments strategies. Changes are estimated by making assumptions about the potential for modal shift, based on mode shares in other corridors. The model is also unable to explicitly account for modal characteristics, such as capacity or infrastructure. Like many methods, the model is limited in accuracy and precision by the data sources and assumptions used to perform the analysis.

Resources: I-95 Corridor Coalition (2009). Mid-Atlantic Rail Operations Phase II Study.

Table 5.2. Mid-Atlantic Rail Operations Freight Flow Scenarios

Example Output of Diversion from Market Segmentation

\begin{tabular}{lcccc}
\hline & $\begin{array}{c}\text { 2001 } \\
\text { (Million Tons) }\end{array}$ & \multicolumn{3}{c}{$\begin{array}{c}\text { 2025 } \\
\text { (Million Tons) }\end{array}$} \\
\cline { 2 - 3 } \cline { 4 - 5 } \cline { 4 - 5 } Base Case & & Without MAROps & With MAROps \\
\hline Truck - Dry Van & 1,151 & 1,157 & 1,136 \\
Truck - Other & 1,216 & 1,283 & 1,216 \\
Rail - Intermodal & 11 & 5 & 27 \\
Rail - Autorack & 3 & 1 & 3 \\
Rail - Unit & 229 & 177 & 229 \\
Rail - Loose Car & 78 & 65 & 78 \\
\hline
\end{tabular}

(Source: Adapted from Mid-Atlantic Rail Operations, Phase I/ Study)

\subsection{Modal Elasticity Models}

A wide range of elasticities for freight transportation have been developed and reported in the transportation economics literature. ${ }^{20}$ These elasticities vary by commodity, route, temporal and geographic scope, and model function form, which makes it difficult to extrapolate a single potential for modal shift in response to price. However, by using careful analysis and judgment, the estimated elasticities between modes, coupled with commodity flow and network-volume data, can be used to project modal shift potential. This method has historically been used to examine the effects of price changes or infrastructure investments. By analyzing a set of scenarios, using elasticities to project the potential modal shift, and subsequently applying the resulting trip tables to the network, the effects of an infrastructure project or change in price on a modal split can be modeled.

Elasticities can be a valuable tool to provide insight into modal shifts. Most research on elasticity has focused on modal cost, either direct cost or cost-incorporating variables, such as travel time. In a review of modes and price relationships between modes, many policies (i.e., fuel taxes, investments that reduce travel times by modes, and costs of environmental regulation) do impact prices. Four models are described below as illustrative of the general approaches used to estimate and apply elasticity estimates.

\subsubsection{Truck-Rail Diversion Spreadsheet Model}

Overview: The Truck-Rail Diversion Spreadsheet Model was developed for the Tennessee Department of Transportation (TDOT) to estimate the modal shift potential from infrastructure improvements. The model utilized existing freight rail network and assignment methodology, along with commodity-specific, truck-rail elasticities to conduct analysis of "No-Build" and "Build "scenarios, as depicted in Figure 5.1.

\footnotetext{
${ }^{20}$ See, for example, Clark et al. (2005); Oum (1989); Friedlaender and Spady (1980); Winston (1981); and Abdelwahab (1998).
} 


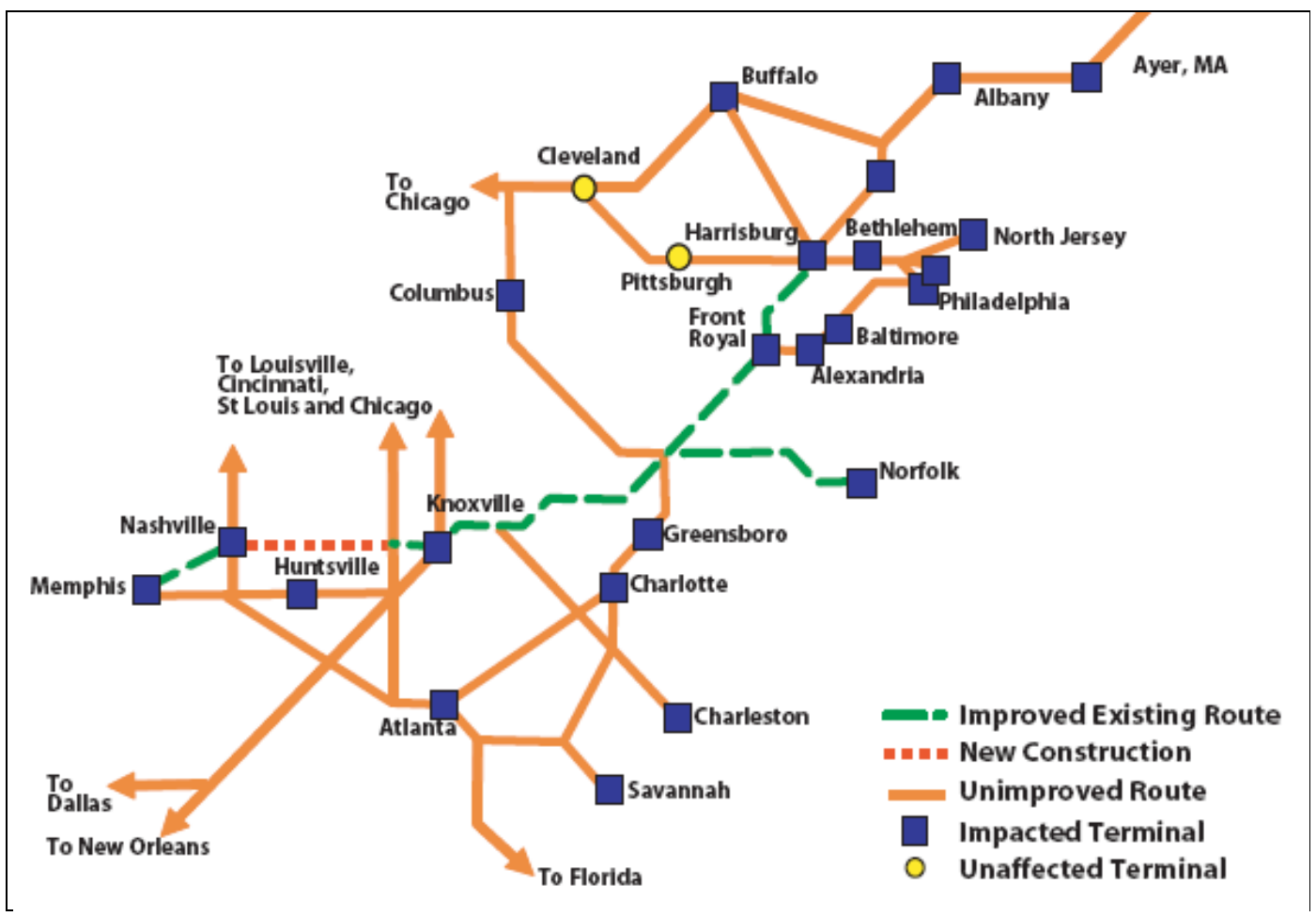

Figure 5.1. Infrastructure differences between the build and no-build TDOT scenarios

(Source: TDOT 2007)

Developer/Owner: Cambridge Systematics, Inc.

Examples of Specific Models: Analysis of truck-to-rail freight diversion scenario for the I-40/I-81 corridor. This was used as a preprocessor to the TDOT statewide freight model.

Intellectual Property Rights and Transparency: Use of the TDOT TRANSEARCH data is subject to contract restrictions, but the Federal Railroad Administration (FRA) shapefiles of the network are publicly available; TransCAD Transportation Planning Software is commercially available.

Major Inputs: TDOT freight network data, TDOT rail freight model, rail cost formulas developed as part of the New York City Economic Development Commission Cross Harbor Freight Movement Project, commodity-specific cross-elasticities, including potential build scenarios, commodity O/D flow data, and elasticities between modes by commodity. Obtained from Abdelwahab (1998).

Major Outputs: Percentage diversion from truck to rail, suitable for use in a statewide freight demand model.

Overview of Calculations: No-build and build scenarios were run to determine the rail travel distance between all O/D pairs in the rail freight-trip table. The cost for all O/D pairs was determined based on these distances. The percentage change in cost for all O/D pairs was calculated based on the change in distance between the scenarios. Freight diversion by commodity was then calculated based on changes in rail cost, and the percentage diversion from truck-to-rail was added to the TDOT freight model truck tables.

Scope: Analysis was targeted at the highway/rail corridor level, while results were applied to the statewide model.

Strengths and Weaknesses for Modal Share Analysis: Strengths include the ability to estimate the projected modal shift associated with a change in infrastructure and associated changes in distance. This 
model also allows the simultaneous analysis of multiple O/D pairs, where other models can only handle traffic between a single $\mathrm{O} / \mathrm{D}$ pair. Results can be integrated into a larger regional freight model.

Weaknesses include the need for disaggregate, link-level network data and the inclusion of data on elasticities from a previous research study, which has limitations in that it is unclear how well the elasticities from one study can be applied to other problems without limiting the reliability of the results (Oum 1989; Clark et al. 2005).

Resources: Clark et al. (2005). A Survey of the Freight Transportation Demand Literature and a Comparison of Elasticity Estimates. Navigation Economics.

Beuthe et al. (2001). A Geographic Multimodal Transportation Network Analysis. Transportation Research Part E 37: 253-266.

Abdelwahab (1998). Elasticities of mode choice probabilities and market Elasticities of demand: Evidence from a simultaneous mode choice/shipment size freight transport model. Transportation Research Part E (34)4, p. 257-266.

\subsubsection{Intermodal Transportation and Inventory Cost Models (ITIC)}

Overview: The ITIC model was developed to compute estimates of diversion potential (and subsequent economic benefits) generated by a change in the transportation levels of service or price caused by improvements in infrastructure, operations, or policy. The model includes a significant number of decision variables determining mode choice, supplier, and shipment size (see Figure 5.2). ITIC is part of a larger family of inventory cost models that model mode choice as a factor in inventory/warehousing decision models.

Developer/Owner: Developed in 1995 by Transmode Consultants, as part of a joint effort between the U.S. Department of Transportation (U.S. DOT), FRA, FHWA, and the Bureau of Transportation Statistics. Based on the Translog Shipper Cost Model developed at the Massachusetts Institute of Technology.

Examples of Specific Models: ITIC is implemented and documented by the FRA.

Intellectual Property Rights and Transparency: Non-proprietary model and documentation is available in the user's manual. However, no definitions and derivations for parameters are provided. Data sources are publicly available.

Major Inputs: Road and rail movements by commodity and O/D; truck and rail rates, payload factors, other parameters such as wage rates and fees.

Major Outputs: Modal shares, including truck, rail, and intermodal. Comparison between scenarios can be used to determine modal shifts.

Overview of Calculations: Data are entered into a Microsoft Excel workbook. The model calculates the modal share based on a set of assumptions and parameters defined within the model. Parameters can be changed by the user in order to run scenarios. The modal shares in each scenario can be compared in order to determine modal shift.

Scope: Movements by O/D pair for truck, rail, and intermodal. Most useful on a national scale and intended for use with FAF3 or related datasets that provide shipments at the county or larger level.

Strengths and Weaknesses for Modal Share Analysis: Strengths include ease of use - the model is built upon an Excel platform and can run using publicly available data. The model allows the user to adjust parameters to run scenario analysis, so that modal shifts due to change in a variety of parameters can be examined.

Weaknesses include the aggregation of data and the inability to apply the results to a network, or to incorporate routing or congestion. Drayage and other factors to and from rail intermodal terminals can be 
included, but door-to-door routings cannot be modeled because the O/D pairs are at the county level. O/D pairs are analyzed individually, making it difficult to apply results to a regional or national freight model.

Intensive data requirements are also a significant weakness of this model and make it unsuitable for use in many places. Parameters at the individual shipper or corridor level are often not available or not updated regularly. In order to properly apply the model, assumptions and parameters should be adjusted to reflect the specifics of each scenario; however, the data needed to do so can be difficult to obtain.

Resources: U.S. DOT (1994). Truck-Rail, Rail-Truck Diversion Model. User's Manual, Draft, Washington, D.C., developed by Transmode Consultants.

U.S. DOT FRA (2005). ITIC-IM Version 1.0: Intermodal Transportation and Inventory Cost Model: Highway-to-Rail Intermodal User's Manual. U.S. DOT FRA.

\subsubsection{Intermodal Competition Model (ICM)}

Overview: The Intermodal Competition model (ICM) is designed to analyze a sample of actual rail movements taken from the Surface Transportation Board (STB) Carload Waybill Sample and the North American Trucking Survey, and to estimate which movements will be diverted and which will be retained with a change in railroad and truck costs. The data are used to construct elasticities between modes and determine modal shift. The model employs methodologies and assumptions that are not available to the general public, so its application to other work is limited.

Developer/Owner: Association of American Railroads (AAR).

Intellectual Property Rights and Transparency: The AAR model is proprietary. The STB Carload Waybill Sample is updated annually, and a public version of the Waybill Sample is available to public sector agencies. Due to the proprietary nature of the Waybill Sample, the full version can only be accessed by filing a request with the STB (U.S. DOT STB 2012a).

Major Inputs: Road and rail movements by commodity and O/D from a waybill sample. Estimates of road and rail logistics costs.

Major Outputs: Elasticities between road and rail; modal shifts from road to rail and vice versa.

Overview of Calculations: Actual methodology is maintained by the AAR, and little information about the specific elasticity calculations is publically available. Elasticities are applied to O/D freight movements to estimate the potential for a modal shift.

Scope: National road and rail movements

Strengths and Weaknesses for Modal Share Analysis: Strengths include the use of actual rail and road movement data. Once the movement, cost, and elasticity data are constructed, the calculations are straightforward and easy to implement.

Weaknesses include the use of out-of-date data; the North American Trucking Survey was conducted in 1994. Results also suggest that the ICM model may overestimate diversion. Truck costs in the model presume that there are no differences between truck load-capacity, and the results assume an increase in oversize and overweight trucks that may not be feasible. The waybill sample does not identify true origin and destination, so it underestimates costs and diversion of intermodal movements. Finally, because the model is not publicly available, its methodology cannot be independently validated nor can it be used for other work.

Resources: National Cooperative Highway Research Program (NCHRP) (1995). Characteristics and Changes in Freight Transport Demand: A Guidebook for Planners and Policy Analysts. NCHRP Project 8-30. 


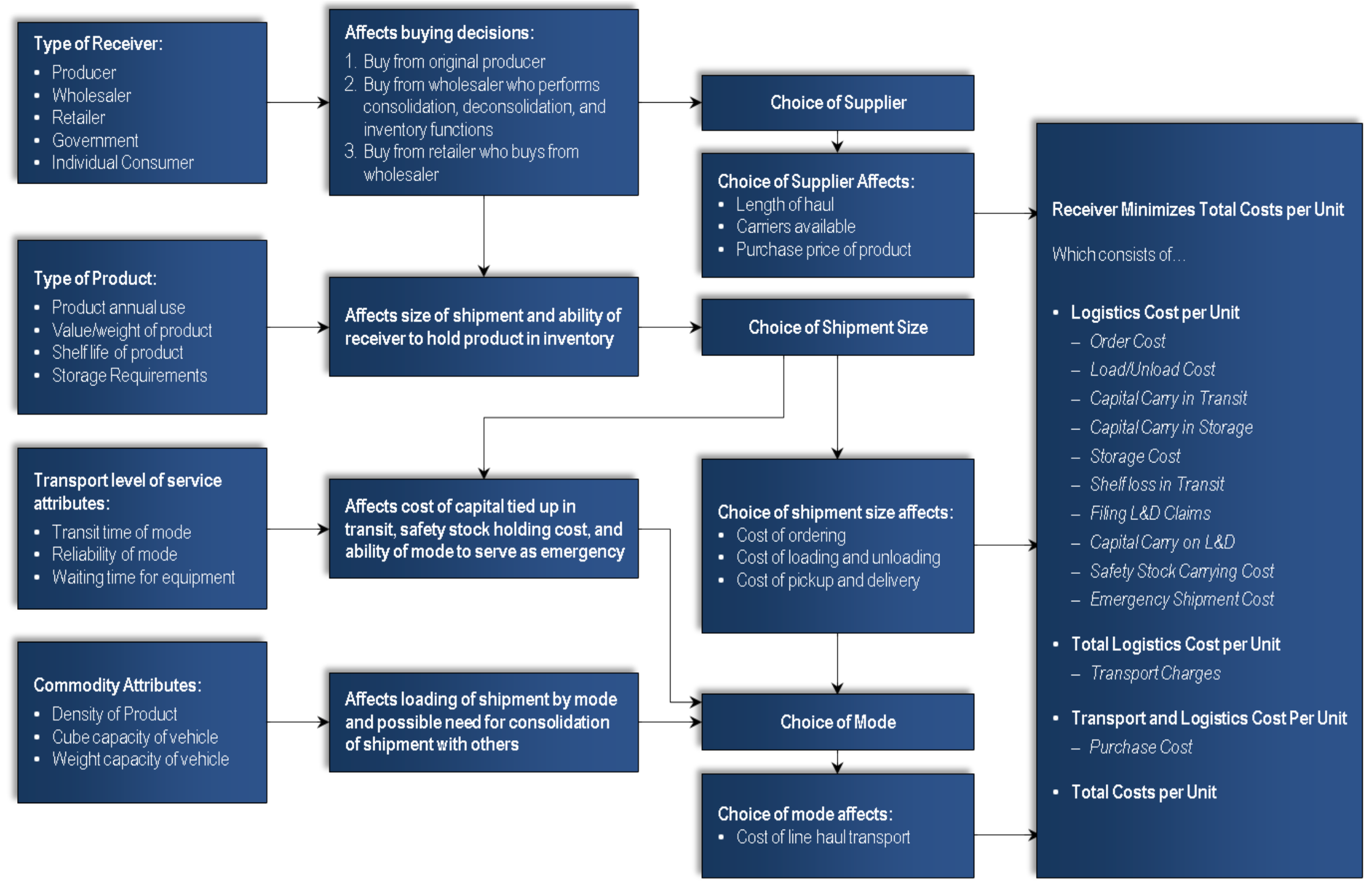

Figure 5.2. Variables affecting choice of supplier, shipment size, and mode in freight transportation in the ITIC-IM Model (Source: U.S. DOT FRA 2005) 
Dennis (1988). The Intermodal Competition Model. Association of American Railroads, Washington, D.C. (TRB 1997).

FHWA (1990). Modal Diversion Effects of Changes in Truck Size and Weight Limits. Working Paper, prepared for the Federal Highway Administration, Washington, D.C. (TRB 1997).

\subsubsection{Economic Cost Models for Freight Transportation}

Overview: Shipper decisions are modeled using an economic cost functions whose arguments include industry-level outputs, capital and materials, labor prices, and generalized prices for truck and rail. From this function input demands are derived and used to develop price elasticities for rail and truck.

Developer/Owner: Ann Friedlaender and Richard Spady

Intellectual Property Rights and Transparency: Methodology and results published in an academic journal.

Major Inputs: Freight movement and economic census data. Industry-level aggregate outputs, quasi-fixed stocks of capital and materials, labor prices, and generalized prices for truck and rail.

Major Outputs: Industry-specific own-price and cross-price demand elasticities for rail and truck freight, which can be used to generate modal shift potential.

Overview of Calculations: Shippers choose productive inputs, including truck and rail freight, along with labor, materials, and capital. Input demand equations for rail and truck. Parameter estimates from these equations are used to calculate industry-specific own- and cross-price demand elasticities that show how freight expenditures respond to relative changes in input prices.

Scope: National truck and rail movements.

Strengths and Weaknesses for Modal Share Analysis: Use of economic models provides broader and longer term perspective on the potential that railroads have to attract freight. However, economic models are based on aggregate data and do not account for the variability within the market. Subsequent research has identified Friedlaender-Spady estimates as optimistic, or upper bounds, for cross-price elasticities.

Resources: Friedlaender and Spady (1980) "A Derived Demand Function for Freight Transportation." The Review of Economics and Statistics, 62(3), 432-441.

\subsection{Mode Choice Models}

Mode choice models are often used by state DOTs, MPOs, and other agencies as part of the four-step transportation modeling process. These models, which are rooted in passenger transportation, have been applied to freight movements to create commodity mode choice models by adjusting explanatory variables, utility functions, and coefficients.

Mode choice models are typically discrete choice models estimated using disaggregate data, such as stated-preference surveys, and attempt to predict the decision-making behavior of a group of decision makers. Models can be constructed using aggregate data (often called mode-split models); however, these models have significant identified limitations. Joint choice and simultaneous equation models also have been used to model mode choice. ${ }^{21}$

These models, while prevalent in the industry, can be extremely complex to develop and apply, and often lack the ability to effectively analyze competition between modes. Estimation of mode choice models requires significant amounts of detailed data from surveys or other sources. These models also depend on the existence of actual competition between O/D pairs, which in many cases does not exist due to infrastructure or logistics requirements. Commodity mode choice models also involve a conversion of

\footnotetext{
${ }^{21}$ See Clark et al. (2005) for a discussion of aggregate models, behavioral discrete choice models, and joint choice and simultaneous equation models.
} 
commodity flow data (measured in tonnage) to freight truck trips ${ }^{22}$ by applying commodity-specific payload factors, typically from state-specific sources or from the national Vehicle Inventory and Use Survey (VIUS) database.

The most commonly used mode choice models are behavioral discrete choice models used within the four-step modeling process for transportation planning. Freight commodity choice models are less often used, and are in general less advanced than those from the passenger transportation sector. Many freight mode choice models are largely based on existing modal shares. Because so few freight mode choice models have been developed, the base of existing models is not large enough to readily borrow from among their factors in development of a national model. Below are some examples of freight mode choice models.

\subsubsection{Discrete Choice Commodity Mode Choice Models}

Overview: For transportation planning, discrete choice (utility maximization) models are often used. These models typically use a logit function, but other functions are available. Other model types include joint choice and simultaneous equation models, nested logit models, mixed continuous/discrete choice models, and aggregate mode-split models. In general, stated or revealed-preference surveys are used to fit models that give insight into the likelihood that a specific mode is utilized. Forecasts or scenarios can then be applied in the model to predict the resulting mode shift. In discrete choice models, the choices of individual decision makers or groups are predicted and then aggregated to determine the larger mode split or shift. Elasticity between modes can also be estimated through the modeling process.

Developer/Owner: These models are typically developed and applied by state and regional transportation agencies, DOTs, and MPOs using commercially available software. All MPOs are required to maintain travel demand forecasting models for use in transportation planning and, if needed, air quality analysis.

Examples of Specific Models: Indiana Commodity Transport Model; Florida Intermodal Statewide Highway Freight Model.

Intellectual Property Rights and Transparency: Software platforms are typically licensed for use by the public agency. Input data and methods are documented in the public domain.

Major Inputs: Flows of goods between zones by commodity, characteristics (i.e., level of service) of modes, shippers and/or carriers, shipments, and O/D zones. Joint/simultaneous choice models may include other aspects, such as choice of destination or shipment size, and variables specific to these problems.

Major Outputs: Mode shares by commodity by O/D zones; joint/simultaneous choice models can output choices, such as destination and shipment size, along with that of mode.

Overview of Calculations: Survey data are used to provide insights into the probability that a shipper will use a specific mode. The model can then be applied to commodity flows for a certain region or time period to determine how choices might be made under different conditions. Network models may assign commodity flows to a specific route, or this can be done as a separate process. This process also can provide elasticity estimates between modes for the specified conditions.

Scope:

- Temporal - Current to long-range forecast freight flows

- Geographic - Metropolitan, statewide, or corridor level

- Modal, vehicle, fuel - Most often truck, but can be multimodal

\footnotetext{
${ }^{22}$ While conversion of rail freight to carloads is not commonly done, there are exceptions.
} 
Strengths and Weaknesses for Modal Share Analysis: Strengths of these models include the ability to model behavior at the individual level or mode splits at the aggregate level. The model structure allows flexibility in the types of data used and the factors included in the analysis. The method is also theoretically able to model multimodal, multicommodity flows, although data requirements make this less feasible in practice.

Weaknesses include the significant investment required to identify decision makers and conduct choice experiments, which is beyond the resources of all but the largest freight studies (TRB 2010). Identifying and engaging with different decision makers (e.g., shippers, carriers, and end customers) is important in these types of models, because different decision makers often have different objectives or weight attributes differently. Surveys and other disaggregate data collection methods can be difficult to implement over a large geography and difficult to repeat at sufficient frequency to continually provide accurate updates. Many behavioral choice models are subject to assumption errors that decrease the validity of results, such as the error term being independent across all modes.

The capability of most four-step travel demand models (which calculate trip generation, trip distribution, mode choice, and trip assignment to the travel network) to test "microscale" infrastructure characteristics is very limited and often nonexistent. Not all models fully incorporate feedback relationships (i.e., how changes in transportation conditions may affect land use patterns which then further affect transportation).

In addition, like most approaches, conventional four-step travel demand models cannot accurately capture the complexities of supply chains and freight systems. However, a few public-sector agencies have developed behavioral models that capture trip chains, less than truckload movements, local truck deliveries, and their associated routings.

Resources: Cohen, Horowitz, and Pendyala (2008). Forecasting Statewide Freight Toolkit. NCHRP Report 606. Transportation Research Board (TRB), National Academy Press, Washington, D.C.

Jiang, Johnson, and Calzada (1999). "Freight Demand Characteristics and Mode Choice: An Analysis of the Results of Modeling with Disaggregate Revealed-preference Data." Journal of Transportation and Statistics Vol. 2, No. 2, December, 1999.

\subsubsection{Pivot Point (Incremental) Choice Models}

Overview: Revealed-preference and/or stated-preference data are used to develop a discrete choice model to predict future modal shares or diversion. The model will not estimate the modal shift directly, but will use an incremental approach to pivot from existing tons- and shipments-moved to calculate the amount that might divert based on changes in utility of competing modes.

Examples of Specific Models: New York/New Jersey Cross Harbor Choice Model, which looks at shipper response to specific investments or project alternatives; Mode Choice component of Florida Intermodal Statewide Highway Freight Model, which was intended to identify needs and test solutions on major freight corridors.

Developer/Owner: The Port Authority of New York and New Jersey, Florida DOT, and Cambridge Systematics.

Intellectual Property Rights and Transparency: The New York/New Jersey Model is described as part of the environmental impact statement on the Cross Harbor website. The Florida model is described in the NCHRP 606 Report.

Major Inputs: Revealed-preference and/or stated-preference data, characteristics of the shippers/receivers, the shipments being made, and the level-of-service attributes (cost, travel time) of each mode.

Major Outputs: Estimates of future freight flows by mode corresponding to project alternatives or future scenarios. 
Overview of Calculations: Stated-preference surveys or revealed-preference data are obtained. Multinomial and nested logit choice models are estimated, and results are applied in a comparative process to calculate how the relative utility of a change in service for one mode (rail) would compare to the relative utility of the base traffic moving by other modes (truck). The estimated diversion is validated through a series of reasonableness checks, and other validation methods.

Scope:

- Temporal - Current and forecast freight flows

- Geographic - New York/New Jersey region. The logistics of special handling, value of shipment, and size of shipment will be explicitly considered through the development of filters and equations for specific commodities

- Modal, vehicle, fuel - truck and rail

Strengths and Weaknesses for Modal Share Analysis: Strengths of the pivot point choice model include an approach that allows a robust range of alternatives to be tested against a broader range of commodities and origin destinations by maximizing the information from the stated-preference surveys without the level of in-depth detail required for other modeling techniques.

Weaknesses of this particular model include the reliance on stated-preference surveys, which are costly and difficult to implement on a national scale, and results from one region are often not transferable to others. Like many similar models, pivot point models are based off of a base year and set of assumed parameters. The accuracy of the forecast is tied to the quality and accuracy of data available and the assumptions made.

Resources: FHWA (2010). Cross Harbor Freight Program Environmental Impact Statement (EIS) Methodology.

Cohen, Horowitz, and Pendyala (2008). Forecasting Statewide Freight Toolkit. NCHRP Report 606.

Kumar (1980). Use of Incremental Form of Logit Models in Demand Analysis. Transportation Research Record.

\subsubsection{Mesoscale Freight Models}

Overview: Mesoscale models are an example of agent-based models, which are models representing the choices of individual decision makers (agents). These models analyze goods movement decisions that are made by individual businesses, and are intended to serve as a bridge between high-level commodity flow data and detailed freight vehicle microsimulations. By focusing on individual businesses, the model can incorporate a broad range of economic and other business strategies that drive the freight-related decisions of businesses.

In addition, mesoscale models evaluate transportation and logistics paths at a detailed level, adapting a holistic perspective of path selection that incorporates tradeoffs between transportation-related factors, such as mode choice, and factors that are not specifically transportation-related, such as inventory costs (see Figure 5.3).

Developer/Owner: Chicago Metropolitan Agency for Planning and Cambridge Systematics.

Intellectual Property Rights and Transparency: The prototype model documentation and working demonstration is published on the Chicago Metropolitan Agency for Planning website.

Major Inputs: Zone systems (such as FAF3), network data, including logistical notes and distribution centers, distances or impedances between O/D pairs, commodity make and use tables, FAF3 commodity flows, macroscale-model commodity flows, and employment data. 
Major Outputs: A freight vehicle trip table, including the following factors: commodity, mode (truck, rail, air, and water), submode (truckload shipment, containerized shipment, etc.), origin, destination, and intermediate stops, shipment size, shipment frequency, and use of logistics facilities.

Overview of Calculations: The mesoscale model uses four processes to transform FAF data into commodity tours, including firm generation, supplier selection (pairing of firms to form supply chains), flow apportionment, and path selection (i.e., modeling individual shipments as they flow over the network). The utility, or cost, to an agent in terms of actual cost, time, and other factors important in the decision-making process is used to predict the path selection and mode utilized.

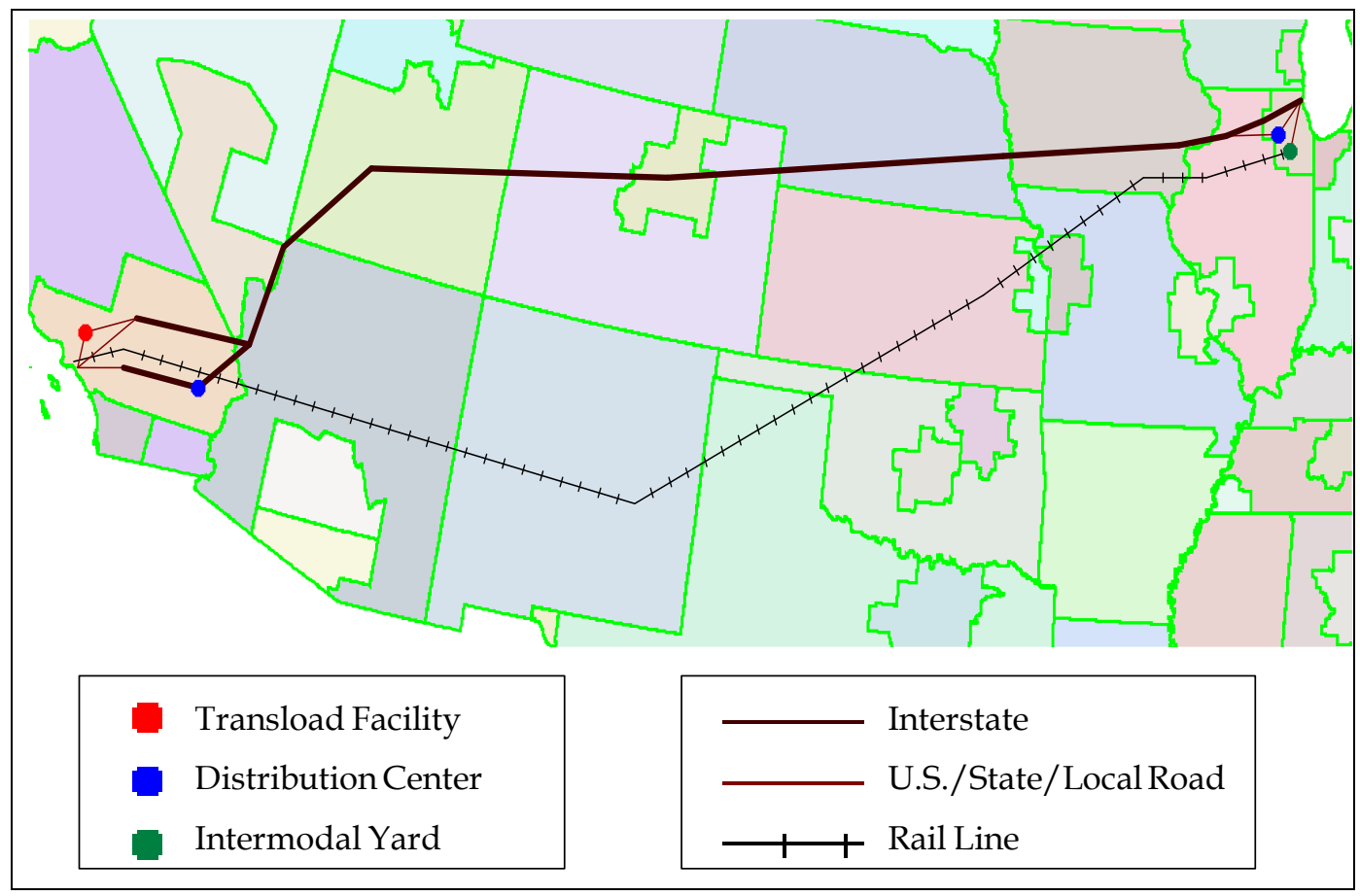

Figure 5.3. Sample links and nodes from mesoscale prototype national network

(Source: Urban and Beagan 2011)

Scope: Bridges macroscale and microscale models for a FAF3 level region - the prototype model focuses on flows in and out of the Chicago region.

Strengths and Weaknesses for Modal Share Analysis: Strengths include a holistic perspective of tradeoffs between transportation and nontransportation-related factors. Mode is considered an output of a series of decisions that model the realistic decision process made by individual firms. Modal disaggregation is allowable at all steps in the process.

Weaknesses include that the prototype model does not yet include through trips, which will be developed later as a macroscale model. Currently, much of the data uses placeholder values, and data on individual preferences is needed to properly determine the values assigned to cost, time, and other mode and path choice factors in the model. Since the model framework is very thorough, it will need and benefit from an equally thorough calibration and validation process.

Resources: Mohammadian, Kawamura, and Auld (2011). A Working Demonstration of a Mesoscale Freight Model for the Chicago Region: Final Report and User's Guide. Chicago Metropolitan Agency of Planning. 


\section{Federal Actions to Influence Freight MOdAL Shifts}

An important objective of this study is to identify and assess the types of policy mechanisms and approaches that could encourage energy-efficient freight mode choices, in the context of a suite of policies aimed at reduction petroleum use and GHG emissions. This section provides a discussion of federal actions that could influence mode shifts and lead to more energy-efficient freight transportation, including a brief overview of prior and current federal action on these issues and discussion of possible future actions. This is not advocate for or against these actions, but attempts to assess their potential, based on empirical evidence and authors' interpretations and judgment. Seven potential federal actions are summarized in Table 6.1.

Table 6.1. Summary of Potential Policy Actions

\begin{tabular}{|c|c|c|}
\hline Potential Policy Action & Agencies and Entities & Modal Shift Potential \\
\hline $\begin{array}{l}\text { Increase truck size and weight } \\
\text { limits }\end{array}$ & - U.S. DOT & Low \\
\hline Increase federal fuel tax & $\begin{array}{ll}\text { - } & \text { U.S. DOT } \\
\text { - } & \text { Internal Revenue Service }\end{array}$ & Low \\
\hline Regulate or price GHG emissions & $\begin{array}{ll}\text { - } & \text { U.S. DOT } \\
\text { - } & \text { EPA/California Air Resources Board } \\
\text { - } & \text { Internal Revenue Service }\end{array}$ & Low \\
\hline Expand use of direct-user fees & - U.S. DOT & Moderate \\
\hline $\begin{array}{l}\text { Invest in freight rail and waterway } \\
\text { corridors }\end{array}$ & $\begin{array}{l}\text { - U.S.DOT } \\
\text { - USACE }\end{array}$ & Moderate \\
\hline $\begin{array}{l}\text { Modify commercial vehicle hours } \\
\text { of service regulations }\end{array}$ & - U.S. DOT & Low \\
\hline Reregulate freight rail rates & $\begin{array}{ll}\text { - } & \text { U.S. DOT } \\
\text { - } & \text { STB }\end{array}$ & Low (likely rail to truck) \\
\hline
\end{tabular}

\subsection{Truck Size and Weight Policy}

Truck size and weight are regulated due to safety and road and bridge maintenance concerns, and relaxation of current limits has been proposed. Increasing truck size and weight limits has the potential to reduce energy use, emissions, labor costs, and other costs, such as warehousing, order processing, and loss and damage. These changes could make truck freight transport more competitive with rail. Modal shares for commodities that are both truck and rail competitive modal shifts could be influenced by truck size and weight policy. These commodities include paper products, pulp and allied products, food and kindred products, lumber and wood products, primary metal industry products, and waste and scrap (FHWA 2000). The net effect of increased truck size and weight on energy use is uncertain because it couples improved truck energy efficiency with potential diversion to truck from rail.

\subsubsection{Overview}

Truck size and weight limits on federal highways have been largely static since 1991, when the Intermodal Surface Transportation Efficiency Act (ISTEA) prohibited states from increasing the size and weight of trucks beyond what they already allowed (Code of Federal Regulations, Title 23, 658.23). Trucks operating on the Interstate system can weigh no more than $80,000 \mathrm{lbs}$ under current law. Longer combination vehicles (i.e., tractor-trailer configurations with two or more trailers that can weigh more than 80,000 lbs) are permitted on certain highways in 21 states (mostly Western states), having been 
grandfathered in under ISTEA. Over the past several years, there has been continuous discussion related to unfreezing ISTEA truck size and weight limits and allowing heavier trucks (e.g., 97,000 lbs on six axles). Legislative attempts to remove the freeze have been unsuccessful except for congressional action last year allowing heavier truck operation on Interstates in Maine and Vermont. ${ }^{23}$

\subsubsection{Government Roles and Authorities}

There are several agencies that have a role in developing, implementing, and enforcing truck size and weight policy. Federal interest in preserving highways goes back to the enactment of the Federal-Aid Highway Act of 1956, authorizing the Interstate and Defense Highway System. The FHWA is responsible for administering the federal regulations governing commercial vehicle (truck and bus) sizes and weights. The Vehicle Size and Weight Program, managed by FHWA's Office of Freight Management and Operations, is guided by several key statutes and regulations. The statutes and regulations provide the program with its authority and govern its structure and performance. The statutory authority for the federal oversight of vehicle size and weight activities is described in three locations within the United States Code:

- Title 23 U.S.C. 127 establishes weight limits that states shall allow and must enforce on the Interstate system

- Title 23 U.S.C. 141 requires states to annually certify that they are adequately enforcing all state laws regarding size and weight limits as a prerequisite for receipt of Federal-aid Highway funding

- Title 49 U.S.C. 31111-31115 establishes minimum size requirements on the National Network and access routes to the National Network

Additional provisions are codified in various locations in Titles 23 and 49. However, the entire set of regulatory provisions that guide the administration of the vehicle size and weight activity are found in the Code of Federal Regulations, Volume 23, Parts 657 and 658. States also have a regulatory role in truck size and weight regulation. States are allowed to determine how and when oversize/overweight permits are issued in the state and enforce these and federal regulations accordingly.

"Counties and other political subdivisions are authorized to set and enforce size and weight laws on their roads and highway networks. One of the primary roles of local government is the identification and posting of weight limits on roadways and bridges." 24

\subsubsection{Cost-Benefit Methods}

No comprehensive, national study of costs and benefits of truck size and weight policy was found in the literature. The American Transportation Research Institute (the research arm of the American Trucking Associations) conducted a study of fuel and emissions savings from increasing weight limits. The study found decreases in fuel consumption and emissions per ton-mile up to $33 \%$ at a weight limit of 140,000 lbs (American Transportation Research Institute 2008).

Only a handful of states, including Minnesota and Wisconsin, have developed and implemented costbenefit methods for assessing the tradeoffs associated with changes in truck size and weight policy. The Wisconsin DOT implemented a detailed benefit-to-cost analysis that estimated the impacts of truck size and weight law changes on roadway safety and infrastructure preservation. Specifically, the Wisconsin study examined six different truck configurations (varying axle spacing and axle weight) to understand how increases in size and weight could affect pavement and bridge condition, safety, congestion, and energy and environment. Costs associated with increases in truck size and weight (e.g., cost to upgrade

\footnotetext{
${ }^{23}$ See http://ops.fhwa.dot.gov/freight/sw/reports/vt_pilot_2012/rptcongress/index.htm and http://fleetowner.com/management/news/senate-bill-me-vt-truck-limits-1102

${ }^{24}$ For further discussion of the roles of state and local governments in truck size and weight enforcement, see Wisconsin Truck Size and Weight Study (Wisconsin Department of Transportation 2009).
} 
bridges to handle heavier loads) were weighed against the potential economic development gains and greater employment that accompany increased trucking productivity.

The major finding of the analysis was that five of the six truck configurations reviewed generate net statewide benefits if they are allowed to operate on non-Interstate highways and if the impacts on bridges are limited to the direct impacts of the new truck configurations. Taking into account the total bridge costs and the ability to operate on the Interstate, the most successful new configuration, in terms of net benefits, was the six-axle 98,000-lb semitrailer, which generated the highest savings in transport costs, safety, and congestion. However, this truck, while currently operating under exception in Wisconsin, does not meet the Federal Bridge Formula with its commonly used axle spacings. The next most beneficial truck was the seven-axle 97,000-lb semitrailer, followed by the marginally beneficial six-axle 90,000-lb semitrailer. The study found reductions in fuel consumption by allowing larger 90,000- or 98,000-lb trucks similar to the findings of the American Transportation Research Institute (2008) research.

The Wisconsin work included a rail sensitivity analysis in addition to a truck/rail diversion analysis. These sensitivity analyses were performed to investigate how different assumptions would affect future truck volumes and associated costs and benefits. Sensitivity tests estimated the effects of increasing the amount of freight carried by trucks by $5 \%, 10 \%$, and $15 \%$ due to a combination of diversion from rail and increases in the total amount of freight shipped. In these tests, transport cost savings are increased since shippers would not shift from rail to truck or increase the amount that they ship unless it is in their economic interest to do so. However, cost savings for pavements and bridge decks, safety, and congestion are reduced or, in some cases, eliminated, because of greater truck VMT.

While sensitivity results indicate potential changes in cost savings and impacts if freight moved from rail to truck, the study concluded that diversion from rail would be negligible (especially if increases in truck weight limits were limited to non-Interstates in Wisconsin) because: 1) most of the competition between truck and rail is for long-distance shipments (e.g., over 500 miles); and 2) private sector outreach participants did not believe truck size and weight changes would divert traffic from rail, in part because of rail's continued focus on long-haul, lower-value commodities (Wisconsin Department of Transportation 2009).

\subsubsection{Scale of Modal Shift Opportunities}

There have been conflicting opinions on the potential for truck-rail modal shift resulting from a nationwide change in truck size and weight limits. The issue has not been addressed comprehensively since the last congressionally mandated Comprehensive Truck Size and Weight Study conducted by the FHWA in the mid-1990s (FHWA 2000). The AAR has indicated that an increase in truck size and weight limits could lead to significant modal shift from rail to truck and could impact rail industry financial performance, particularly short line and regional railroads (Martland 2007). At least one study found that diversion from short line railroads could be 10\%-15\% (Martland 2007). Some industry shippers and carriers do not agree with this assessment. The private sector outreach that was part of Wisconsin's Truck Size and Weight Study found that the industry did not believe that a change in state truck size and weight policy would have a significant impact on truck and rail modal shares. Based on the author's experience, this is likely to be representative of the perception nationally.

We estimate that changing truck size and weight policies would likely have some impact on shifting rail traffic to truck, but only for lower-weight, higher-value commodities moving long distances. On some corridors, diversion rates could approach the higher end of what studies have estimated. However on a national scale, diversion impacts are likely to fall below 5\% (measured in tonnage not vehicle-miles of travel or ton-miles).

\subsubsection{Gaps and Issues}

Past efforts to relax the size and weight limits to improve truck productivity by allowing more freight to be carried in a single trip have not been successful due to concerns about safety, road and bridge 
deterioration. The railroad industry, particularly short line and regional railroads, is also concerned about the potential impacts on its modal share.

The truck size and weight issue takes on more importance if a number of states (or the nation) liberalize weight limits. This would create regional or national corridors and trade lanes along which trucks could more effectively compete with rail over longer distances. That would be a threat to the railroads in the short term, although traffic congestion and fuel prices would affect utilization and modal shares in the longer term.

Although some states have conducted preliminary assessments of modal shift impacts, the tools and processes utilized are still somewhat rudimentary and typically calculate aggregate impacts. More detailed rail diversion impacts would involve conducting market-based assessments of specific corridors or commodities. The amount diverted could be estimated through an analysis of truck/rail modal share in similarly situated corridors/regions, including states with similar geographies, industries, and more liberal truck size and weight laws. The results of the diversion estimate also would need to reflect economic realities of businesses working to minimize shipping unit costs per mile. The results of such an analysis could more definitively assess the impacts on railroads, especially short line or regional haulers. Such analysis could be used to develop better estimates of the net effects of truck size and weight policy change on fuel and emissions.

\subsection{Fuel Tax Policy / GHG pricing}

\subsubsection{Overview}

Current taxes on motor fuel include federal, state, and local taxes, along with some other fees. At the federal level, there are different rates depending on fuel type. The current rates for the most commonly used motor fuels are shown in Table 6.2.

Table 6.2. Federal Tax Rate by Motor Fuel Type

\begin{tabular}{lc}
\hline Fuel Type & Rate (Cents per Gallon) \\
\hline Gasoline & $\$ 0.184$ \\
Diesel and Kerosene & $\$ 0.244$ \\
Liquefied Petroleum Gas & $\$ 0.136$ \\
Liquefied Natural Gas & $\$ 0.119$ \\
Compressed Natural Gas & $\$ 0.043$ \\
\hline
\end{tabular}

(Source: U.S. DOT)

Note: These tax rates are based on energy content equivalency.

Most states have similar types of taxing scales although some do have additional charges such as sales taxes, petroleum business taxes, environmental fees, and clean-up fees. When all sources are combined, taxes on a gallon of fuel account for approximately $12 \%$ of the cost of diesel (at $\$ 3.96$ per gallon), as shown in Figure 6.1 (EIA 2011). 


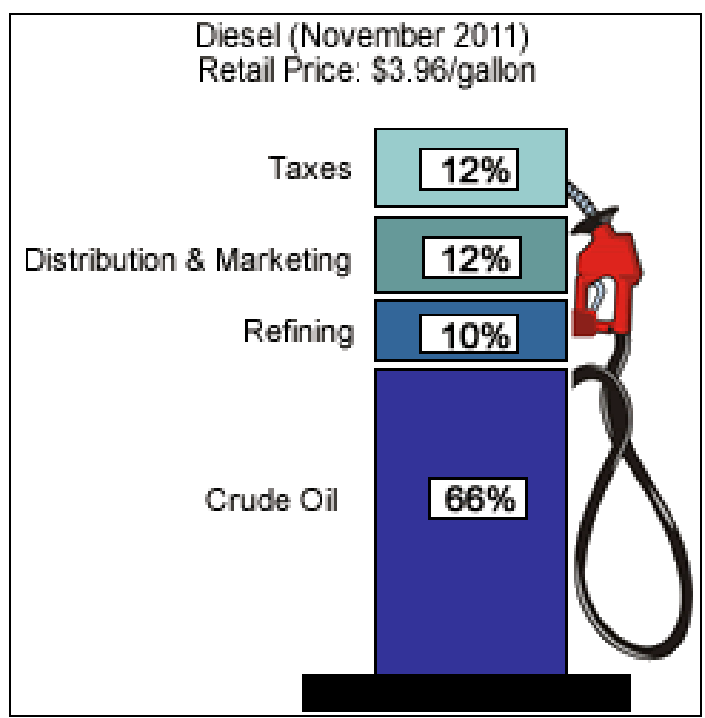

Figure 6.1. What we pay for in a gallon of diesel

(EIA 2011)

The federal diesel fuel tax has remained unchanged at $\$ 0.244$ for diesel for nearly two decades (since 1993). Additionally, the tax is not indexed to the price of crude oil or inflation, so drivers pay a fixed amount whether oil prices are high or low. As a result, the purchasing power of the tax has eroded considerably, diminishing its ability to fund infrastructure investments.

States use fuel and mileage tax reporting to ensure they are getting their fair share of the tax money that the truckers are paying through the International Fuel Tax Agreement, which is an agreement among states and Canadian provinces to simplify the reporting of fuel-use taxes by interstate motor carriers. Miles operated in each state or province are calculated and taxes paid accordingly. The tax receipts go into state coffers for transportation investment.

Railroads do not pay state motor fuel taxes; only fuels sold at commercial pumps have road taxes levied on them. As railroads directly source bulk fuel, they are not subject to paying a motor fuel tax. However, railroads are subject to paying other taxes imposed by states, such as sales and use taxes, which can be significant. Unlike motor fuel taxes, which go toward transportation funds and improvements, sales and use taxes contribute to state and community general funds.

Increases in fuel tax, which would raise the price of fuel, could encourage shippers to use more fuelefficient modes of transportation (i.e., rail or barge in lieu of truck) to save costs. Modal shift from truck to rail or barge could reduce the damage on the state roads; however, as the trucking industry contributes significantly to motor fuel-tax receipts, overall revenue from the diesel fuel tax could drop, limiting the ability of states to invest in their transportation infrastructure. For combination trucks, the Bureau of Transportation Statistics reports consumption of over 28 billion gallons in 2009. Assuming no growth in mileage or change in tax rates, combination trucks alone will pay over $\$ 13.3$ billion in fuel taxes in 2012 .

More stringent regulation of GHG emissions could have different effects on modal shift between truck and rail, depending upon how the regulation changes the relative energy costs for truck and rail. For example, at the Federal level, in 2011 the U.S. EPA and the National Highway Traffic Safety Administration (NHTSA) jointly adopted GHG regulations and fuel efficiency standards for medium and heavy duty vehicles (EPA and NHTSA 2011). Such regulation would, in the long run, have the effect of reducing the cost per ton-mile of moving goods by truck, potentially leading to some mode shift from rail or water to truck on some corridors and trade lanes. On the other hand, regulations that increase the price of fuels for all modes (such as a carbon tax or cap-and-trade system) could have the effect of shifting 
some goods from less-efficient truck to more-efficient rail and water modes. Increasing the cost of carbon economy-wide through a cap-and-trade system, carbon tax, or other regulatory activity, provides an economic incentive to consumers and businesses to use lower-carbon fuels and more energy-efficient modes (EPA GGRP 2012). GHG emission prices would increase the direct cost of fuel, and are not examined separately in this section.

\subsubsection{Government Roles and Authorities}

Fuel taxes currently are administered at both federal and state levels. At the federal level, the majority of the taxes are collected when product is removed from the bulk storage terminals. The companies pay the tax to the Internal Revenue Service.

States have different rules for the point of taxation as some tax the product at the rack, which is upon removal from the bulk terminal, while other states impose the tax at the distributor level, having a series of approved bulk distributors who hold licenses and file regular (usually monthly) returns where the state and local taxes are paid.

The revenue from the collected federal fuel taxes are deposited into the Highway Trust Fund, which has several accounts. Though the percentages vary depending on the fuel type, the majority (approximately $83 \%-87 \%$ ) is deposited into the Highway Trust Fund, to be used on road construction and maintenance. An additional amount (approximately 11\%-15\%) goes to the Mass Transit Account, and for many fuels, \$0.001 per gallon goes to the Leaking Underground Storage Tank Trust Fund (EPA OSWER).

\subsubsection{Cost-Benefit Methods}

The costs and benefits, with respect to modal shift implications, of fuel tax increases are not well defined. Increased diesel fuel taxes may be expected to prompt truck to rail mode shifts of uncertain magnitude, but probably quite small, given the small mode shifts in response to substantial fuel price increases (discussed next). Other potential benefits of fuel tax increases center on benefits achievable if revenues were directed toward highway improvements. The American Trucking Association is on record as favoring an increase in the federal motor fuel tax as long as the increased revenues are applied to highway improvements. ${ }^{25}$ The numerous and substantial benefits of such improvements are beyond the scope of this discussion; however, the magnitude of these revenues from a fuel tax increase would depend in part on whether mode shifting occurred. If higher fuel taxes prompted a modal shift from truck to rail, this would, of course, reduce transportation funds available for highway investment, relative to a tax increase with no modal shift. Similarly, the costs of increased fuel taxes are linked to mode shift opportunities, in that higher truck freight transportation costs are more likely to be pass on to the consumer in the form of higher prices, where mode shifting opportunities are small.

\subsubsection{Scale of Modal Shift Opportunities}

Although changes in fuel prices could result in modal diversions, the price would have to change significantly to have any meaningful effect. As can be seen in Figure 6.2, diesel prices have risen nearly four-fold since the mid-1990s, but rail traffic has not grown apace. Estimates developed by Cambridge Systematics for a private client suggest that a near doubling of the price of a gallon of diesel fuel would result in a shift of freight from truck to rail equivalent to about a $1 \%$ increase in the current, total freight rail tonnage. Estimates of modal elasticities exist for the change in modal demand due to price, but these studies are poorly suited to evaluate potential changes in the effect on multiple modes due to fuel taxes.

\footnotetext{
${ }^{25}$ See for example: “ATA to Congress: Fuel Tax is Most Effective Way to Fund Infrastructure.” Press release of July $23,2009$. available at http://www.trucking.org/Newsroom/Pages/pressreleases.aspx.
} 


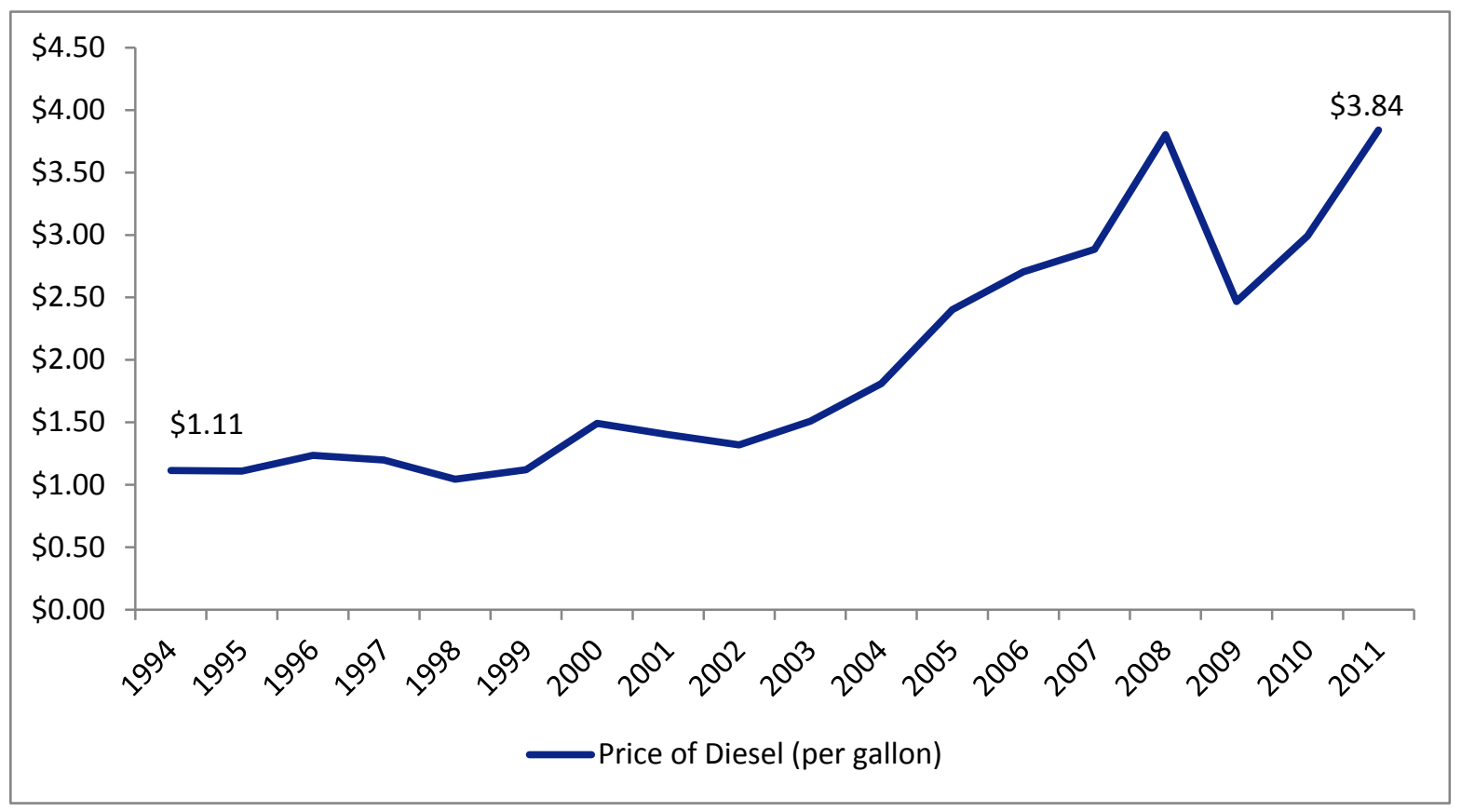

Figure 6.2. U.S. diesel prices, 1994 to 2011

(Source: EIA)

\subsubsection{Gaps and Issues}

Current motor fuel tax policies, if unchanged, can be expected to result in a slower growth in fuel tax revenues for the Highway Trust Fund, because inflation reduces the purchasing power and fuel economy standards reduce fuel use. Revenues will grow with population growth and more cars and VMT, but the incremental revenue yield will drop over time. The topics of motor fuel-tax increases and indexing that tax have been contentious issues in budget and reauthorization discussions of the federal surface transportation programs. On the one hand, additional revenue is needed to maintain the nation's roadways at their current level of performance. On the other hand, there are concerns about the economic impacts of any form of pricing that increases the cost of travel. During the 2007-2009 recession, federal and state legislatures did not take action to increase fuel taxes. However as the economy improved and, possibly due to federal inaction on reauthorization and funding of the highway and transit programs, several states, including Iowa, Maryland, Pennsylvania, Virginia, have discussed state fuel-tax increases as well as imposition of state sales taxes of fuels (e.g., taxing the value of the fuel sale not just the gallons of fuel sales). These funding challenges intersect with questions of mode shifting in a number of ways: higher fuel taxes would increase the fuel portion of trucking costs, but if the fuel tax revenues were invested in highways they would reduce trucking costs associated with highway congestion, maintenance, and safety issues; and new revenues for transportation infrastructures could be considered in the context of overall transportation-sector policy goals.

\subsection{Direct-User Fees}

Direct-user fees are fees that are typically applied at the point and time of use, such as tolls. There are several examples of container charges and other user fees that have been implemented to support freight investments, reduce congestion at freight facilities, or influence travel behavior. There are three types of direct-user fees, described below, that are or could be applied to freight operations, although only a few are currently being used to influence travel behavior. 
- Truck-Only Tolled Facilities. The use of tolls to raise transportation revenue is gaining momentum across the country as a way to accelerate transportation investments and more directly link fees and payments with the use of transportation infrastructure. The primary tolling application for freight involves truck-only toll lanes. The use of tolls on such facilities could accelerate the delivery of freight-specific improvement projects while minimizing public-sector risk. In addition, surplus toll revenue from these facilities could be used to support additional freight investments. Truck-only toll lanes have been the subject of feasibility studies in California (SR 60), Virginia (I-81), the Midwest (I-70), and elsewhere.

- Congestion Pricing. This concept, closely related to tolls, involves offering incentives to use transportation facilities in off-peak hours or charging extra to use them during peak hours. Prices can vary based on a fixed schedule or they can be dynamic, meaning that rates change depending on the level of congestion that exists at a particular time. The PierPass program implemented at the Ports of Los Angeles and Long Beach uses pricing techniques as part of a congestion mitigation and air-quality improvement strategy. Though most commonly used as a congestion mitigation tool, surplus revenue from congestion pricing programs could be used to support other freight improvements.

- VMT or Ton-Mile Fees. Several recent national policy studies have recommended shifting away from fuel-based revenue sources (i.e., motor-fuel taxes) and toward mileage-based charges, such as VMT fees. VMT fees would be levied based on the actual miles traveled by each vehicle or freight container, and current innovations in tolling and tracking technology could help facilitate a transition to this type of revenue-generation strategy. The Oregon DOT is currently conducting the Road User Fee Pilot Program, a test designed to demonstrate the technical and administrative feasibility of implementing an electronic-collection system for mileage-based congestion fees. Ton-mile fees, often referred to as weight-distance taxes, would be levied based on actual tonmiles traveled by each commercial vehicle. Oregon, Kentucky, New York, and New Mexico currently levy a weight-distance tax on commercial vehicles operating within their states; though in 2003, proceeds from these weight-distance taxes represented less than $1 \%$ of total state highway revenue collections. ${ }^{26}$ Several states, including Arkansas, Idaho, and Nevada, repealed weight-distance taxes, primarily as a result of legal challenges. ${ }^{27}$

- In the European Union, VMT fees for heavy trucks are currently in place using several systems, including vignettes or time-based windshield stickers, on-board GPS systems, and manual toll booths. Toll rates are generally based on distance traveled, number of axles, and emissions class (European Parliament 1999). In 2006, 3 billion Euros (approximately $\$ 43.75$ billion) were collected in Germany alone-an average tolling rate of 0.12 Euros per kilometer-and appropriated to road building and maintenance (50\%), upgrades to the railway network (38\%), and inland waterway maintenance (12\%). Although this system did lead to more efficient freight operations and increased use of lower-emissions trucks (that are charged a lower toll rate), it is unclear whether more than a slight modal shift can be attributed to this practice (Broaddus and Gertz 2008).

\footnotetext{
${ }^{26}$ FHWA Highway Statistics, 2003. Weight-distance taxes are typically calculated on miles traveled in a state and the registered weight of the truck (and occasionally, the actual loaded weight). The mileage, weight, and calculated taxes are self-reported by carriers and subject to retroactive audit. At one time, Oregon maintained an extensive network of truck weigh stations where trip logs were inspected and compared to the current operating weight of the truck to ensure that carrier permits were in order and paid to date, and to provide basis for state audits of carrier records. Although much streamlined today by computer systems, weight-distance taxes are regarded by many as excessively paperwork- and labor-intensive relative to the revenues collected (FHWA 2003).

${ }^{27}$ American Trucking Associations, via correspondence.
} 


\subsubsection{Agencies and Entities}

Many agencies from the federal and local level are involved in the implementation of user fees. At the federal level, the U.S. DOT and FHWA have funded research for a variety of user-fee methods and would likely administer any national or mileage-based user fees for commercial vehicles. State DOTs and MPOs also levy fees on commercial vehicles within their jurisdiction. Toll and turnpike authorities are often granted the authority to build roads by issuing bonds backed by future toll revenues. Private sector concessionaires can also be involved in the construction and management of toll roads and may have an involvement in future optional toll or fee strategies. In Europe, public-private partnerships have been crucial to the operation of tolling facilities and collection of tolls.

\subsubsection{Cost-Benefit Methods}

Assessment of the costs and benefits of direct-user fees considers modal shifts, induced demand, and administrative costs. Modal shift and induced demand effects are calculated using price elasticity models, etc. Administrative costs are generally extrapolated from comparable programs or pilot tests. An example of the latter is the Oregon Road Fee Pilot Program, which assessed the costs and benefits shown in Table 6.3 (Oregon DOT 2007). The pilot focused on the costs and benefits of a VMT program for automobiles, but the category of assessment would be similar for motor carriers. Most of these costs and benefits can be directly calculated. Those that cannot, like ease-and-convenience to vehicle owners can be estimated using survey techniques.

Table 6.3. Cost and Benefit Factors of Oregon Road Fee Pilot Program

\begin{tabular}{ll}
\hline Costs & Benefits \\
\hline Start-up costs: capital and retrofitting & Ease and convenience to vehicle owners \\
Operating and maintenance & Transparency \\
Enforcement and auditing & Net revenue production \\
Cost of collection relative to fuel tax & \\
Hardware and software costs & \\
Costs to vehicle owners/operators & \\
Cost of enforcement & \\
\hline
\end{tabular}

(Source: Oregon DOT 2007)

\subsubsection{Scale of Modal Shift Opportunities}

Pricing techniques could represent a significant source of transportation revenue that offers a direct link between costs and benefits. If truck volumes are high enough on these facilities, they could be funded entirely by private sector investment capital, minimizing risk to and investments by public sector transportation planning agencies. However, these facilities are most viable only if located along corridors with high volumes of truck traffic and few/no rail options. As a result, their ability to affect a truck/rail modal shift is severely limited. Although tolling schemes for freight vehicles in Europe have produced increased revenue for infrastructure construction and maintenance and promoted a shift to more efficient vehicles and logistics practices, evaluations of the program have found little modal shift directly attributable to these tactics (Broaddus and Gertz 2008).

The recently completed feasibility study of dedicated truck lanes along the I-70 corridor between Missouri and Ohio (I-70 Coalition 2011) concluded that dedicated truck lanes are a financially viable alternative worth further exploration. However, the study determined that along the 800-plus-mile I-70 alignment, truck traffic would not be attracted to alternate modes, such as rail. The minimum distance for rail to be competitive with truck is typically 500 miles; $82 \%$ of truck trips in the corridor were less than 300 miles; and 69\% were less than 200 miles. Additionally, truck trips provide door-to-door connectivity 
for industry, warehousing, and distribution centers in the corridor, and the existing rail network is not aligned to provide the same type of connectivity.

\subsubsection{Gaps and Issues}

Political barriers currently are the strongest barrier to any form of pricing that increases the cost of travel. Privacy issues related to monitoring of travel also need to be addressed. Pricing is more likely to be accepted if it is optional (e.g., optional Pay-As-You-Drive, optional high-occupancy toll lanes). The freight sector has shown some interest in voluntary Pay-As-You-Drive insurance, but to have full effectiveness it would need to be mandatory, requiring federal and/or state legislative action.

Feasibility studies have revealed several other issues that may impact the development and implementation of truck-only tolled facilities. For example, tolling projects are often conceived with the goal of improving economic opportunities and reducing congestion and emissions. Many also expect toll roads to be self-sustaining. However, studies, such as the I-81 truck tolling study, have found that pricing levels best serving the first goals are often significantly less than those required to finance the project's infrastructure costs. Therefore, to reach economic, congestion, and environmental goals, truck lane projects would need other (likely public) funding sources.

For the few trade lanes where toll, non-toll, and rail alternatives exist in parallel, toll increases would prompt toll-to-non-toll diversion before causing truck-to-rail diversion, unless accompanied by other restrictions on non-toll facilities. In the case of I-81, diversion from the tolled facility would increase VMT and congestion on surrounding non-tolled roads because of the lack of competitive rail service. Limited access to alternative modes, such as rail, serves as a further barrier to modal diversion through tolling methods.

\subsection{Freight Rail Corridor and Waterway Investments}

\subsubsection{Overview}

Targeting investments in non-truck modes to make them more viable options for shippers presents an attractive opportunity for federal agencies to influence mode choice decisions.

The Highway Trust Fund was established to provide funding for infrastructure-related projects that are a part of the Federal Highway System. As such, investments made with those dollars are primarily focused on highway users and, to some extent, transit users. Rail and water investments are determined by entities outside the Highway Trust Fund investment discussions. Both the railroads and waterways must be strategic with their infrastructure investments and, as such, may invest to improve their system for existing customers, not necessarily to effect modal shift.

The freight rail system is owned and operated by private freight rail companies and has historically not been eligible for award of Highway Trust Fund dollars. Each railroad must plan and pay for capital, operations, and maintenance expenses for its system out of its own coffers.

The inland waterway system is funded jointly by the Inland Waterways Trust Fund and the congressional appropriations from the federal government's General Fund. ${ }^{28}$ In recent years, the Inland Waterways Trust Fund has been aggressively used — so much so, that today the fund does not have resources sufficient to meet inland waterway lock and dam maintenance and modernization needs. Expenditures today are limited to the amount of annual fuel-tax revenues collected for a particular year. In 2010, this was only $\$ 85$ million against an annual average backlog of $\$ 900$ million in projects (Waterways Council 2010).

\footnotetext{
${ }^{28}$ Revenues for the Inland Waterways Trust Fund are collected by the Treasury and funded projects are managed by the U.S. Army Corps of Engineers at the direction of Congress. See 26 U.S.C. 9506 - Inland Waterways Trust Fund (U.S. Government Printing Office 2012).
} 
In contrast to the United States, as discussed in the previous section, the European Union uses taxes and tolls on freight road vehicles, in addition to other sources, to fund investments in other modes. The European Union also promotes freight modal shift through a grant program aimed at funding projects that shift freight from the road to other, more environmentally friendly means. Under the Marco Polo I (2001) and Marco Polo II (2006; revised in 2009) programs, a company with a project to transfer freight from road to rail or short-sea shipping routes or inland waterways may qualify for a Marco Polo grant. The program budget for 2007-2013 is 450 million Euros ( $\$ 560$ million), with $79 \%$ of funding going to modal shift actions (European Commission).

\subsubsection{Agencies/Entities}

There are several federal players involved in decision-making related to freight investments. While most federal freight investments has been focused at the trucking industry, recent U.S. DOT programs have also invested in projects benefiting other modes. U.S. DOT's administered TIGER (Transportation Investment Generating Economic Recovery) grant program considers public and private benefits and costs in making grant awards. Congress dedicated \$1.5 billion for TIGER I, \$600 million for TIGER II, and \$511 million for TIGER III to fund projects that have a significant impact on the nation, a region, or a metropolitan area. In the recent TIGER III award, $12 \%$ of the funds went to port projects and $10 \%$ went to rail projects.

The USACE is responsible for 12,000 miles of the waterways, including the Intracoastal Waterway. Most of the commercially important inland waterways are maintained by the USACE, including 11,000 miles of fuel-taxed waterways. Commercial operators on these designated waterways pay a $\$ 0.20$-per-gallon diesel fuel tax, deposited in the Inland Waterways Trust Fund, which funds half the cost of new construction and major rehabilitation of the inland waterways infrastructure.

Freight railroads are responsible for all capital, operations, and maintenance costs of their systems. Combined there are over 140,000 miles of freight rail track in the United States. Freight railroads have invested more than $\$ 480$ billion since 1980 to maintain and improve their tracks, bridges, tunnels, locomotives, freight cars, and other infrastructure and equipment. ${ }^{29}$

Actors at the state and local level are increasingly engaged in freight planning, and their investment activities have evolved considerably. In recent years states and MPOs began undertaking efforts to learn about freight movements, freight stakeholders, and freight impacts; and to more explicitly incorporate freight-related issues within existing transportation planning and programming activities. As a result, these public-sector agencies are now more aware of how freight movements impact the condition and performance of their systems, and how improving freight efficiency could impact business attraction and retention efforts, regional and state economies, and quality of life.

\subsubsection{Cost-Benefit Methods}

Using a sound cost-benefit methodology to evaluate public investment strategies facilitates public decision-making processes. Evaluating diverse options and accounting for differing stakeholder priorities may involve the calculation of benefits over a variety of metrics or use of scenario analysis to estimate a range of benefits.

For the MAROps study, three types of benefits were estimated: 1) changes in travel costs for truck and rail; 2) changes in travel costs for vehicles remaining on the highway after truck traffic was shifted to rail; and 3) economic impacts, including changes in business activity (e.g., business output, value added) and changes in employment (e.g., jobs and wage income) (I-95 Corridor Coalition 2009). Travel cost savings accrue to shippers through less expensive shipping costs for those who shift from truck to rail; faster rail operations for those who continue to ship by rail; and faster truck operations for those who continue to ship by truck. The construction of MAROps improvements increases business activity by creating

\footnotetext{
${ }^{29}$ Association of American Railroads, economic impacts white papers (AAR 2012a).
} 
construction jobs, and those construction jobs increase spending in other sectors throughout the economy. The cumulative effect on the economy is measured by the increase in business activity and employment.

Determining benefits for large non-highway investments can be particularly challenging due to the fact that the projects may span multiple corridors or modes and impact a range of stakeholders and communities. For the TIGER grant program, benefits considered can be diverse, such as reduced highway maintenance costs, logistics cost savings due to reduced truck ton-miles, environmental and congestion savings, and safety benefits resulting from truck VMT avoided.

\subsubsection{Scale of Modal Shift Opportunities}

Making significant capacity and operational investments in non-highway modes represents a significant opportunity for public policies to affect mode choice decisions in some corridors. The MAROps Study, for instance, estimated the truck/rail diversion impacts of a $\$ 12$ billion investment in the rail system. After the investment, average trains per day in the region increased by approximately $12 \%$ (from 446 to 501 ). The Virginia DOT's I- 81 study (Page 2010) estimated that approximately $17 \%$ of trips greater than 500 miles and 6\% of all truck trips would be diverted to rail by 2035 with $\$ 2.1$ billion rail investment along the parallel Norfolk Southern rail line.

On a national scale, however, diversion rates resulting from non-highway capacity investments would likely be more modest, as these investments are most effective only in corridors with sufficient volumes of divertible commodities, such as the I-95 and I-81 corridors. The 2007 AAR National Rail Freight Infrastructure Capacity and Investment Study compared the current and projected freight demand along the nation's primary rail corridors to existing capacity. The study estimated that an investment of $\$ 148$ billion (in 2007 dollars) in infrastructure expansion over the next 28 years was required just to keep pace with economic growth and meet the U.S. DOT's freight demand forecast (AAR 2007). Freight railroads are private sector businesses and cannot be expected to invest in additional capacity to carry truck freight at unprofitable rates solely for the public purpose of reducing highway congestion and truck energy use and emissions. For investment to shift demand towards rail nationally, it would therefore likely have to be in addition to investment already planned.

In Europe, there has been some success in creating measured modal shift through the Marco Polo I and II projects, with more than 20,000 ton-miles of freight reportedly shifted from road to other modes, as shown in Table 6.4. However, this represents only about one-third of the projected values of the program. The 2009 update to the program increased the funding available and decreased the criteria for program participation, in order to promote higher levels of modal shift (European Commission 2012a).

Table 6.4. Marco Polo I (2003-2006) and II (2007-2009) Evaluation of Total Modal Shift

\begin{tabular}{lccc}
\hline Ton-Miles per Year & Expected & Achieved & Percentage \\
\hline 2003 & 8,491 & 4,968 & $59 \%$ \\
2004 & 9,851 & 4,333 & $44 \%$ \\
2005 & 6,531 & 3,089 & $47 \%$ \\
2006 & 7,809 & 2,310 & $30 \%$ \\
2007 & 19,065 & 4,495 & $24 \%$ \\
2008 & 11,188 & 1,166 & $10 \%$ \\
2009 & 11,765 & 260 & $2 \%$ \\
Total & $\mathbf{7 4 , 7 0 0}$ & $\mathbf{2 0 , 6 2 2}$ & $\mathbf{2 8 \%}$ \\
\hline
\end{tabular}

(Source: Europe Economics)

Note that the achieved modal shift is expected to increase over time for the years of 2007-2009 as many of these projects were still ongoing at early stages at the time of the report. 


\subsubsection{Gaps and Issues}

Lack of funding remains a challenging issue for all transportation projects, particularly those involving building or upgrading the rail and waterway systems. Even for highways and roads, rising maintenance costs, along with decreasing revenues, often absorb what little funds are available for transportation investment. Projects with strong investment cases, especially off-road rail and waterway projects, often do not receive public funding. In order to secure public funding for rail and waterway projects, it is often necessary to not only present the benefits of these investments to the public sector, but also have a strategy for justifying making non-highway investments.

\subsection{Commercial Vehicle Hours of Service Regulations}

\subsubsection{Overview}

The Hours-of-Service (HOS) regulations put limits in place for when and how long commercial motor vehicle drivers may drive. These regulations are based on scientific reviews and are designed to ensure truck drivers get the necessary rest to perform safe operations. The regulations are designed to continue the downward trend in truck fatalities and maintain motor carrier operational efficiencies. Updated in December 2011, HOS regulations state that truck drivers have an 11-hour daily driving limit and 70-hour work week limit. In addition, truck drivers cannot drive after working eight hours without first taking a break of at least 30 minutes. HOS regulations have only been modified a handful of times since the original regulations were published in 1938. In 2003, the HOS rule had a 10-hour daily driving limit, which was increased to 11 hours in 2008. However, these recent and other future changes could impact mode choice decisions by making trucks a less competitive option on some trade lanes.

\subsubsection{Agencies/Entities}

Regulating safety is the primary function of the Federal Motor Carrier Safety Administration (FMCSA). Since its inception, FMCSA has implemented changes impacting how hazardous materials are transported and international cargo is secured, and have instituted measures that provide benefits to users who share the road with truckers, such as assisting trucking companies to prescreen their employees and most recently, banning texting. Although the HOS regulations are found in Code of Federal Regulations, Title 49, Part 395 of the Federal Motor Carrier Safety Regulations, many states have identical or similar regulations for intrastate traffic. The December HOS Rule Change was issued jointly by the FMCSA and the Pipeline and Hazardous Materials Safety Administration.

\subsubsection{Cost-Benefit Methods}

Prior to enacting HOS rule changes, the FMCSA conducted a regulatory impact analysis of the proposed rule (U.S. DOT FMCSA 2011). This analysis considered and assessed the consequences of four potential regulatory options: 1) retaining the 2008 HOS rule (do nothing); 2) limiting allowable daily driving to 10 hours, the driving limit that existed prior to the 2003 rule; 3) retaining the 11 hours of driving allowed under the current rule (this was the option selected in the final rule); and 4) allowing only 9 hours of driving, or one hour less than Option 2. Options 2 through 4 all limit daily duty time to 13 hours (from 14 hours), require at least one break during the duty day, and limit the use of the 34-hour restart provision to once every 168 hours with at least two nights off-duty. Options 2 through 4 differ only in driving time allowed between 10-hour breaks. The regulatory impact analysis compared the costs and benefits (in 2008 dollars) of Options 2 through 4 relative to the 2008 rule and assumed that there is full compliance with each of the options.

Summing the different cost components resulted in a total annualized cost of $\$ 1.0$ billion for Option 2, $\$ 520$ million for Option 3, and $\$ 2.3$ billion for Option 4, that is, the shorter the window truck drivers are allowed on the road, the higher the cost. ${ }^{30}$ Though these costs are estimated using impacts on industry

\footnotetext{
${ }^{30}$ Total revenue for the industry was approximately $\$ 180$ billion in 2007 (U.S. DOT FMCSA 2010).
} 
productivity, they would most likely be passed along as increases in freight transportation rates, which ultimately would be passed on to consumers in increased prices for the goods that are transported by truck (U.S. DOT FMCSA 2010). As the cost to ship via truck increases, the attractiveness of other modes also increases.

\subsubsection{Scale of Modal Shift Opportunities}

If HOS rules are made more stringent, it could increase the total cost of truck movements, making rail more competitive for some commodities along some trade corridors. However, according to the regulatory impact analysis, the costs would be relatively small, limiting the probable magnitude of the effect.

\subsubsection{Gaps and Issues}

HOS rules are in place primarily to ensure safety for drivers and other road users. Since the current rules limiting hours and requiring breaks went into effect in 2004, fatalities have fallen $29.9 \%$, as overall miles traveled for trucks increased by tens of billions of miles. ${ }^{31}$ Although the new HOS rules are designed in part to improve safety, there are drawbacks to the new rules. Due to restart requirements, the new rule may put more truck traffic onto the roadways during morning rush hour. This could potentially increase congestion in certain areas during these peak times, as well as potentially increase the number of crashes, as the largest percentage of truck-involved crashes occurs between 6:00 a.m. and noon. ${ }^{32}$ The rule does not go into full effect until 2013, so it is not yet known whether these rule changes will results in changes to traffic patterns or commercial vehicle safety.

\subsection{Freight Rail Rate Reregulation}

\subsubsection{Overview}

The nation's Class I railroads (Norfolk Southern, CSX, Union Pacific, BNSF, and Kansas City Southern) have enjoyed nearly three decades of substantial productivity growth since the passage of the Staggers Rail Act in 1980, driven by a series of mergers and acquisitions and the abandonment or sale of underperforming lines. Since 2006, however, the STB, the body within the U.S. DOT that is responsible for resolving freight railroad rate and service disputes, is reported in the trade press to have adopted a more shipper-friendly stance, issuing a number of rate decisions in favor of shippers, which probably would have been resolved in favor of the railroads in previous years.

In January of 2011, the STB announced that it may conduct a review of competition in the railroad industry to assess whether rail market power is threatening economic efficiency, and the Obama administration appears to be receptive to increased rail oversight (Boyd 2011). Moreover, recent Congresses, including the current one, have introduced legislation that would further tilt the regulatory balance towards shippers. The immediate prospects for passage of such legislation are fading, but, if additional economic regulation of the rail industry does pass in the future, it would be very unlikely to benefit the railroads. Reregulation of the freight rail industry - even partially - would have important impacts on mode choice decisions, and railroads could lose market share to trucks for certain commodities and trade lanes.

\subsubsection{Agencies/Entities}

The STB was created in the ICC Termination Act of 1995 and is the successor agency to the Interstate Commerce Commission. The STB is an economic regulatory agency that Congress charged with resolving railroad rate and service disputes and reviewing proposed railroad mergers. The STB is an independent decision-making body, although it is administratively affiliated with the U.S. DOT. The STB serves as both an adjudicatory and a regulatory body. It has jurisdiction over railroad rate and service

\footnotetext{
${ }^{31}$ FMCSA data.

${ }^{32}$ American Trucking Associations.
} 
issues and rail restructuring transactions (mergers, line sales, line construction, and line abandonments); certain trucking company, moving van, and noncontiguous ocean shipping company rate matters; certain intercity passenger bus company structure, financial, and operational matters; and rates and services of certain pipelines not regulated by the Federal Energy Regulatory Commission (U.S. DOT STB 2012b, 2012c).

\subsubsection{Cost-Benefit Methods}

The issue of rail rate competition has been a continuous topic of study by the STB as it ponders freight rail reregulation. In January 2010, the latest installment of its analysis was issued-An Update to the Study of Competition in the U.S. Freight Railroad Industry. This study investigated how the deregulation of the railroad industry ushered in increased market flexibility, competitive and differential rates for rail service, and a climate open to innovation. But as financial performance of railroads improved, the railroad industry's stakeholders continued to be concerned over competition, captivity, rates, service performance, and financial viability.

Through detailed analysis of STB waybill data and shipper interviews, the study identified many findings, including several elements related to modal shift:

- For most years in the 1987 to 2006 study period, the Class I railroad industry did not appear to have earned above-normal profits.

- Railroads use differential pricing to recover their total costs.

- Different commodity groups face different markups of railroad rates over marginal costs.

- Within commodity groups, shippers with no or very limited transportation options tend to pay higher rates than shippers with the same shipment characteristics who enjoy more or better transportation alternatives (U.S. DOT STB 2010).

\subsubsection{Scale of Modal Shift Opportunities}

Reregulation freight rail industry rates could result in a shift from rail to truck in two important ways. Reregulation that would raise rates for some rail traffic could make truck more cost competitive for some commodities and some trade lanes. Second, reregulation could dampen railroad profits, making it more difficult for them to maintain their existing networks or make investments to increase capacity. This could drive even more traffic from rail to truck. Conversely, further deregulation of the rail industry could enhance rail competition, potentially lowering rail rates and attracting some traffic from truck to rail.

Despite these issues, however, we estimate that the overall impact of freight rail reregulation would shift less than $10 \%$ of rail tonnage to truck due to fundamental considerations of the type of commodity, trip length, and other considerations discussed in other sections.

\subsubsection{Gaps and Issues}

In 2006, the Government Accountability Office (GAO) recommended that STB analyze the state of competition and consider appropriate actions - this was, in part, the thrust behind the rail competition study noted above. The GAO also recommended additional actions, including the U.S. DOT taking into consideration strategies to level the playing field for all freight modes to maximize public benefits from federal investment. The STB disagreed with this recommendation because it would take resources from efforts it believed would address GAO concerns, among other reasons (U.S. GAO 2006). The rail industry as represented by the AAR is generally against reregulation. 


\subsection{Summary}

The opportunity matrix in Table 6.5 assumes current technology and regulatory framework and shows potential federal policy actions along two dimensions: the probability of their implementation; and the likely payoff measured in terms of the size of the potential modal share shift from truck to rail. The allocation of the actions is based on best professional judgment.

Table 6.5. Opportunity Matrix for Freight Transportation Modal Share Shifts

\begin{tabular}{|c|c|c|c|}
\hline & & Potential Mod & rom Truck to Rail \\
\hline & & Low & Moderate \\
\hline \multirow{2}{*}{ 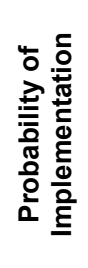 } & 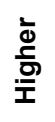 & $\begin{array}{c}\text { Truck Size and Weight Regulation } \\
\text { Truck Hours-of-Service Regulation } \\
\text { Freight Re-Regulation }\end{array}$ & Direct User Fees \\
\hline & ఏ్̀ & $\begin{array}{c}\text { Fuel Tax } \\
\text { GHG Regulation/Pricing }\end{array}$ & $\begin{array}{l}\text { Freight Rail and Waterway Infrastructure } \\
\text { Improvements and Expansion }\end{array}$ \\
\hline
\end{tabular}




\section{Conclusions}

Today's allocation of freight by mode has developed under the historical influences of technology improvement, economic circumstances, and regulatory frameworks. Future modal allocations may shift due to changes in underlying drivers of mode choice, such as time-sensitivity of shipments, logistical constraints, and type of commodity flows. The energy efficiency of freight transportation could be improved substantially, especially in urban areas, but shifting longer-haul freight from one mode to another presents relatively modest opportunities to reduce energy use because mode choice is not very responsive to energy prices. For policies to have a large impact on national petroleum consumption and GHG emissions, they would likely need to be more dramatic than the suggestions reviewed here.

\section{Mode Choice Influenced By Characteristics of Mode, Commodity, and Logistics}

Transportation of freight includes diverse shipments with distinct service needs, and modes vary in terms of speed, reliability, and cost. Freight transportation markets match service needs to modes, resulting in transportation choices based on value, density, time-sensitivity, and other attributes of the freight.

Truck, rail, water, air freight, and pipeline services each offer different characteristics, such as price, speed, reliability, accessibility, visibility, security, and safety. These differences mean that, while modes do compete, they are also complementary, since each mode targets the commodities and markets that it serves most effectively. Higher-value, lower-weight, and more time-sensitive freight generally uses truck and air modes, while lower-value, heavier-weight, and less time-sensitive freight uses rail and water freight transportation services.

\section{Opportunities for Modal Shifts Face Constraints}

The comparison of modal shares and ton-miles in Figure ES.2 uses ton-miles as a broad proxy for the amount of energy consumed in freight transportation. This distribution of substantial ton-miles in the 250to 1,500-mile distance bands suggests opportunities to reduce energy use by improving the energy efficiency of truck, rail, and water freight operations, as well as by shifting more tons and ton-miles from truck to rail in 250- to 750-mile range.

Service differentiation limits opportunities for shifting freight from one mode to another, because the different modes are not perfect substitutes for one another. Truck-to-rail modal shifts have the greatest overall potential for energy reduction, because trucks are the dominant mode in terms of freight tonnage and freight commodity value, while rail serves many of the same routes and uses substantially less energy.

\section{Methods for Projecting Freight Modal Shares Continue to Improve}

Methods for projecting freight modal shares include market segmentation, modal elasticity, and modechoice modeling. Mode-choice modeling tends to be applied locally and regionally, while the other types of tools apply nationally, as well. While market segmentation methods are most easily implemented at a national scale, mode-choice models can represent specific behaviors of market players that are of analytic interest, including representation of destinations and routes. Modal elasticity models can use goods movement data and address infrastructure and policy change.

All of these methods rely on data on commodity flows, networks of transportation corridors, and characteristics of the different transportation modes. Data issues, including the magnitude of data requirements, limitations in the quality and availability of data, and the cost of obtaining necessary data, are among the limitations of these methods. 


\section{Policy Influences Modal Choice Through Price and Regulation}

While policy measures can influence freight mode choice at the margin, major mode shifts are unlikely without substantial changes in costs or strong regulatory measures. Transportation economics literature, historical case studies, and industry market assessments demonstrate that federal policy is capable of influencing mode choice, but these government actions are likely to result in relatively small shifts of tons and ton-miles from truck to rail.

The types of policy measures that affect freight mode choice include pricing of fuel, roadway access, or emissions; regulations on trucking (trucker service hours, truck size and weight) or railroads; and infrastructure and service improvement investments. Our assessments of potential federal actions and anticipated modal shifts are as follows:

Increasing Motor Fuel Taxes or Adding GHG Pricing Because trucking is less fuel efficient per tonmile than rail, an increase in diesel fuel taxes could increase the cost of trucking relative to rail and make it more economically attractive to shippers to shift traffic from truck to rail. Carbon taxes and regulations restricting GHG emissions could also increase the cost of trucking and air freight operations relative to rail and water. However, in the authors' opinion, diesel prices would have to nearly double to increase rail tonnage by the equivalent of about $1 \%$ in the current total freight rail tonnage.

Charging User Fees. User fees (e.g., charging tolls for roadway access) would increase the cost of trucking and encourage shippers to explore other modes. Several studies have examined the potential for modal diversion associated with tolls on truck-only highways. Truck-to-rail mode shifting potential associated with such charges is low, because only a small fraction of truck trips would be long enough with high enough tolls to encourage diversion would shift trucks to non-tolled roads.

Reducing Truck Driver Hours of Service. The federal government has reduced the number of consecutive hours that a truck driver can drive and work in a week to minimize the number of fatalities and injuries caused by badly fatigued drivers. Current federal regulations limit drivers to 11 hours of driving a day and a 70-hour work week (including driving and rest time). Hours of service could be reduced further, which would force carriers to hire more drivers or cut back service, both of which would likely increase trucking costs, especially for long distances. Without a strong safety justification, reducing hours of service further will be difficult politically, and the effect on truck-to-rail diversion is judged to be similar to a motor fuel tax increase.

Changing Truck Size and Weight Limits. Current federal regulations limit the gross weight of freight vehicles (truck and payload) to 80,000 lbs on Interstate highways. Prior studies and carrier experience have shown that increasing allowable truck sizes and weights on Interstates and major state roads would divert freight from rail to truck. National studies estimate that as much as $10 \%-15 \%$ of shortline railroad traffic could be diverted, but shortline traffic represents only $12.5 \%$ of total rail ton-miles. We estimate that allowing a nationwide increase truck size and weight, permitting 100,000-pound trucks on all Interstate routes might result in 5\% of tonnage shift in rail to truck shipments. Decreasing truck size and weight would have the reverse effect. There are no readily available estimates of the effects of a decrease on modal share.

Re-regulating Freight Rail Rates and Services. From about 1880 to 1980, the federal government regulated almost all interstate freight rail rates. Captive shippers (shippers served by a single railroad) have called for reintroduction of interstate freight rate regulation, especially for chemicals, coal, and agricultural products. Regulation would reduce prices for some shippers, but also reduce railroad profitability and access to capital for rail-line refurbishment and expansion.

Investing in Freight Rail Corridor and Service Improvements. The major (Class I) railroads as a group spend about $\$ 10$ billion- $\$ 12$ billion per year to replenish, replace, and expand rail lines, bridges, and equipment. National rail infrastructure capacity and investment studies have estimated that an additional \$2 billion-\$4 billion capital investment is needed annually to retain market share. Public sector 
investment in the rail industry today is small, with much of it focused on upgrading short line railroad track serving local industry. A radical increase in public investment in rail could reduce prices and improve service, allowing rail to capture more freight from trucking. For example, a study of a \$12billion investment program for a Norfolk Southern rail corridor parallel to I-81 in Virginia determined that the program had the potential to divert $17 \%$ of truck trips longer than 500 miles and $6 \%$ of all truck trips along the corridor to rail. We estimate that a major program to expand capacity and improve service to levels to make freight rail more competitive with trucking could increase rail tonnage by $10-20 \%$. The cost of re-establishing rail lines, and subsidizing service to capture a large portion of freight trips shorter than 500 miles would be quite high. No national estimates of the total cost are available.

Table 7.1 shows the potential of federal policy actions along two dimensions: the probability of their implementation, and the likely payoff measured in terms of the size of the potential modal share shift from truck to rail.

Table 7.1. Opportunity Matrix for Freight Transportation Modal Share Shifts

\begin{tabular}{|c|c|c|c|}
\hline & & Potential Mod & rom Truck to Rail \\
\hline & & Low & Moderate \\
\hline \multirow{2}{*}{ 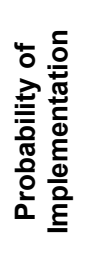 } & 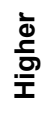 & $\begin{array}{c}\text { Truck Size and Weight Regulation } \\
\text { Truck Hours-of-Service Regulation } \\
\text { Freight Re-Regulation }\end{array}$ & Direct User Fees \\
\hline & ఏँ̀ & $\begin{array}{c}\text { Fuel Tax } \\
\text { GHG Regulation/Pricing }\end{array}$ & $\begin{array}{l}\text { Freight Rail and Waterway Infrastructure } \\
\text { Improvements and Expansion }\end{array}$ \\
\hline
\end{tabular}

(Source: Cambridge Systematics, Inc.)

Of the seven policy potential policy actions, user fees and infrastructure investment demonstrate the greatest promise for delivering significant freight transportation mode shifts.

\section{A Baseline for Additional Research}

This report provides a baseline for future research on the potential of freight transportation mode shifts to reduce energy use and emissions. Additional research would be needed to improve estimates of modal share projections, as summarized in Table 7.2.

Table 7.2. Summary of Areas Recommended for Additional Research

\begin{tabular}{|c|c|c|c|}
\hline Research Gap & Current State of Practice & $\begin{array}{c}\text { Additional Work } \\
\text { Needed }\end{array}$ & Potential Benefits \\
\hline $\begin{array}{l}\text { Identifying Crossover } \\
\text { Goods for Market } \\
\text { Segmentation }\end{array}$ & $\begin{array}{l}\text { Some research, but no } \\
\text { national, large-scale } \\
\text { analysis }\end{array}$ & $\begin{array}{l}\text { Additional market- } \\
\text { segmentation research; } \\
\text { analysis of mode choice } \\
\text { factors at the commodity } \\
\text { level }\end{array}$ & $\begin{array}{l}\text { A crucial component for improving } \\
\text { large-scale, national models for } \\
\text { modal share and shift }\end{array}$ \\
\hline $\begin{array}{l}\text { Constructing Freight } \\
\text { Demand Elasticities }\end{array}$ & $\begin{array}{l}\text { Poorly developed; not } \\
\text { available for factors other } \\
\text { than price }\end{array}$ & $\begin{array}{l}\text { Analysis of elasticities } \\
\text { and sensitivities for price, } \\
\text { travel time, and reliability }\end{array}$ & $\begin{array}{l}\text { Increased understanding of modal } \\
\text { shift potential and guidance for } \\
\text { developing effective policy }\end{array}$ \\
\hline $\begin{array}{l}\text { Developing Effective } \\
\text { Freight Mode Choice } \\
\text { Models }\end{array}$ & $\begin{array}{l}\text { Some implementation, but } \\
\text { mostly among truck } \\
\text { services and between truck } \\
\text { and rail }\end{array}$ & $\begin{array}{l}\text { Provide resources and } \\
\text { support to planning } \\
\text { agencies }\end{array}$ & $\begin{array}{l}\text { Increased understanding of modal } \\
\text { shares and broader impacts of } \\
\text { freight on the transportation sector }\end{array}$ \\
\hline
\end{tabular}




\begin{tabular}{llll}
\hline Research Gap & Current State of Practice & \multicolumn{1}{c}{$\begin{array}{c}\text { Additional Work } \\
\text { Needed }\end{array}$} & \multicolumn{1}{c}{ Potential Benefits } \\
\hline $\begin{array}{l}\text { Analyzing Interaction } \\
\text { between Mode Choice and } \\
\text { the Supply Chain }\end{array}$ & $\begin{array}{l}\text { Some work in Europe and } \\
\text { Japan }\end{array}$ & $\begin{array}{l}\text { Analysis of supply chain } \\
\text { factors; synthesis } \\
\text { between supply chain and } \\
\text { mode choice analysis }\end{array}$ & $\begin{array}{l}\text { Greater insight into business models } \\
\text { and decisions as related to supply } \\
\text { chain transportation; insight for } \\
\text { policy development }\end{array}$ \\
$\begin{array}{llll}\text { Developing Performance } \\
\text { Measures }\end{array}$ & $\begin{array}{l}\text { Many proposed measures, } \\
\text { but none implemented }\end{array}$ & $\begin{array}{l}\text { Define crucial measures } \\
\text { and identify opportunities } \\
\text { for implementation }\end{array}$ & $\begin{array}{l}\text { Assessment of transportation } \\
\text { system, which can be used to target } \\
\text { funding towards projects with } \\
\text { greatest potential and/or to identify } \\
\text { best-performing systems }\end{array}$ \\
\hline
\end{tabular}

(Source: Cambridge Systematics, Inc.)

Although more work is needed in this area, our research begins to characterize opportunities to improve the energy efficiency of freight transportation by shifting from one mode to another, especially opportunities for truck-to-rail shifts. Federal policy could support these shifts by providing financial and regulatory motivation for these changes, while recognizing the diversity of service needs in freight transportation. Although direct energy savings and emissions reductions from mode shifts may be small compared to other opportunities, they could be a component of a comprehensive strategy. 


\section{Appendix A: AdDitional Analysis}

This section provides brief descriptions of additional research that could produce better estimates of modal share projections to support U.S. Department of Energy policy and program analysis.

\section{A.1 Identifying Markets of Crossover Goods for Market Segmentation}

The development and use of low-cost analytical methods (i.e., market segmentation) appear to be the most direct way to approach the issues of national modal share and diversion. Ideally these methods are used to create baseline freight flows, upon which more advanced modeling and estimation techniques can be applied. Since market segmentation and similar methodologies rely on identification of crossover goods, or those goods with potential for modal shift, it is important to properly identify the set of qualities which define these goods. An unrealistic assumption is that there is uniform or total potential for shifting all goods from between any two modes. However, currently no consensus on the makeup or crossover potential of these groups exist, and so it is often up to the researcher to determine the best potential candidates. $^{33}$

Within the literature and practice there is significant observed, experience-driven, and other types of information about the commodities and markets that are the best candidates for modal shift. Oftentimes it is unclear whether and to what degree these candidates are applicable in other contexts. By combining research into factors influencing mode choice with existing market-segmentation research, it may be possible to create a set of guidelines or characteristics that will provide insight into which commodities have high modal-shift potential for a given context, leading to potential accuracy increases in estimations and forecasts of modal shifts.

\section{A.2 Constructing Freight Demand Elasticities}

Elasticities describe the sensitivity of a mode to changes in factors, such as price. Because they are dependent on a wide range of characteristics, elasticities can vary significantly by commodity, market, and region. Determining elasticities for freight is complex, as there are a number of players (shippers, carriers, receivers), and factors (shipment size, cost, reliability, etc.) that interplay to determine the relationship between modes.

Although several studies have been conducted on the elasticities of freight modes (Clark et al. 2005; U.S. DOT FRA 2005; NCHRP 1995; TRB 1997), there is significant room for continued research into this area. Elasticities between transportation modes are poorly developed for mode choice and not generally available for factors other than modal price or cost. A more complete understanding of elasticities and relationships between modes would provide insight into the potential for modal shift and define possible modal shift outcomes of policies or investments.

\section{A.3 Developing Effective Freight Mode Choice Models}

Currently, the ability to develop a national mode choice freight model remains limited due to cost constraints, complexity of national systems, and lack of available data on preferences at the national level. Although a staple of transportation planning in the passenger sector, mode choice models in the freight sector are much less advanced and less widely used. Although some local and regional freight mode choice models have been developed, the base of existing models is not large enough to readily borrow from among their factors in development of a national model.

As discussed earlier, many freight mode-choice models today are largely based on existing mode shares. Others use techniques, such as pivot points, which act as a hybrid between mode choice models and those

\footnotetext{
${ }^{33}$ See Chapter 3 of Analysis of Freight Movement Mode Choice Factors (Florida DOT 2008) for an example of identifying groups that are candidates for mode shift.
} 
based on methods such as market segmentation. These and other models in use today are often inadequate to capture the full range of complexities of the freight decision-making process. More ambitious models, such as the freight "mesoscale" model, which attempts to model the individual behavior of shippers, remain in the early stages of development. However, the development process for these models has made clear that any national level freight mode choice model will require significant investment and resources (Mohammadian, Kawamura, and Auld 2011).

\section{A.4 Analyzing Interaction between Mode Choice and the Supply Chain}

The interaction between mode choice and the supply chain is a complex area that deserves increased attention, because supply chain effects are an integral part of business shipping decisions. For example, current trends are to locate manufacturing and distribution processes away from urban areas, which can increase the potential for intermodal connectivity within the supply chain while simultaneously increasing road VMT to deliver final products to consumers. Additionally, many businesses use a multistep manufacturing and distribution process, which must be designed around the abilities and constraints of the transportation system. Each step in the supply chain may have a different set of decision makers, which complicates the story for those seeking to understand how policy decisions affect future demand.

Aligning forecasts for the different stages of the manufacturing process is complex, and often overlooked as part of the modeling process. For example, forecasting the demand for household furniture is necessary to accurately forecast the demand for unfinished wood products. The nature of the complex relationships between different aspects of the supply chain leads to the difficulty in constructing a one-size fits all freight model.

To date, freight models have focused on estimating separately the demands for, and commodity flow patterns associated with, the products in each link in such supply chains, such as in Figure A.1. Hence, one model might estimate the demand for lumber, one for wood products, and a third estimates the demand for furniture, or a commodity class, such as wood product-based manufactured goods.

Some work has been done to model the interactions between the supply chain and freight demand and mode choice. The SMILE model developed in the Netherlands (Tavasszy, Vlist, and Ruijgrok 1999) incorporates the physical aspects of supply chain logistics through the freight distribution stage of a multistep freight planning model at the national level. Supply chain modeling of urban freight also has become more popular of late with researchers in Japan (Wisetjindawat, Sano, and Matsumoto 2006), where microsimulation is combined with logistic demand, inventory theoretic, and optimal vehicle routing algorithms to develop day-to-day simulations of the agents involved in Tokyo's food freight supply chain (Donnelly et al. 2007).

In the United States, integrating supply chain analysis with freight movements and mode choice is still in the formative stages. As companies continue drawing on national and global supply chains, it will become increasingly important to capture the effects of changes on one stage of the supply chain on freight moved in other stages, and to include these effects in models to understand how policy changes will affect the shipment of goods. 


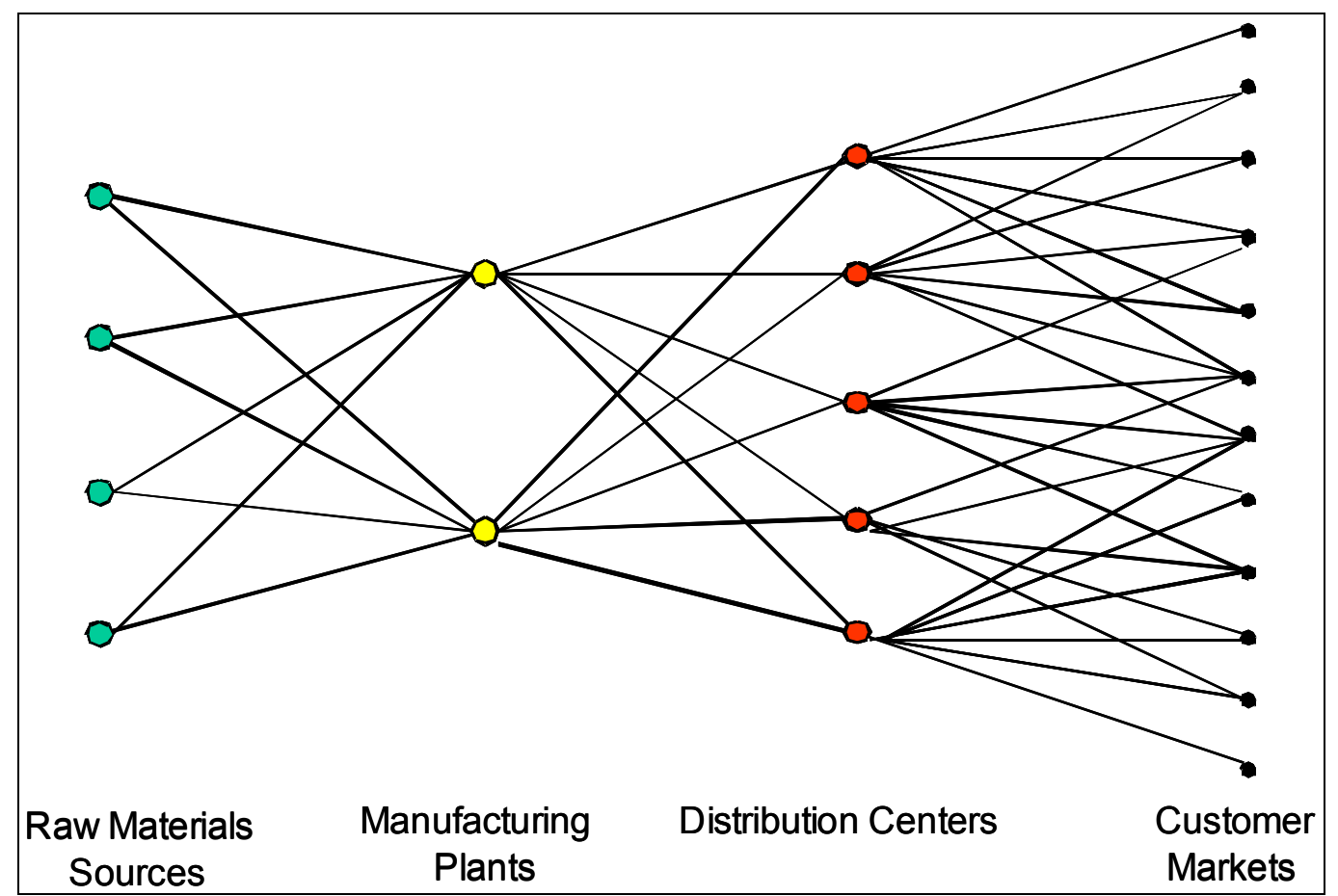

Figure A.1. A conceptual supply chain linking sources to markets

(Source: Donnelly et al. 2007)

\section{A.5 Developing Performance Measures}

There has been an accelerating effort to evaluate and track the performance of the U.S. freight transportation system. Several reports have addressed this issue, including NCFRP Report 10, Performance Measures for Freight Transportation, which recommended creation of a Freight System Report Card to track performance of the system using existing data sources. The report also commented on the overall lack of performance measures for evaluating the system performance, stating that data for infrastructure condition are more available than that for system performance. Data on the condition of bridges and pavements, maritime infrastructure, and rail infrastructure is often available. However, overall performance measured by travel time, or reliability, is not being produced.

Data on the relative speed of individual modes are sometimes available. However, the overall speed and travel reliability of supply chains that rely upon handoffs between modes is not available in the public domain. Firms such as UPS and FedEx, major truck carriers, and the Class I railroads generally use GPS to track packages and freight. These data are available to their customers only for individual shipments, yet are not aggregated for publication (TRB 2011a).

Performance measures also can be used to evaluate the potential for modal shift, identify investment or policy opportunities, track modal shifts, and increase overall the ability to understand and model modal shifts. Table A.1 is a nonexhaustive summary of performance measures identified as being relevant to modal diversion and related policy needs, such as rail planning and project prioritization. 
Table A.1. Performance Measures Corresponding to Modal Diversion and Related Policy Needs

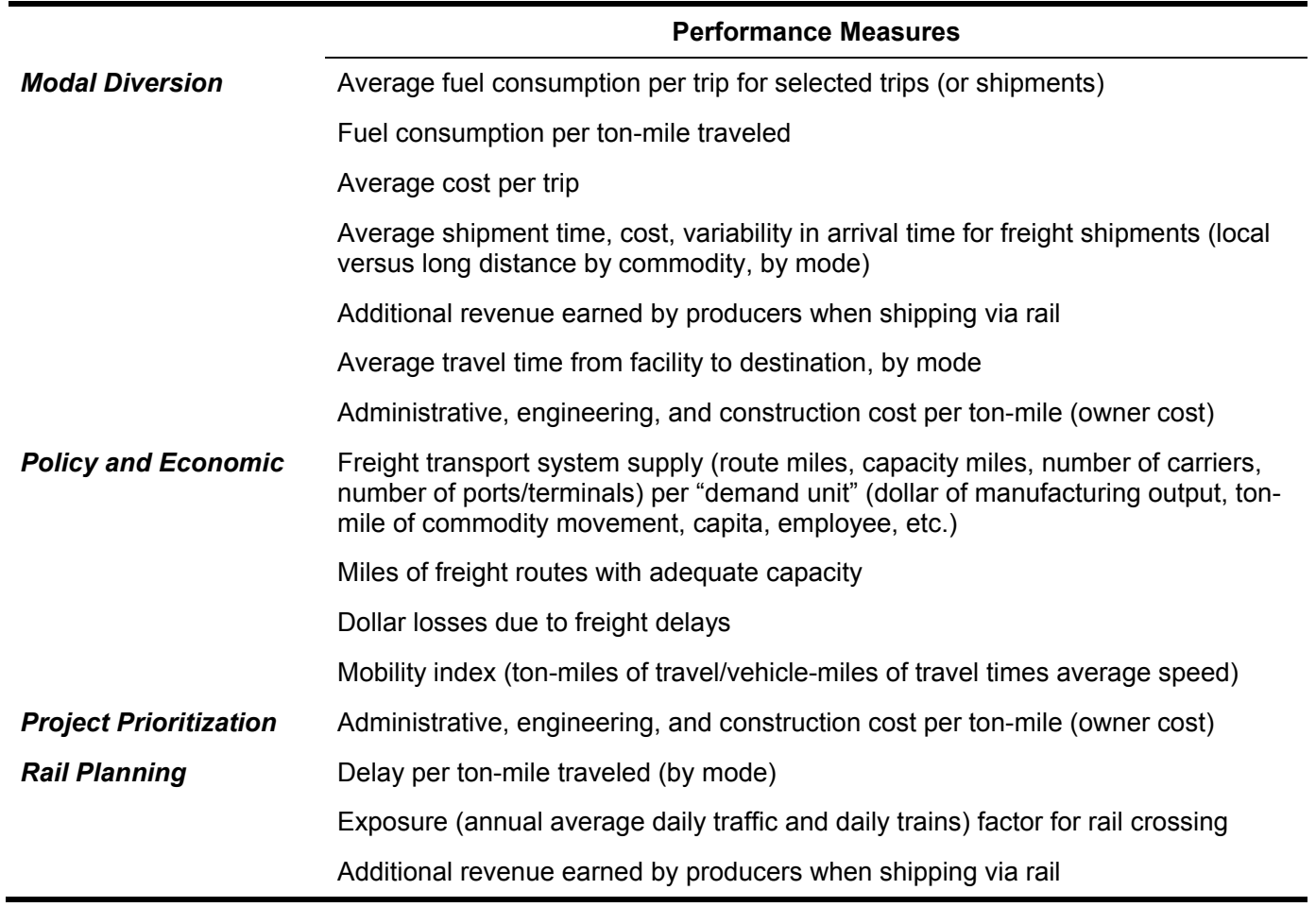

(Source: NCFRP Report 8, Table 4.2) 


\section{REFERENCES}

3M. 2012. Sustainability at 3M. Cited Oct. 4, 2012. http://solutions.3m.com/wps/portal/3M/en_US/3MSustainability/Global/?WT.mc id=www.3m.com/sustainability

Abdelwahab, Walid M. 1998. "Elasticities of mode choice probabilities and market elasticities of demand: Evidence from a simultaneous mode choice/shipment-size freight transport model." Transportation Research Part E: Logistics and Transportation Review no. 34 (4):257-266. http://dx.doi.org/10.1016/S1366-5545(98)00014-3

American Association of State Highway and Transportation Officials (AASHTO). 2003. Transportation: Investment in America: Freight-Rail Bottom Line Report. Prepared by Cambridge Systematics, Inc. for the American Association of State Highway and Transportation Officials. Washington, DC: American Association of State Highway and Transportation Officials, $140 \mathrm{pp}$. http://www.camsys.com/pubs/FreightRailReport.pdf

American Council for an Energy-Efficient Economy (ACEEE). Freight. American Council for an Energy-Efficient Economy Cited April 17, 2012. http://www.aceee.org/topics/freight.

American Transportation Research Institute. 2008. Energy and Emissions Impacts of Operating Higher Productivity Vehicles, Update: 2008. Alexandria, VA, September. http://www.atri-online.org/research/results/environmentalfactors/2008 atri hpv 1 pager.pdf

American Transportation Research Institute. 2011. An Analysis of the Operational Costs of Trucking: 2011 Update. Arlington, VA: American Transportation Research Institute, 2 pp. http://atrionline.org/research/results/Op_Costs_2011_Update_one_page_summary.pdf

Association of American Railroads (AAR). 2007. National Rail Freight Infrastructure Capacity and Investment Study. Washington, DC: Association of American Railroads, 69 pp. http://www.camsys.com/pubs/AAR_Nat \%20Rail_Cap_Study.pdf

_. 2009. "AAR Issues 2009 Edition of Railroad Facts." Railroad Facts. http://www.aar.org/NewsAndEvents/Press-Releases/2009/12/Rail\%20Fact\%20Book.aspx

. 2012a. Economy. Cited October 5, 2012. http://www.aar.org/Economy.aspx

. 2012b. Freight Railroads Help Reduce Greenhouse Gas Emissions. Washington, DC: Association of American Railroads. 3 pp. http://www.aar.org/ /media/aar/Background-Papers/Freight-RR-Help-Reduce-Emissions.ashx

. 2012c. Rail Cost Indexes. Cited October 5, 2012.

http://www.aar.org/StatisticsAndPublications/Rail-Cost-Indexes.aspx .

Beningo, Steven, Matthew Chambers, Chester Ford, Kenneth Notis. 2011. National Transportation Statistics: 2011. U.S. Department of Transportation, Research and Innovative Technology

Administration, 513 pp. http://www.bts.gov/publications/national transportation_statistics/pdf/entire.pdf

Beuthe, Michel, Bart Jourquin, Jean-François Geerts, Christian Koul à Ndjang' Ha. 2001. "Freight transportation demand elasticities: a geographic multimodal transportation network analysis." Transportation Research Part E: Logistics and Transportation Review no. 37 (4):253-266. http://dx.doi.org/10.1016/S1366-5545(00)00022-3

Boyd, John D. 2011. “STB's Nudge to Regulate.” The Journal of Commerce Magazine.

Broaddus, Andrea, Carsten Gertz. 2008. "Tolling Heavy Goods Vehicles: Overview of European Practice and Lessons from German Experience." Transportation Research Record: Journal of the Transportation Research Board no. 2066:106-113. http://dx.doi.org/10.3141/2066-12 
California Air Resources Board. 2011a. Drayage Truck Regulation. Sacramento, CA: California Air Resources Board, 19 pp. http://www.arb.ca.gov/msprog/onroad/porttruck/finalregdrayage.pdf

2011b. Status of Scoping Plan Recommended Measures. Sacramento, CA: California Air Resources Board, 8 pp. http://www.arb.ca.gov/cc/scopingplan/status_of scoping plan measures.pdf 2012a. Cap-and-Trade Program. California Environmental Protection Agency Air Resources Board. Cited October 9, 2012. http://www.arb.ca.gov/cc/capandtrade/capandtrade.htm .

2012b. Mandatory Greenhouse Gas Emissions Reporting. California Environmental Protection Agency Air Resources Board, Aug. 31, 2012. Cited October 9, 2012.

http://www.arb.ca.gov/cc/reporting/ghg-rep/ghg-rep.htm

Cambridge Systematics, Inc. 2006. Washington State Statewide Rail Capacity and System Needs Study. Prepared for the Washington State Transportation Commission, Olympia, WA. http://www.wstc.wa.gov/Rail/default.htm

Cambridge Systematics, Inc. 2011. Georgia Freight Modal Profile Draft Executive Summary. Prepared for the Georgia Department of Transportation.

http://www.dot.state.ga.us/informationcenter/programs/georgiafreight/logisticsplan/Pages/Documentation.aspx

Center for Economic Development Education and Research. 2005. Columbia Snake River System and Oregon Coastal Cargo Ports Marine Transportation System Study; Appendix C: Short Sea Shipping in the Columbia/Snake River System. Portland, OR: The Center for Economic Development Education and Research, $11 \mathrm{pp}$.

http://www.pnwa.net/ceder/Appendix\%20C\%20CEDER\%20Short\%20Sea\%20Shipping.pdf

Clark, Chris, Helen Tammela Naughton, Bruce Proulx, Paul Thoma. 2005. A Survey of the Freight Transportation Demand Literature and a Comparison of Elasticity Estimates. IWR Report 05-NETS-R01. Alexandria, VA: U.S. Army Corps of Engineers, Institute for Water Resources, $56 \mathrm{pp}$.

http://www.iwr.usace.army.mil/docs/iwrreports/05-NETS-R-01.pdf

Cohen, Harry, Alan Horowitz, Ram Pendyala. 2008. Forecasting Statewide Freight Toolkit. NCHRP Report 606. Washington, DC: Transportation Research Board, 169 pp.

http://onlinepubs.trb.org/onlinepubs/nchrp/nchrp rpt 606.pdf

Davis, Stacy C., R. Boundy, S. Diegel. 2012. “2011 Vehicle Technologies Market Report,” ORNL/TM2012/016, Oak Ridge, TN. http://cta.ornl.gov/cta/publications.shtml

Davis, Stacy C., S.W. Diegel and R.G. Boundy. 2008. Transportation Energy Data Book: Edition 27, ORNL-6981. http://cta.ornl.gov/cta/publications.shtml

Davis, Stacy C., Susan W. Diegel, Robert G. Boundy. 2008. Transportation Energy Data Book: Edition 28. ORNL-6984 (Edition 28 of ORNL-5198). Oak Ridge, TN: Oak Ridge National Laboratory, 379 pp. http://info.ornl.gov/sites/publications/files/Pub20096.pdf

- 2012. Transportation Energy Data Book: Edition 31 (Chapter 2). ORNL-6987 (Edition 31 of ORNL-5198). Oak Ridge, TN: Oak Ridge National Laboratory., 19 pp.

http://cta.ornl.gov/data/chapter2.shtml (chapter 2) and http://cta.ornl.gov/data/tedb31/Edition31_Full_Doc.pdf (full report)

Dennis, Scott M. 1988. The Intermodal Competition Model. Washington, DC: Association of American Railroads.

Donnelly, R., S. Lahsene, R. Walker, and M. Turnquist. 2007. The Policy Context for Freight Modeling. Transportation Research Board Transportation Research Circular: Innovations in Freight Transportation Modeling.Transportation Research Board: National Research Council, Washington, D.C., August. 
Energy Information Administration. 2010. Annual Energy Outlook 2010 with Projections to 2035. Washington, DC: U.S. Energy Information Administration, 221 pp.

http://www.eia.gov/oiaf/archive/aeo10/pdf/0383(2010).pdf

2011. What We Pay for in a Gallon of Regular Gasoline. U.S. Energy Information Administration (DOE) 20112011. http://www.eia.gov/todayinenergy/detail.cfm?id=470

EPA. Undated. SmartWay. U.S. Environmental Protection Agency. Cited April 17, 2012. http:/www.epa.gov/smartway/

-2009. EPA Analysis of the American Clean Energy and Security Act of 2009 H.R. 2454 in the 111th Congress. Washington, DC: U.S. Environmental Protection Agency.

- 2011a. EPA and NHTSA Adopt First-Ever Program to Reduce Greenhouse Gas Emissions and Improve Fuel Efficiency of Medium-and Heavy-Duty Vehicles. EPA-420-F-11-031. Washington, DC: U.S. Environmental Protection Agency, 8 pp. http://www.epa.gov/oms/climate/documents/420f11031.pdf

- 2011b. Inventory of U.S. Greenhouse Gas Emissions and Sinks: 1990 - 2009. EPA 430-R-11005. Washington, DC: U.S. Environmental Protection Agency, 459 pp.

. 2012a. National Clean Diesel Campaign (NCDC). U.S. Environmental Protection Agency, September 28, 2012. Cited October 5, 2012. http://www.epa.gov/cleandiesel/

. 2012b. Renewable Fuel Standard (RFS). U.S. Environmental Protection Agency, September 13, 2012. Cited October 5, 2012. http://www.epa.gov/otaq/fuels/renewablefuels/index.htm

EPA GGRP. 2012. Greenhouse Gas Reporting Program. U.S. Environmental Protection Agency, October 4. Cited October 5, 2012. http://www.epa.gov/ghgreporting/ghgdata/index.html

EPA OSWER. 2012. Office of Solid Waste and Emergency Response (OSWER). U.S. Environmental Protection Agency, October 4. Cited October 5, 2012. http://www.epa.gov/aboutepa/oswer.html

EPA and National Highway Traffic Safety Administration (NHTSA). 2011. Greenhouse Gas Emissions Standards and Fuel Efficiency Standards for Medium- and Heavy-Duty Engines and Vehicles; Final Rule. Federal Register Vol. 76 No. 179, pp. 57106-57513.

Esty, Daniel C., Andrew S. Winston. 2006. Green to Gold: How Smart Companies Use Environmental Strategy to Innovate, Create Value, and Build Competitive Advantage. New Haven, CT: Yale University Press.

European Commission. 2011. Roadmap to a Single European Transport Area-Towards a competitive and resource efficient transport system. COM(2011) 144 final. Brussels, Belgium, $31 \mathrm{pp}$. http://eurlex.europa.eu/LexUriServ/LexUriServ.do?uri=COM:2011:0144:FIN:EN:PDF

. 2012a. About the Marco Polo Programme. European Commission, March 30, 2012. Cited October 5, 2012. http://ec.europa.eu/transport/marcopolo/about/index en.htm

- 2012b. Marco Polo - New ways to a green horizon. European Commission, March 30, 2012.

Cited October 5, 2012. http://ec.europa.eu/transport/marcopolo/index_en.htm

European Parliament. 1999. Taxation of heavy goods vehicles: Eurovignette Directive. Directive 1999/62/EC, European Parliament and the Council.

Federal Highway Administration. 2009. Development of Truck Payload Equivalent Factor (TPEF): Table 1. Average Payload (lbs) by Gross Vehicle Weight Group VIUS-by State. U.S. Department of Transportation, Federal Highway Administration, July 1. Cited October 5, 2012. http://ops.fhwa.dot.gov/freight/freight_analysis/faf/faf2_reports/reports9/s501_2_ 3 tables.htm\#_Toc1693 $\underline{99555}$ 
1990. Modal Diversion Effects of Changes in Truck Size and Weight Limits. Washington, DC:

U.S. Department of Transportation, Federal Highway Administration.

2000. Comprehensive Truck Size and Weight Study. FHWA-PL-00-029. Washington, DC: U.S. Department of Transportation, Federal Highway Administration.

http://www.fhwa.dot.gov/policy/otps/truck/finalreport.htm

. 2003. Highway Statistics 2003. U.S. Department of Transportation Federal Highway

Administration, April 5. Cited October 10, 2012. http://www.fhwa.dot.gov/policy/ohim/hs03/

- 2009. "Policies to Reduce Greenhouse Gas Emissions Associated with Freight Movements."

Innovations for Tomorrow's Transportation (1 May 2009).

. 2010. Cross Harbor Freight Program: Environmental Impact Statement (EIS) Methodology.

New York, NY; Washington, DC: The Port Authority of NY \& NJ, U.S. Department of Transportation, Federal Highway Administration, $61 \mathrm{pp}$.

https://www.panynj.gov/about/pdf/EIS-Methodology-Draft-Appendices.pdf

. 2012. Congestion Mitigation and Air Quality Improvement (CMAQ) Program. U.S. Department of Transportation Federal Highway Administration, September 212011 Cited October 92012. http://www.fhwa.dot.gov/environment/air quality/cmaq/.

. 2012. Freight Analysis Framework (FAF Data and Documentation). U.S. Department of

Transportation, Federal Highway Administration, February 27, 2012. Cited April 18, 2012.

http://www.ops.fhwa.dot.gov/freight/freight analysis/faf/

Federal Register. 2011. LCV Freeze; Cargo-Carrying Unit Freeze. Washington, DC: U.S. Government Printing Office.

Florida Department of Transportation. 2008. Analysis of Freight Movement Mode Choice Factors.

Prepared by Center for Urban Transporation Research. Tallahassee, FL: Florida Department of

Transportation, Rail Planning and Safety, $79 \mathrm{pp}$.

http://www.dot.state.fl.us/rail/Publications/Studies/Planning/ModeChoiceFactors.pdf

Friedlaender, Ann F., Richard H. Spady. 1980. "A Derived Demand Function for Freight Transportation." The Review of Economics and Statistics no. 62 (3):432-441. http://www.jstor.org/stable/1927111

Fries, Nikolaus, Zachary Patterson. 2008. "Carrier or Mode? The Dilemma of Shippers' Choice in Freight Modelling." Paper read at 8th Swiss Transport Research Conference, at Ascona, Switzerland. http://www.strc.ch/conferences/2008/2008_Fries_Patterson_CarrierOrMode.pdf

Goodwin, P.B. 1992. "A Review of New Demand Elasticities with Special Reference to Short and Long Run Effects of Price Changes.” Journal of Transport Economics and Policy no. 26 (2):155-169.

http://www.jstor.org/stable/20052977

Gordon, Benjamin. 2009. "The Short Tail: Near-Sourcing Trends Create New Winners and Losers in the Supply Chain.” Supply Chain Management Review.

Grenzeback, L. R., A. Brown, M. J. Fischer, N. Hutson, Y. L. Pei, L. Vimmerstedt, A. D. Vyas, J. J. Winebrake. 2013. Freight Transportation Demand: Energy-Efficient Scenarios for a Low-Carbon Future. Transportation Energy Futures Series. DOE/GO-102013-3711. Washington, DC: U.S. Department of Energy, $82 \mathrm{pp}$.

Holguin-Veras, J. 2009. “An Experimental Economics Investigation of Shipper-Carrier Interactions on the Choice of Mode and Shipment Size in Freight Transport." Networks and Spatial Economics, 11(3), p. 509-532.

HP. 2012. HP's Environmental Goals and Policies. Hewlett-Packard Development Company, L.P. http://www.hp.com/canada/corporate/hp_info/environment/commitment/goals.html . 
I-70 Coalition. 2011. I-70 Dedicated Truck Lanes Feasibility Study. Columbus, OH. http://www.i70dtl.org/images/I-70_Phase 22 Final Report_FINAL_2011-11-02.pdf

I-95 Corridor Coalition. 2005. Short-Sea and Coastal Shipping Options Study: Final Report. Rockville, MD, 133 pp. http://www.i95coalition.org/i95/Portals/0/Public Files/pm/reports/full343.pdf

2009. Mid-Atlantic Rail Operations Phase II Study: Final Report. Rockville, MD: I-95 Corridor Coalition, $118 \mathrm{pp}$.

http://www.i95coalition.org/i95/Portals/0/Public_Files/pm/reports/MAROps\%20Phase $\% 20 I I \% 20$ Final\%2 OReport.pdf

International Air Transport Association (IATA). Undated. International Air Transport Association. Cited April 17, 2012. http://www.iata.org/Pages/default.aspx .

Jiang, Fei, Paul Johnson, Christian Calzada. 1999. "Freight Demand Characteristics and Mode Choice: An Analysis of the Results of Modeling with Disaggregate Revealed Preference Data." Journal of Transportation and Statistics no. 2 (2):149-158. http://ntl.bts.gov/lib/7000/7600/7600/4jiang.pdf

Kerry-Boxer. 2009. S 1733 - 2009 Clean Energy Jobs and American Power Act. Washington, DC: OpenCongress.

Kruse, C. James, Annie Protopapas, Leslie E. Olson, David H. Bierling. 2009. A Modal Comparison of Domestic Freight Transportation Effects on the General Public. Washington, DC: U.S. Department of Transportation, Maritime Administration; Arlington, VA: National Waterways Foundation, 83 pp. http://www.americanwaterways.com/press room/news releases/NWFSTudy.pdf

Kumar, A. 1980. "Use of Incremental Form of Logit Models in Demand Analysis." Transportation Research Record no. 775:21-27.

Martland, Carl D. 2007. Estimating the Competitive Effects of Larger Trucks on Rail Freight Traffic. 18 pp. http://www.minnesotarailroads.com/News/Short_Line_Diversion_Report.pdf

McPherson, James M. 1988. Battle Cry of Freedom, The Civil War Era. New York and Oxford: Oxford University Press.

Mohammadian, Kouros, Kazuya Kawamura, Joshua Auld. 2011. A Working Demonstration of a Mesoscale Freight Model for the Chicago Region: Final Report and User's Guide. Chicago, IL: Chicago Metropolitan Agency for Planning, 99 pp.

National Cooperative Highway Research Program (NCHRP). 1995. Characteristics and Changes in Freight Transportation Demand: A Guidebook for Planners and Policy Analysts, Phase II Report. National Cooperative Highway Research Program. http://ntl.bts.gov/lib/4000/4300/4318/ccf.html

National Cooperative Freight Research Program. 2010. Freight-Demand Modeling to Support PublicSector Decision Making, Report 8 (NCFRP 8). Prepared by Cambridge Systematics, Inc., Cambridge, MA, and GeoStats, LLP, Atlanta, GA, for the Transportation Research Board, Washington, DC. http://onlinepubs.trb.org/onlinepubs/ncfrp/ncfrp rpt 008.pdf

Oregon Department of Transportation. 2007. Oregon's Mileage Fee Concept and Road User Fee Pilot Program Final Report. Salem, OR: Oregon Department of Transportation, 101 pp. http://www.oregon.gov/ODOT/HWY/RUFPP/docs/rufpp finalreport.pdf

Oum, Tae Hoon. 1989. "Alternative Demand Models and their Elasticity Estimates." Journal of Transport Economics and Policy no. 23 (2):163-187. http://www.bath.ac.uk/e-journals/jtep/pdf/Volume_XX111_No_2 163-187.pdf

Oum, Tae Hoon, W.G. Waters, Jong-Say Yong. 1992. "Concepts of Price Elasticities of Transport Demand and Recent Empirical Estimates: An Interpretative Study." Journal of Transport Economics and Policy no. 26 (2):139-154. http://www.jstor.org/stable/20052976 
Page, Kevin. 2010. Feasibility Plan for Maximum Truck to Rail Diversion in Virginia's I-81 Corridor. Richmond, VA: Virginia Department of Transportation; Virginia Department of Rail and Public Transportation, 28 pp. http://www.ctb.virginia.gov/resources/2010/April/cm_5_Update_I-81 041410.pdf

Raborn, C. 2010. Transportation Infrastructure Spending and Climate Outcomes: Effects of Reinvesting Transportation Carbon Fee Revenues in Transportation Infrastructure. Durham, NC: Duke University, $41 \mathrm{pp}$. http://nicholasinstitute.duke.edu/climate/lowcarbontech/transportation-infrastructure-spendingand-climate-outcomes

Ramseur, Jonathan L., Larry Parker. 2009. Carbon Tax and Greenhouse Gas Control: Options and Considerations for Congress. Washington, DC: Congressional Research Service, $51 \mathrm{pp}$.

http://www.fas.org/sgp/crs/misc/R40242.pdf

Seabury Aviation Aerospace. 2009. International Air Freight 2008-2013 Turbulence Ahead. Distributed by American Shipper.

Smith, Herbert. 2010. Norfolk Southern, Crescent Corridor Intermodal Freight Program.

Solomon, Mark B. 2009. "Fleeing China? Look Before You Leap.” DC Velocity.

Southworth, F., Peterson, B.E., and Lambert, B.P. (2007). Development of a Regional Routing Model for Strategic Waterway Analysis. Transportation Research Record 1993: 109-116.

Tavasszy, L.A., van der Vlist, C.J. Ruijgrok. 1999. Scenario-Wise Analysis of Transport and Logistics Systems with a SMILE. Delft, The Netherlands: TNO Inro, 16 pp.

Tennessee Department of Transportation (TDOT). 2007. I-40/I-81 Corridor Feasibility Study-From Bristol to Memphis, TN. Tennessee Department of Transportation. Cited September 19, 2012. http://www.tdot.state.tn.us/i40corridor/library.shtml

Transport Canada. 2004. Cross Border Shortsea Shipping Study. Ottawa, ON, Canada, 78 pp. http://resources.wcog.org/border/sss phase1report.pdf

Transportation Research Board (TRB). 1997. A Guidebook for Forecasting Freight Transportation Demand. Washington, DC: Transportation Research Board, 169 pp.

http://trid.trb.org/view.aspx?id=483009

- 2010. Freight-Demand Modeling to Support Public-Sector Decision Making. NCFRP Report 8. Washington, DC: Transportation Research Board, 67 pp. http://onlinepubs.trb.org/onlinepubs/ncfrp/ncfrp_rpt 008.pdf

- 2011a. Performance Measures for Freight Transportation. NCFRP Report 10. Washington, DC: Transportation Research Board, 169 pp. http://onlinepubs.trb.org/onlinepubs/ncfrp/ncfrp rpt 010.pdf

- 2011b. Policy Options for Reducing Energy Use and Greenhouse Gas Emissions from U.S. Transportation. Special Report 307. Washington, DC: Transportation Research Board, 228 pp. http://onlinepubs.trb.org/onlinepubs/sr/sr307.pdf

U.S. Department of Transportation (U.S. DOT). 1994. Truck-Rail, Rail-Truck Diversion Model. Users Manual. Washington, DC: U.S. Department of Transportation.

U.S. DOT, Federal Highway Administration, Office of Freight Management and Operations. 2001. Freight Financing Options for National Freight Productivity.

U.S. DOT, Research and Innovative Technology Administration, Bureau of Transportation Statistics. 2010. Freight Transportation: Global Highlights, 2010, Washington, D.C.

U.S. DOT FMCSA. 2010. 2010 to 2011 Hours of Service Rule Regulatory Impact Analysis (proposed). Washington, DC: U.S. Department of Transportation Federal Motor Carrier Safety Administration, 119 pp. http://www.fmcsa.dot.gov/rules-regulations/TOPICS/hos-proposed/AB26\%20HOS\%20RIA.pdf 
U.S. DOT Federal Motor Carrier Safety Administration. 2011. 2010-2011 Hours of Service Rule, Regulatory Impact Analysis RIN 2126-AB26. Analysis Division, Federal Motor Carrier Safety Administration. http://www.fmcsa.dot.gov/documents/hos/2011_HOS_Final_Rule_RIA.pdf

U.S. DOT FRA. 2005. ITIC-IM Version 1.0, Intermodal Transportation and Inventory Cost Model, Highway-to-Rail Intermodal, User's Manual. Washington, DC: U.S. Department of Transportation, Federal Railroad Administration, 35 pp. http://www.fra.dot.gov/downloads/Policy/ITIC-IM\%20documentation\%20v1 0.pdf

U.S. DOT STB. 2010. An Update to the Study of Competition in the U.S. Freight Railroad Industry. Washington, DC: The Surface Transportation Board, $147 \mathrm{pp}$. http://www.stb.dot.gov/stb/docs/CompetitionStudy/Final/January\%202010\%20Report.pdf

2012a. Economic Data: Waybill. U.S. DOT Surface Transportation BoardCited 10/3/2012. http://www.stb.dot.gov/stb/industry/econ waybill.html

. 2012b. Overview of the STB. U.S. DOT Surface Transportation Board. Cited 10/3/2012. http://www.stb.dot.gov/stb/about/overview.html

_. 2012c. STB Home. U.S. DOT Surface Transportation Board. Cited 10/3/2012.

http://www.stb.dot.gov/stb/index.html

U.S. Government Accountability Office (GAO). 2006. Freight Railroads: Industry Health Has Improved, but Concerns About Competition and Capacity Should be Addressed. GAO-07-94. Washington, DC: U.S. Government Accountability Office, 95 pp. http://www.gao.gov/new.items/d0794.pdf

U.S. Government Printing Office. 2012. 26 U.S.C. 9506 - Inland Waterways Trust Fund. Washington, DC: Internal Revenue Service.

Urban, Monique S., Dan Beagan. 2011. "CMAP Prototype Mesoscale Freight Model: Status Update.” Paper read at Peer Exchange Panel.

http://www.cmap.illinois.gov/documents/20583/38796704-5e9b-48d5-bd50-7f18a7ad2161

Waterways Council. 2010. Inland Marine Transportation Systems (IMTS) Capital Projects Business Model. Arlington, VA: Waterways Council, Inc., 237 pp.

http://www.waterwayscouncil.org/WCIExtras/IMTS_IWUB_Report.pdf

Waxman-Markey. 2009. H.R.2454 - American Clean Energy And Security Act of 2009 Washington, DC: OpenCongress.

Winston, C. "A Disaggregate Model of the Demand for Intercity Freight Transportation." Econometrica, July 1981.

Wisconsin Department of Transportation. 2009. Wisconsin Truck Size and Weight Study. Madison, WI: Wisconsin Department of Transportation, $295 \mathrm{pp}$.

http://www.topslab.wisc.edu/workgroups/tsws/deliverables/FR1 WisDOT TSWStudy R1.pdf

Wisetjindawat, Wisinee, Kazushi Sano, Shoji Matsumoto. 2006. "Commodity Distribution Model Incorporating Spatial Interactions for Urban Freight Movement." Transportation Research Record: Journal of the Transportation Research Board no. 1966 (-1):41-50. http://dx.doi.org/10.3141/1966-06 



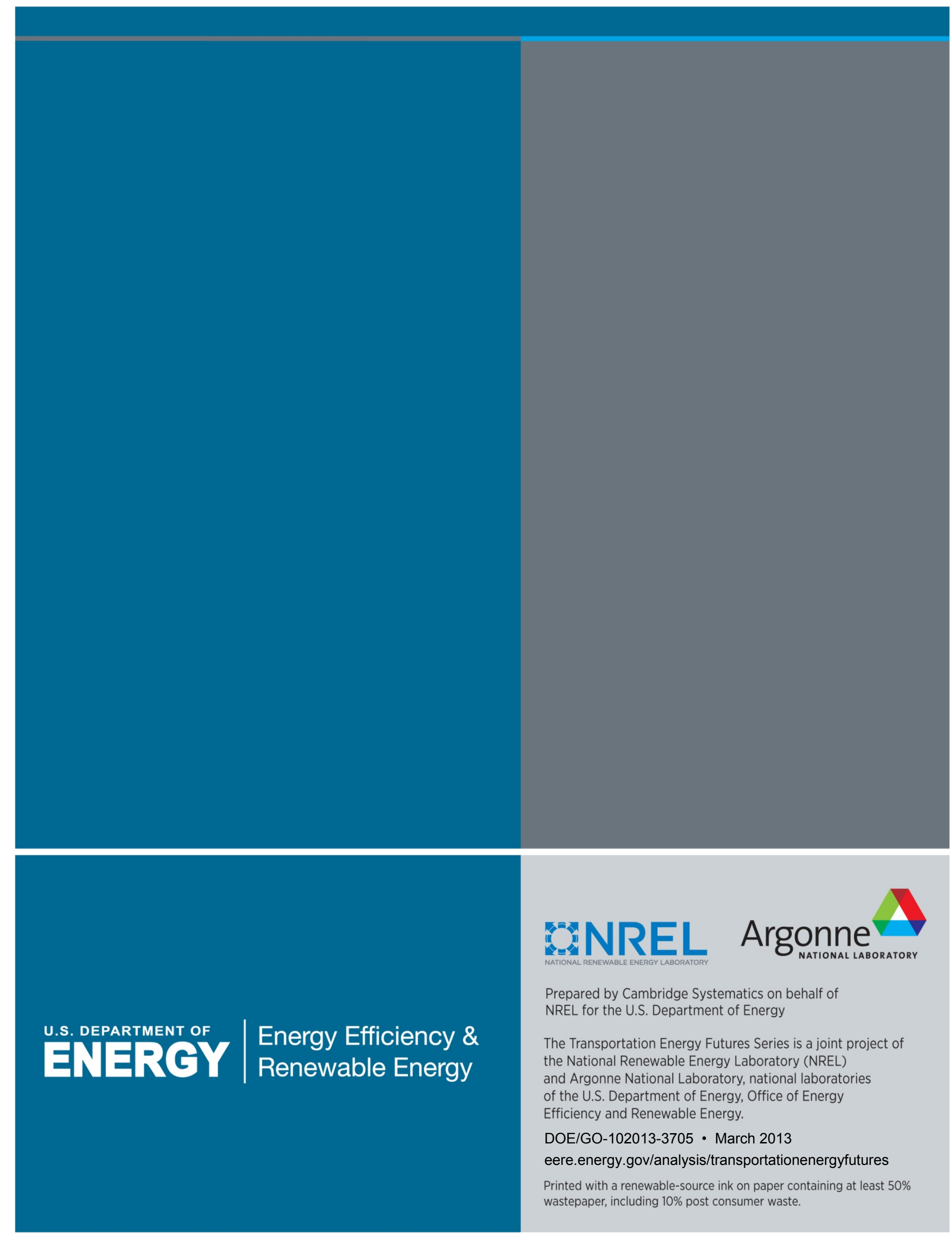

